San Jose State University

SJSU ScholarWorks

Master's Theses

Master's Theses and Graduate Research

1993

\title{
Modeling and measurement of solid-liquid phase transformation enthalpy for fusible heat sink applications
}

Cheng-Kuan Wu

San Jose State University

Follow this and additional works at: https://scholarworks.sjsu.edu/etd_theses

\section{Recommended Citation}

Wu, Cheng-Kuan, "Modeling and measurement of solid-liquid phase transformation enthalpy for fusible heat sink applications" (1993). Master's Theses. 661.

DOI: https://doi.org/10.31979/etd.8kys-nhdx

https://scholarworks.sjsu.edu/etd_theses/661

This Thesis is brought to you for free and open access by the Master's Theses and Graduate Research at SJSU ScholarWorks. It has been accepted for inclusion in Master's Theses by an authorized administrator of SJSU ScholarWorks. For more information, please contact scholarworks@sjsu.edu. 


\section{INFORMATION TO USERS}

This manuscript has been reproduced from the microfilm master. UMI films the text directly from the original or copy submitted. Thus, some thesis and dissertation copies are in typewriter face, while others may be from any type of computer printer.

The quality of this reproduction is dependent upon the quality of the copy submitted. Broken or indistinct print, colored or poor quality illustrations and photographs, print bleedthrough, substandard margins, and improper alignment can adversely affect reproduction.

In the unlikely event that the author did not send UMI a complete manuscript and there are missing pages, these will be noted. Also, if unauthorized copyright material had to be removed, a note will indicate the deletion.

Oversize materials (e.g., maps, drawings, charts) are reproduced by sectioning the original, beginning at the upper left-hand corner and continuing from left to right in equal sections with small overlaps. Each original is also photographed in one exposure and is included in reduced form at the back of the book.

Photographs included in the original manuscript have been reproduced xerographically in this copy. Higher quality $6 " \times 9^{\prime \prime}$ black and white photographic prints are available for any photographs or illustrations appearing in this copy for an additional charge. Contact UMI directly to order.

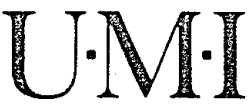


Order Number 1354176

Modeling and measurement of solid-liquid phase transformation enthalpy for fusible heat sink applications

Wu, Cheng-Kuan, M.S.

San Jose State University, 1993

Copyright (C)1993 by Wu, Cheng-Kuan. All rights reserved. 



\title{
Modeling and Measurement of Solid-Liquid Phase Transformation Enthalpy for Fusible Heat Sink Applications
}

\author{
A Thesis \\ Presented to \\ The Faculty of the Department of Materials Engineering \\ San Jose State University
}

\author{
In Partial Fulfillment \\ of the Requirements for the Degree \\ Master of Science
}

by

Cheng-Kuan Wu

August, 1993 
APPROVED FOR THE DEPARTMENT OF MATERIALS ENGINEERING

Tuna Selvadura

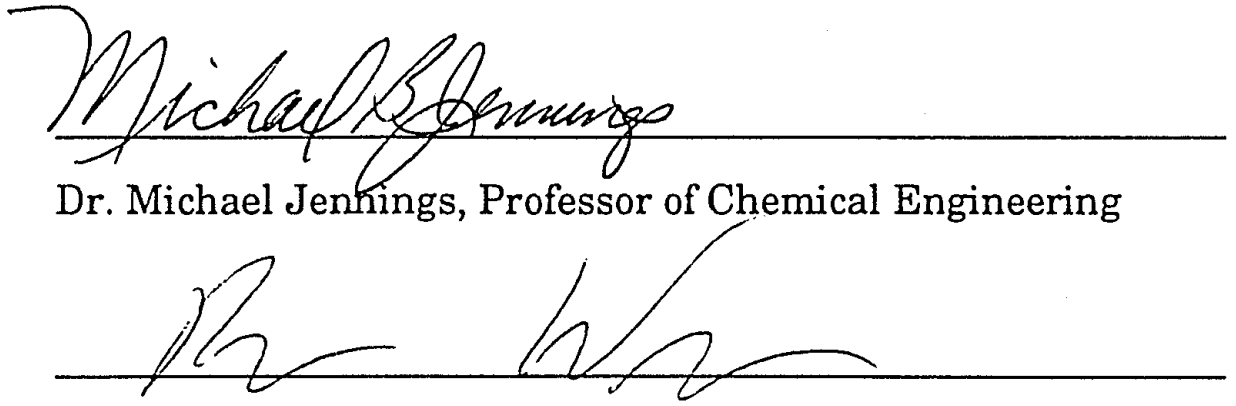

Dr. B. Webbon, NASA-Ames Research Center

APPROVED FOR THE UNIVERSITY

In. Dou Cewandowhi 


\section{ABSTRACT \\ Modeling and Measurement of Solid-Liquid Phase Transformation Enthalpy for Fusible Heat Sink Applications \\ By Cheng-Kuan Wu}

Modeling the fusion enthalpy of organic compounds and aqueous solutions was the objective of this project. From the literature, models for predicting the fusion enthalpy for both organic compounds and aqueous solutions were identified and tested against experimental data obtained from differential scanning calorimetry (DSC) measurements.

The model proposed by Chickos, for predicting the fusion enthalpy of organic compounds, was found to have an average percent deviation of $26.3 \%$. The Rule of Mixtures and Horvath's model, for predicting the fusion enthalpy of aqueous solutions, were found to have average percent deviations of $75.9 \%$ and $142.9 \%$, respectively.

A new model, termed the "Modified Mixture Rule," for predicting the fusion enthalpy of aqueous solutions, was developed. The average percent deviation of the Modified Mixture Rule, when tested against experimental data, was $12.5 \%$. This modification significantly improved the accuracy of predicting the value of enthalpy of fusion from models. 


\section{ACKNOWLEDGEMENTS}

The author wishes to thank his thesis adviser, Dr. Guna Selvaduray, Associate Professor, Department of Materials Engineering, for his guidance and perseverance in seeing this project through to its completion. A special note of thanks is due to Dr. Michael Jennings, Professor, Department of Chemical Engineering, for his valuable advice and for chairing the author's thesis committee.

The author is grateful to Dr. Bruce Webbon, Branch Chief, Life Sciences Division, NASA-Ames Research Center, for partial sponsorship of this project, for serving on his thesis committee, and for the valuable input that served to improve this study.

A special thank you is due to Mr. Frank Lewandowski, who so graciously consented to help edit this thesis, and gave his time so freely.

The author thanks his parents, Mr. and Mrs. Woei-Tsuen Wu, and his wife, Huei-Fang Lin, for their endearing support and patience throughout the duration of this study. To them, a very special Thank You. 


\section{TABLE OF CONTENTS}

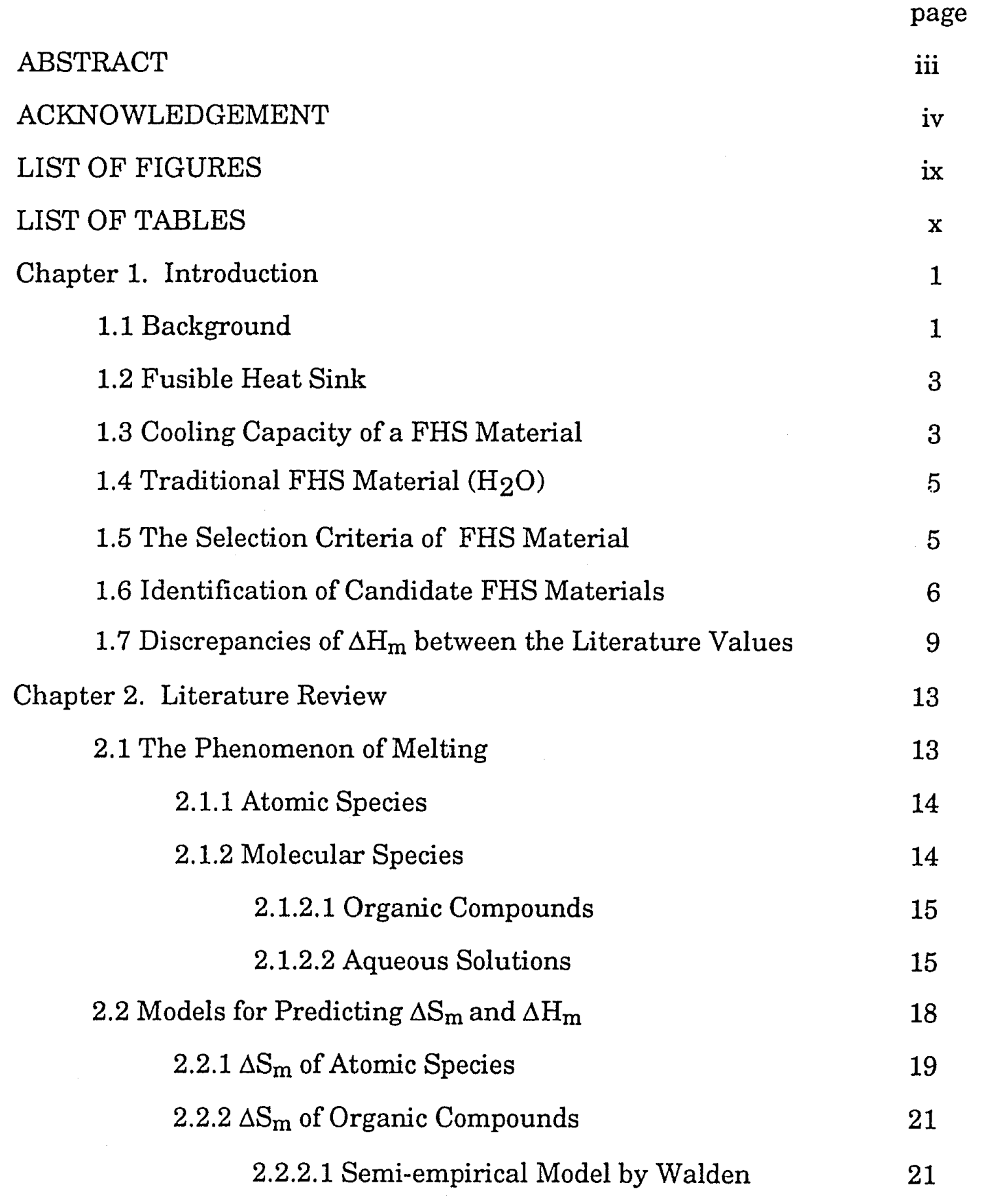


2.2.2.2 Semi-empirical Model by Pirsch 25

2.2.2.3 Semi-empirical Model by Procopiu 25

2.2.2.4 Quantitative Model by Chickos 26

2.2.3 $\Delta \mathrm{H}_{\mathrm{m}}$ of Aqueous Solutions $\quad 31$

2.2.3.1 The Rule of Mixtures $\quad 31$

2.2.3.2 Horvath's Model $\quad 31$

Chapter 3. Investigation Methodology 33

3.1 Theoretical 33

3.1.1 Organic Compounds 33

3.1.2 Aqueous Solutions $\quad 35$

3.2 Experimental 36

3.2.1 Materials $\quad 36$

3.2.2 Equipment and Experimental Methodology $\quad 40$

3.2.2.1 Experimental Setup $\quad 40$

3.2.2.2 Principle of Measurement 43

3.2.2.3 Procedure for Operating the DSC 44

3.2.2.4 Appearance of DSC Curve 48

3.2.2.5 Determination of $\mathrm{T}_{\mathrm{m}}, \Delta \mathrm{H}_{\mathrm{m}}, \mathrm{C}_{\mathrm{p}, \mathrm{s}}$, and $\mathrm{C}_{\mathrm{p}, \mathrm{l}} \quad 48$

Chapter 4. Results and Discussion $\quad 52$

4.1 Validity of the Semi-empirical Models 52

4.1.1 Procopiu's Model for $\Delta S_{\mathrm{m}}$ of Atomic Species $\quad 52$

4.1.2 Walden's Model for $\Delta \mathrm{S}_{\mathrm{m}}$ of Organic Compounds $\quad 58$

4.1.3 Pirsch's Model for $\Delta \mathrm{S}_{\mathrm{m}}$ of Organic Compounds $\quad 58$

4.1.4 Procopiu's Model for $\Delta \mathrm{S}_{\mathrm{m}}$ of Organic Compounds $\quad 61$ 
4.2 Experimental Data 62

4.3 Evaluations of the Models for Prediction of $\Delta \mathrm{H}_{\mathrm{m}} \quad 68$

4.3.1 Chickos's Model for $\Delta \mathrm{H}_{\mathrm{m}}$ of Organic Compounds $\quad 68$

4.3.2 The Rule of Mixtures for $\Delta \mathrm{H}_{\mathrm{m}}$ of Aqueous Solutions 70

4.3.3 Horvath's Model for $\Delta \mathrm{H}_{\mathrm{m}}$ of Aqueous Solutions $\quad 73$

$\begin{array}{ll}\text { Chapter 5. Modified Mixture Rule } & 77\end{array}$

5.1 The Phenomenon of Hydration 78

5.2 The Equation for Predicting $\Delta \mathrm{H}_{\mathrm{m}}$

5.3 Results 83

5.4 Discussion of Results 83

5.5 Identification of FHS Material by the Model 95

Chapter 6. Verification of Candidate FHS Materials 98

$\begin{array}{ll}\text { Chapter 7. Conclusion } & 101\end{array}$

$\begin{array}{ll}\text { References } & 103\end{array}$

Appendix A. Derivation of Horvath's Model 106

Appendix B. Values of $\Delta \mathrm{H}_{\mathrm{m}}$ of Solutes from Published Sources 108

Appendix C. Heating Rate v.s. Weight of Sample 109

Appendix D. Sample Calculations of Fusion Enthalpies from the DSC 111

Appendix E. Calculations of the accuracy of the DSC-4 112

Appendix F. Calculations of Fusion Enthalpy from Chickos's Model 113

Appendix G. Sample Calculations of Fusion Enthalpies from the 118 Rule of Mixtures

Appendix H. Sample Calculations of Fusion Enthalpies from $\quad 119$ Horvath's Model

Appendix I. Hydration Numbers of Electrolytes 120

Appendix J. Hydration Numbers of Non-electrolytes 121 
Appendix K. Sample Calculations of Fusion Enthalpies from the Modified Mixture Rule

Appendix L. Calculations of Maximum Concentrations

128

Appendix M. Calculations of Cooling Capacities

129 


\section{LIST OF FIGURES}

page

Figure 1. Components of a Space Suit 2

Figure 2. Principle of Operation of Fusible Heat Sink 4

Figure 3. Arrangement of Molecules in the Ice Crystal 17

Figure 4. View of DSC and the System-4 Microprocessor Controller 41

Figure 5. View of Accessories for the Equipment 41

Figure 6. View of an Aluminum Pan and Pan Cover 42 Illustrating Relative Sizes

Figure 7. View of the Sample Chamber 42

Figure 8. Experimental Arrangement of DSC 43

Figure 9. The Process for Preparing a Sample Pan 45

Figure 10. DSC Scan Plot 49

Figure 11. Plot of $\Delta \mathrm{H}_{\mathrm{m}}$ vs. $\mathrm{T}_{\mathrm{m}}$ for 59 Atomic Species 54

Figure 12. Plot of $\Delta \mathrm{H}_{\mathrm{m}}$ vs. $\mathrm{T}_{\mathrm{m}}$ for 572 Organic Compounds 59

Figure 13. Dissolution of an Ionic Crystal by the Action of a Solvent 79

Figure 14. Orientations of Water Dipoles in an Electrolytic Solution $\quad 80$

Figure 15. Comparison of Models for Predicting Fusion Enthalpies of $\quad 86$ 5 Electrolytic Aqueous Solutions

Figure 16. Comparison of Models for Predicting Fusion Enthalpies of 88 5 Non-electrolytic Aqueous Solutions

Figure 17. Bent \& Stretched H-Bond Configuration in Water 


\section{LIST OF TABLES}

page

Table 1. Materials with Higher Fusion Enthalpies than Water 7

Table 2. Comparative values of $\Delta \mathrm{H}_{\mathrm{m}}$ in Two Literature Sources 11

Table 3. Summary of Models for Predicting $\Delta \mathrm{H}_{\mathrm{m}}$ and $\Delta \mathrm{S}_{\mathrm{m}} \quad 20$

Table 4. $\Delta \mathrm{S}_{\mathrm{m}}$ of 13 Atomic Species Determined by Procopiu 22

Table 5. $\Delta \mathrm{S}_{\mathrm{m}}$ of 31 Organic Materials, as Determined by Walden 23

Table 6. Carbon Group Contributions to Fusion Entropies 29

Table 7. Functional Group Contributions to Fusion Entropies 30

Table 8. Organic Materials Selected for $\mathrm{H}_{\mathrm{m}} \& \mathrm{~T}_{\mathrm{m}}$ Measurements $\quad 37$

Table 9. Aqueous Solutions Selected for $\mathrm{H}_{\mathrm{m}} \& \mathrm{~T}_{\mathrm{m}}$ Measurements 38

Table 10. Test of Procopiu's Model for $\Delta S_{\mathrm{m}}$ of Atomic Species 55

Table 11. Test of Pirsch's Model for $\Delta \mathrm{S}_{\mathrm{m}}$ of Organic Materials 60

Table 12. Test of Procopiu's Model for $\Delta \mathrm{S}_{\mathrm{m}}$ of Organic Materials 63

Table 13. Experimental Fusion Enthalpy, Melting Point, 64 and Heat Capacity

Table 14. Test of Chickos's Model for $\Delta \mathrm{H}_{\mathrm{m}}$ of Organic Materials 69

Table 15. Test of the Rule of Mixtures for $\Delta \mathrm{H}_{\mathrm{m}}$ of Aqueous Solutions 71

Table 16. Test of Horvath's Model for $\Delta \mathrm{H}_{\mathrm{m}}$ of Aqueous Solutions $\quad 74$

Table 17. Test of the Modified Mixture Rule for $\Delta \mathrm{H}_{\mathrm{m}}$ of Aqueous $\quad 84$ Solutions

Table 18. The Maximum Allowable Concentration of the Solutions 94 in the Application of the Modified Mixture Rule

Table 19. Solutes with a Fusion Enthalpy Higher than Water 96

Table 20. Verification of Candidate FHS Materials 99 


\section{CHAPTER 1 INTRODUCTION}

Fusible Heat Sink (FHS) materials are a possible source for thermal regulation of space suited astronauts. The fusion enthalpy values of the FHS material is one of the major factors used to determine the duration of Extra Vehicular Activity (EVA). Modeling the fusion enthalpy of FHS materials is therefore the objective of this project. This chapter describes the applications, specifications, and identification of FHS materials.

\subsection{Background}

A space suit is a special suit designed for a human being in space. During Extra Vehicular Activity (EVA), a space suit provides the environment necessary to protect the human body from the atmospheric and temperature conditions that exist in space. The Portable Life Support System (PLSS), an integral part of the space suit, supplies astronauts with breathing air and removes metabolic heat. The components of a space suit are shown in Figure 1.(1) Inside the space suit during activity periods, the body gives off approximately 2900 calories per minute, which is equivalent to a 100 watt light bulb.(2) In daily life, one may not notice the metabolic heat generated because it will be exhausted to the environment through the clothing that is worn. When one wears a thermally insulated space suit, the excess metabolic heat cannot be exhausted to the outside. The space suit, therefore, must be capable of managing the metabolic heat generated during the EVA. 


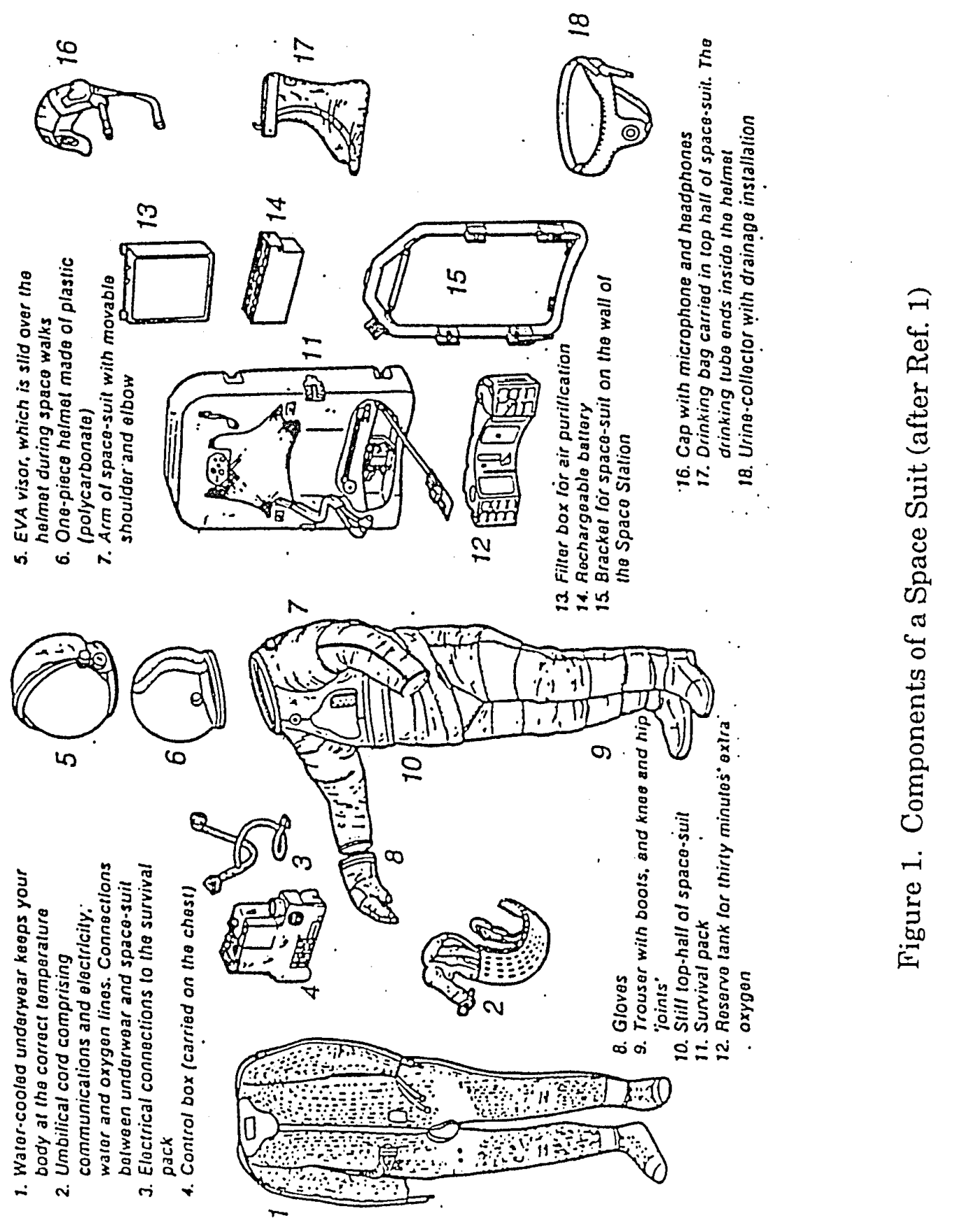




\subsection{Fusible Heat Sink}

Due to the requirement that the space suit both isolate and insulate its occupant from the environment, exhaustion of the metabolic heat to the outside is not easily achievable. If the metabolic heat cannot be exhausted, then it must be stored. One possible method of "storage" is in a fusible heat sink (FHS), which is a reservoir that contains a material that is initially solid and is transformed to a liquid during operation, as shown in Figure 2. The excess heat generated during the EVA will be absorbed by this material which goes through a solid-liquid phase transformation in the process, thus continually providing cooling capacity. (3) The ability to store this heat will be one of the factors that determines the length of the Extra Vehicular Activity. The fusible heat sink is built inside the Portable Life Support System, or survival pack, which is also shown in Figure 1.

\subsection{Cooling Capacity of a FHS Material}

The amount of heat that a FHS is able to absorb during operation is defined as its cooling capacity, $\Delta \mathrm{H}_{\text {tot }}$, and is given by Equation 1 .

$$
\Delta \mathrm{H}_{\text {tot }}=\int_{T_{\mathrm{s}, \mathrm{i}}}^{\mathrm{T}_{\mathrm{m}}} \mathrm{c}_{\mathrm{p}, \mathrm{s}} \mathrm{dT}+\Delta \mathrm{H}_{\mathrm{m}}+\int_{\mathrm{T}_{\mathrm{m}}}^{\mathrm{T}_{\mathrm{l}, \mathrm{f}} \mathrm{c}_{\mathrm{p}, \mathrm{l}}} \mathrm{dT}
$$

where $\quad T_{s, i}$ is the initial solid temperature,

$\mathrm{T}_{\mathrm{l}, \mathrm{f}}$ is the final liquid temperature,

$\mathrm{T}_{\mathrm{m}}$ is the melting point of the material,

$\mathrm{C}_{\mathrm{p}, \mathrm{l}}$ is the heat capacity of the liquid phase,

$\mathrm{C}_{\mathrm{p}, \mathrm{s}}$ is the heat capacity of the solid phase, and

$\Delta \mathrm{H}_{\mathrm{m}}$ is the latent heat of fusion at the melting point. 


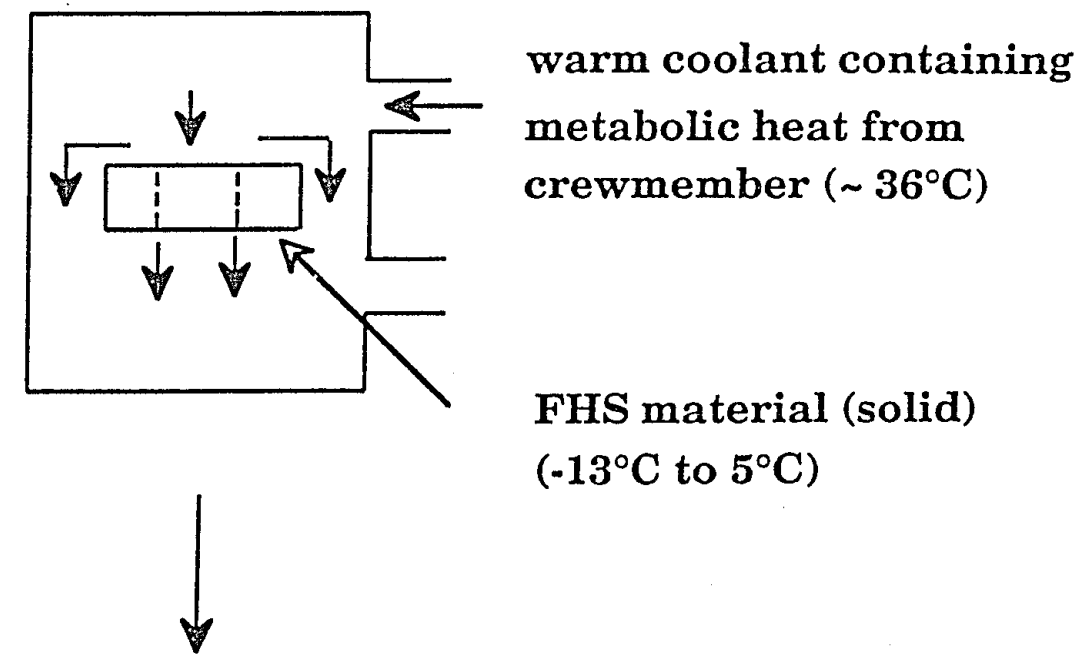

Phase Transformation of FHS material

(absorbs heat from coolant)

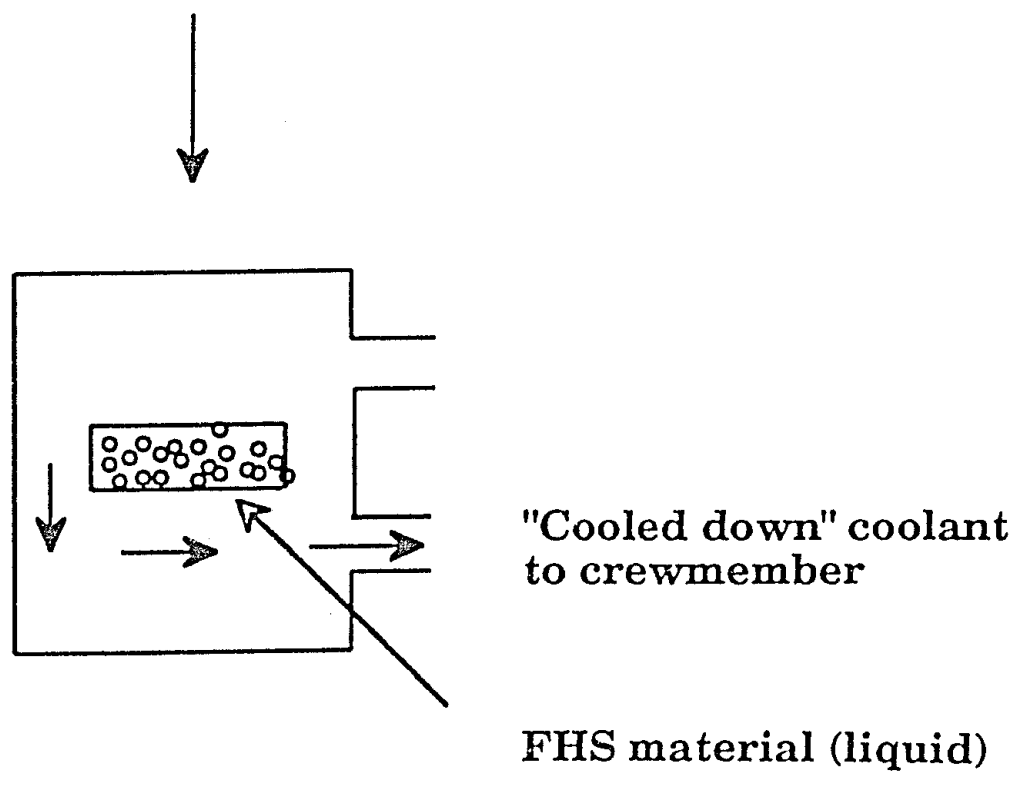

Figure 2. Principle of Operation of Fusible Heat Sink 
$\Delta \mathrm{H}_{\mathrm{m}}$ plays a significant role in determining the cooling capacity because it contributes between $80 \%$ to $90 \%$ of the total cooling capacity ${ }^{(3)}$ and therefore, is the parameter chosen for modeling in this project.

\subsection{Traditional FHS Material $\left(\mathrm{H}_{2} \mathrm{O}\right)$}

In the conventional design, the reservoir of the FHS initially contains ice. During the EVA, the ice will absorb the metabolic heat and melt into water. Therefore the latent heat of fusion for water, and the amount of ice, determines the maximum duration of the EVA. Water has been the traditional choice as a FHS material because it is non-toxic, non-flammable and inexpensive. (3)

\subsection{Selection Criteria for FHS Material}

The primary selection criterion for a FHS material is the requirement that the material have a solid-liquid phase transformation within the temperature range of $-13^{\circ} \mathrm{C}\left(0^{\circ} \mathrm{F}\right)$ to $5^{\circ} \mathrm{C}\left(40^{\circ} \mathrm{F}\right)$. This temperature range bounds the practical limits. A temperature lower than $-13^{\circ} \mathrm{C}$ could pose a hazard to living cells, while a temperature higher than $5^{\circ} \mathrm{C}$ could require excessive heat transfer. The second criterion is the requirement that the cooling capacity of the material be greater than that of water, which is 90.97 $\mathrm{cal} / \mathrm{g}^{(3)}$. As stated earlier, a material with a high enthalpy of solid to liquid phase transformation, within the $-13^{\circ} \mathrm{C}$ to $5^{\circ} \mathrm{C}$ temperature range, could enable both an extension of time between recharging and/or a reduction in size and/or mass of the Portable Life Support System (PLSS). Therefore, promising alternatives should have a higher cooling capacity than water. 
Besides the previous two criteria, several other criteria must be taken into account. The material identified should not pose any significant health risks to the astronaut, not be degraded during thermal cycling, not expand or contract excessively during the phase change, and be compatible with exsiting EVA PLSS.

\subsection{Identification of Candidate FHS Materials}

Selvaduray and Lomax ${ }^{(3)}$ conducted initial studies for NASA to determine the availability of candidate FHS materials that would be viable alternatives to water. The initial effort to identify suitable materials was restricted to employing the first two criteria listed above, namely that the solid-liquid transition temperature be within the $-13^{\circ} \mathrm{C}$ to $5^{\circ} \mathrm{C}$ temperature range, and that the total cooling capacity, $\Delta \mathrm{H}_{\text {tot }}$, be greater than that for water. Based on data available in the literature, Selvaduray and Lomax identified a total of 49 candidate materials that appeared to be promising alternatives to water. The results of their study is shown in Table 1.(3)

The values of $\Delta \mathrm{H}_{\text {tot }}$ in the third column of Table 1 were calculated according to Equation 1, with an initial temperature of $-13^{\circ} \mathrm{C}$ and a final temperature of $5^{\circ} \mathrm{C}$. The data necessary for computing $\Delta \mathrm{H}_{\text {tot }}$ are the values of $\Delta \mathrm{H}_{\mathrm{m}}, \mathrm{C}_{\mathrm{p}, \mathrm{s}}$, and $\mathrm{C}_{\mathrm{p}, \mathrm{l}}$. The authors were not able to find $\mathrm{C}_{\mathrm{p}, \mathrm{s}}$, and $\mathrm{C}_{\mathrm{p}, \mathrm{l}}$ for all of the compounds identified. Compounds containing the remark " $\Delta \mathrm{H}_{\mathrm{m}}$ data only" in Table 1 means that $\Delta \mathrm{H}_{\text {tot }}$ was computed based solely on $\Delta \mathrm{H}_{\mathrm{m}}$. They justified including compounds for which $\mathrm{C}_{\mathrm{p}, \mathrm{s}}$ and $\mathrm{C}_{\mathrm{p}, \mathrm{l}}$ data were not available because inclusion of the heat capacity contribution would only increase the value of $\Delta \mathrm{H}_{\text {tot. }}$ Initial estimates of the cooling capacity, $\Delta \mathrm{H}_{\text {tot }}$, in Table 1 
Table 1. Materials with Higher Fusion Enthalpies than Water (after Ref. 3)

\begin{tabular}{|c|c|c|c|}
\hline Compound Name & $\begin{array}{l}\text { Ielting Point } \\
\left({ }^{\circ} \mathrm{C}\right)\end{array}$ & $\begin{array}{l}\Delta \mathrm{H}_{\text {tot }} \\
\text { (cal/g) }\end{array}$ & Remarks \\
\hline Glycerol triacetate & -7.8 & 1457.84 & $\Delta \mathrm{H}_{\mathrm{m}}$ data only \\
\hline Triethylene glycol & -7.2 & 1289.28 & \\
\hline Benzene, hexafluoro & 5 & 1280.07 & \\
\hline Heptanoic acid & -9 & 1119.59 & $\Delta \mathrm{H}_{\mathrm{m}}$ data only \\
\hline 2-Methyl-2-butanol & -8.4 & 1028.93 & $\Delta \mathrm{H}_{\mathrm{m}}$ data only \\
\hline 2,3-Butanedione & -2 & 1016.74 & $\Delta \mathrm{H}_{\mathrm{m}}$ data only \\
\hline Benzoic acid,2-fluoro & 1 & 969.07 & $\Delta \mathrm{H}_{\mathrm{m}}$ data only \\
\hline Cyclohexanol,2-methyl(trans,dl) & -4 & 897.73 & \\
\hline Cyclohexanol,4-methyl(cis) & -9 & 874.47 & \\
\hline Cyclohexanol,3-methyl(trans,1) & -1 & 835.06 & \\
\hline Tert-Butyl hydroperoxide & -8 & 778.96 & $\Delta \mathrm{H}_{\mathrm{m}}$ data only \\
\hline Benzene,1,4-difluoro & -13 & 717.29 & $\Delta \mathrm{H}_{\mathrm{m}}$ data only \\
\hline Cyclohexanone,2-methyl(dl) & -13 & 613.34 & $\Delta \mathrm{H}_{\mathrm{m}}$ data only \\
\hline Cinnamonitrile & -4 & 593.5 & \\
\hline 4-Methoxybenzaldehyde & 0 & 469.34 & $\Delta \mathrm{H}_{\mathrm{m}}$ data only \\
\hline Coniine & -2 & 453.34 & $\Delta \mathrm{H}_{\mathrm{m}}$ data only \\
\hline Arsinic trichloride & -8.5 & 405.61 & \\
\hline Benzyl alcohol & -1.5 & 366.42 & \\
\hline Indene & -1.8 & 234.64 & \\
\hline Benzene,1,2,3,4-tetramethyl & -6 & 202.64 & \\
\hline Methyldiphenolamine & -7.6 & 164.17 & \\
\hline Cyclohexane1,2-dibromo(trans,dl) & 1) -4 & 160.35 & $\Delta \mathrm{H}_{\mathrm{m}}$ data only \\
\hline Benzene & 5 & 159.26 & \\
\hline Biphenyl,2-methyl & 0 & 153.35 & $\Delta \mathrm{H}_{\mathrm{m}}$ data only \\
\hline 1,2-Dihydronaphthalene & -8 to -7 & 138.26 & $\Delta \mathrm{H}_{\mathrm{m}}$ data only \\
\hline Biphenyl,3-methyl & 4 & 121.25 & $\Delta \mathrm{H}_{\mathrm{m}}$ data only \\
\hline Piperidene & -7 & 97.99 & \\
\hline
\end{tabular}


Table 1. Materials with Higher Fusion Enthalpies than Water (after Ref. 3) (continued)

\begin{tabular}{llll}
\hline Compound Name & $\begin{array}{c}\text { Melting Point } \\
\left({ }^{\circ} \mathrm{C}\right)\end{array}$ & $\begin{array}{l}\Delta \mathrm{H}_{\text {tot }} \\
(\mathrm{cal} / \mathrm{g})\end{array}$ & Remarks \\
\hline Sodium chloride & -4.378 & 94.30557 & Conc. $7.0 \%$ \\
Potassium chloride & -4.3 & 93.5291 & Conc. 9.0\% \\
Sodium bromide & -4.206 & 93.08707 & Conc. 11.0\% \\
Lithium chloride & -3.727 & 92.94917 & Conc. $4.0 \%$ \\
Potassium chromate & -4.05 & 92.8657 & Conc. 18.0\% \\
Potassium bromide & -4.122 & 92.73127 & Conc. 13.0\% \\
Formic acid & -4.267 & 92.64415 & Conc. 10.0\% \\
Glycerol & -4.094 & 92.5118 & Conc. 16.0\% \\
Sodium nitrate & -3.841 & 92.50245 & Conc. 10.0\% \\
Potassium iodide & -3.869 & 92.46738 & Conc. 16.0\% \\
Cesium chloride & -4.224 & 92.42732 & Conc. 19.0\% \\
Sodium hydroxide & -4.074 & 92.33973 & Conc. $4.5 \%$ \\
Acetic acid & -4.259 & 92.23876 & Conc. 13.0\% \\
Ethylene glycol & -4.16 & 92.1678 & Conc. 12.0\% \\
Silver nitrate & -2.862 & 91.90444 & Conc. 16.0\% \\
Potassium nitrate & -2.754 & 91.8233 & Conc. 10.0\% \\
Potassium sulfate & -2.754 & 91.8233 & Conc. 5.0\% \\
Ethanol & -4.21 & 91.34832 & Conc. 9.5\% \\
Potassium hydroxide & -4.144 & 91.27768 & Conc. 6.0\% \\
Potassium dichromate & -0.435 & 91.26456 & Conc. 2.5\% \\
Methanol & -4.41 & 91.18045 & Conc. $7.0 \%$ \\
Alinine & -6 & 91.1 & $\Delta \mathrm{H}_{\mathrm{m} \text { data } 0 \text { only }}$ \\
Water & 0 & 90.97 & \\
\hline & & & \\
\hline
\end{tabular}


were therefore on the conservative side.

For the case of aqueous solutions contained in Table 1, thermodynamic data was available only for the individual components, but not the solutions. $\Delta \mathrm{H}_{\mathrm{m}}, \mathrm{C}_{\mathrm{p}, \mathrm{s}}$, and $\mathrm{C}_{\mathrm{p}, \mathrm{l}}$ were therefore calculated according to the Rule of Mixtures, and these values in turn, were used to calculate $\Delta H_{\text {tot }}$.

Selvaduray and Lomax subsequently undertook a modest effort to confirm their results experimentally. During the course of experimental confirmation, and also during critical evaluation of the data contained in the literature, they discovered several discrepancies.

\subsection{Discrepancies of $\Delta H_{m}$ between the Literature Values}

As can be seen from Table 1, triethylene glycol was found to be very attractive compared to water. Therefore an attempt to measure the melting point of triethylene glycol was made. Experiments showed that triethylene glycol would not freeze at temperatures as low as $-40^{\circ} \mathrm{C}$. The Material Safety Data Sheet from the manufacturer of triethylene glycol also stated that its melting point was $-7^{\circ} \mathrm{C}$. The manufacturer was contacted, and they were not able to obtain a melting/freezing temperature despite lowering the temperature to $-40^{\circ} \mathrm{C}$.

The reported values for $\Delta \mathrm{H}_{\mathrm{m}}$ of triethylene glycol also varied widely. One value of $1278 \mathrm{cal} / \mathrm{g}$ was reported by Moureu et al.(4) in 1937, and another value of $29 \mathrm{cal} / \mathrm{g}$ was reported by Pickard et al.(5) in 1911.

Discrepancies also occur in the recently published literature. The values of fusion enthalpies of some materials reported in the CRC Handbook of

Chemistry and Physics ${ }^{(6)}$ are somewhat different from those reported in 
Lange's Handbook of Chemistry. (7) Comparative values of fusion enthalpies from these two sources are tabulated in Table 2.

Uncertainties in existing literature values made it necessary to conduct an experimental program to measure the thermodynamic properties of candidate FHS materials. Selvaduray and Lomax had identified 1215 compounds that had a solid-liquid transition within the temperature range of $-13^{\circ} \mathrm{C}$ to $5^{\circ} \mathrm{C}$. This represents an extremely large number and an experimental program involving the measurement of thermodynamic properties of all these 1215 compounds would be impractical. Therefore it was decided to model the enthalpy of fusion first, and then verify the reliability of the model by experimentation. The most reliable models for predicting fusion enthalpy may identify suitable FHS materials for space suit applications and therefore evaluating these models is one of the primary objectives of this project.

Chapter 2 is a review of the literature to locate existing models that have been proposed for determining the enthalpy of fusion. Chapter 3 describes the methodology for investigating the values of fusion enthalpy. Both a theoretical and an experimental approach were taken to obtain the values of fusion enthalpy. Models reviewed from the literature for predicting fusion enthalpy were employed to calculate the theoretical $\Delta \mathrm{H}_{\mathrm{m}}$ and experiments were subsequently conducted to test the reliability of the findings from the theoretical models. Chapter 4 evaluates the current models for predicting the values of fusion enthalpy. Chapter 5 introduces modifications of the current models for predicting the fusion enthalpy of 
Table 2. Comparative Values of $\Delta \mathrm{H}_{\mathrm{m}}$ in Two Literature Sources (after Ref. 6 and 7 )

\begin{tabular}{lcc}
\hline Material & $\begin{array}{c}\Delta \mathrm{H}_{\mathrm{m}}(\mathrm{cal} / \mathrm{mole}) \\
\text { from } \mathrm{CRC} \text { handbook }\end{array}$ & $\begin{array}{c}\Delta \mathrm{H}_{\mathrm{m}}(\mathrm{cal} / \mathrm{mole}) \\
\text { from Lange's handbook }\end{array}$ \\
\hline $\mathrm{MgCl}_{2}$ & 8100 & 10300 \\
$\mathrm{NaF}$ & 7000 & 7970 \\
$\mathrm{KCl}$ & 6410 & 6282 \\
$\mathrm{LiBr}$ & 2900 & 4220 \\
$\mathrm{LiCl}$ & 3200 & 4740 \\
$\mathrm{CaCl}$ & 6100 & 6800 \\
$\mathrm{NaCl}$ & 7220 & 6730 \\
$\mathrm{KBr}$ & 5000 & 6100 \\
$\mathrm{NaNO}$ & 3760 & 3490 \\
$\mathrm{KI}$ & 4100 & 5740 \\
$\mathrm{CsCl}$ & 3600 & 3800 \\
$\mathrm{NaOH}_{\mathrm{KNO}}$ & 2000 & 1580 \\
$\mathrm{~K}_{2} \mathrm{SO} 4$ & 2840 & 2300 \\
\hline
\end{tabular}


aqueous solutions. These modifications were the result of this study and its reliability and possible application are discussed. Chapter 6 presents the results of experimental verification of candidate FHS materials. Chapter 7 contains the summary of this study and the recommendations for future study. 


\section{CHAPTER 2}

\section{LITERATURE REVIEW}

This chapter contains two main topics: an examination of the solid-liquid phase change mechanism and a summary of thermodynamic models for that process. The phenomenon of melting, in terms of atomic species and molecular species, is introduced in Section 2.1 since this is essential for understanding the meaning of fusion or melting. Considering the value of fusion enthalpy as the most significant determining factor for choosing a FHS material, the purpose of the literature review was to locate existing models for determining the enthalpy of fusion, $\Delta \mathrm{H}_{\mathrm{m}}$. Models for computing the entropy of fusion, $\Delta \mathrm{S}_{\mathrm{m}}$, have also been reviewed since $\Delta \mathrm{H}_{\mathrm{m}}$ can be computed by the product of $\Delta \mathrm{S}_{\mathrm{m}}$ and the melting point, $\mathrm{T}_{\mathrm{m}}$. These models are reviewed in Section 2.2.

\subsection{The Phenomenon of Melting}

For quasi-equilibrium conditions during melting, the free energy of the solid state is equal to that of the liquid state and therefore both phases coexist. From the viewpoint of chemical bonding of materials there is a difference between the solid and liquid states and this difference accounts for the enthalpy of fusion. All materials can be grouped as either atomic or molecular species and the phenomenon of melting in each case is different. They are therefore described individually. 


\subsubsection{Atomic Species}

This class of materials, typically elemental species such as $\mathrm{Cu}, \mathrm{Al}, \mathrm{Pb}$, etc., have a specific crystal structure in their solid state. Each atom is surrounded by a certain number of nearest neighbor atoms, which is referred to as the coordination number. Most models assume that the force that binds these atoms together is the inter-atomic bond, such as $\mathrm{Cu}-\mathrm{Cu}, \mathrm{Al}-\mathrm{Al}$ or $\mathrm{Pb}-\mathrm{Pb}$ bonds. The higher the coordination number, the more tightly the atoms are bound, and therefore the lower the energy level. During melting, the thermal energy becomes high enough to break some of the inter-atomic bonds, and therefore the coordination number decreases. For example, the coordination number of $\mathrm{Al}$ decreases from 12, in the solid phase, to 10.6 in the liquid phase. (8) The structure of liquid $\mathrm{Al}$ corresponds to a close-packed solid, but with a coordination number of 10.6 instead of 12 , i.e., each $\mathrm{Al}$ atom in the liquid state has on the average 10.6 atoms and 1.4 holes as the nearest neighbors. The phenomenon of melting for this type of material involves the rupture of inter-atomic bonds.

\subsubsection{Molecular Species}

Materials that are molecular in nature can be divided into organic and aqueous species. The phenomenon of melting in organic compounds and aqueous solutions are also different from each other, and are described separately. 


\subsubsection{Organic Compounds}

Unlike atomic species, inter-molecular bonding dominates the liquidsolid phase transformation in the case of organic compounds. Most models assume that van der Waal's bonding and dipole-dipole interactions are the two types of inter-molecular bonds that bind neighboring organic molecules. Van der Waal's bonding is caused by the instantaneous location of a few more electrons on one side of the nucleus than on the other, thus providing a weak fluctuating dipole moment to attract the neighboring molecules. Dipoledipole interactions result from the charge asymmetry of the molecule, thus contributing the dipole moment to attract the neighboring molecules. For those molecules which are symmetric (e.g., $\mathrm{CH}_{4}, \mathrm{CCl}_{4}$ ), the inter-molecular bonds consist of van der Waal's bonding only, while for those molecules which are asymmetric (e.g., CO, CHN), the inter-molecular bonds consist of both van der Waal's bonding and dipole-dipole interactions. During melting, the

thermal energy is high enough to break some of the van der Waal's bonds and dipole-dipole bonds. The amount of these inter-molecular bonds which are broken will account for the value of the enthalpy of fusion. The thermal energy gained from melting is insufficient to break the inter-atomic primary bonds such as $\mathrm{C}-\mathrm{H}, \mathrm{C}-\mathrm{Cl}, \mathrm{C}-\mathrm{O}$, or $\mathrm{C}-\mathrm{N}$, contained within the organic molecule.

\subsubsection{Aqueous Solutions}

Hydrogen bonding is the major bond type in the case of aqueous solutions and water. It is caused by the hydrogen atom in a $\mathrm{H}_{2} \mathrm{O}$ molecule being attracted to a highly electronegative oxygen atom in the neighboring $\mathrm{H}_{2} \mathrm{O}$ molecule, thus providing a dipolar interaction to bind the nearby 
aqueous species or $\mathrm{H}_{2} \mathrm{O}$ molecules. Besides aqueous solutions and water, hydrogen bonding also exists in other compounds such as $\mathrm{HF}, \mathrm{NH}_{3}, \mathrm{HCl}$, etc., due to the high value of the electronegativity of $\mathrm{F}, \mathrm{N}$, and $\mathrm{Cl}$ atoms. However, only the bonding characteristics of aqueous solutions is introduced here.

Considering that the major component (solvent) in aqueous solutions is water, an understanding of the model for melting of water is helpful in understanding the melting phenomenon of aqueous solutions. Figure 3 shows the structure of $\mathrm{H}_{2} \mathrm{O}$ in its solid state.(9) As seen from Figure 3, the ice crystals are arranged in a hexagonal configuration. The dashed line in Figure 3 represents the hydrogen bonding which binds the neighboring $\mathrm{H}_{2} \mathrm{O}$ molecules, and therefore constitutes the lattice energy in $\mathrm{H}_{2} \mathrm{O}$. During melting some hydrogen bonds are broken by the thermal energy which is added. In other words, the lattice energy will be exceeded by other energy forms. The ratio of the values of the fusion enthalpy to the lattice energy is therefore a measure of the percentage of hydrogen bonds being broken during melting. The values of the fusion enthalpy and the lattice energy of $\mathrm{H}_{2} \mathrm{O}$ were reported in the literature to be $1.436 \mathrm{kcal} / \mathrm{mol}^{(6,7)}$ and $13.4 \mathrm{kcal} / \mathrm{mol}^{(10)}$ respectively. The ratio of the fusion enthalpy $(1.436 \mathrm{kcal} / \mathrm{mol})$ to the lattice energy $(13.4 \mathrm{kcal} / \mathrm{mol})$ was calculated to be approximately $11 \%$. This means that only $11 \%$ (1.436/13.4) of the hydrogen bonds are broken during the melting of ice. However, the inter-atomic $\mathrm{O}-\mathrm{H}$ primary bonds are not broken during melting. 


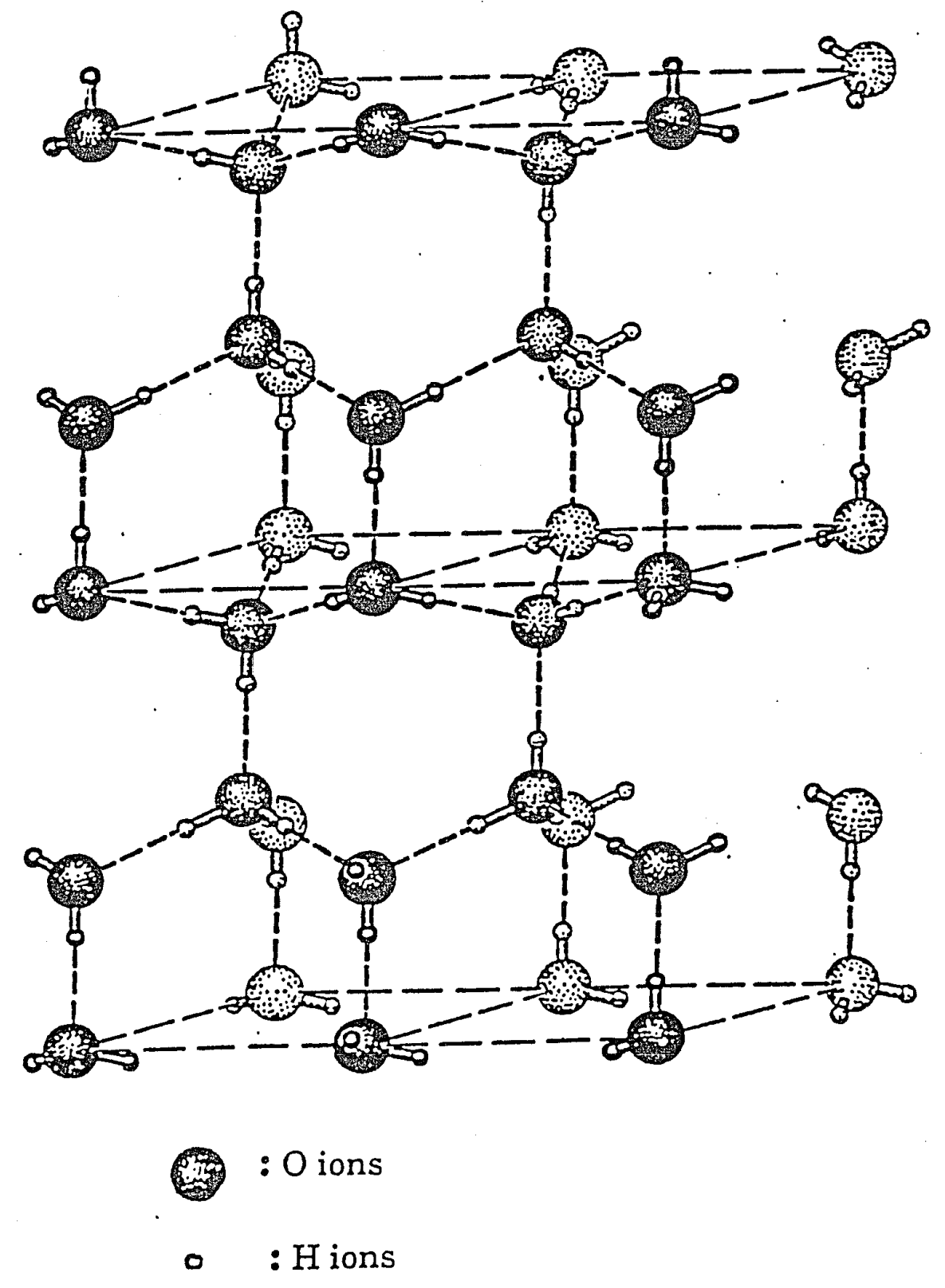

Figure 3. Arrangement of Molecules in the Ice Crystal (after Ref. 9) 


\subsection{Models for Predicting $\Delta \mathbf{S}_{\mathbf{m}}$ and $\Delta \mathbf{H}_{\mathbf{m}}$}

The purpose of the literature review was to locate models for predicting the enthalpy of fusion, $\Delta \mathrm{H}_{\mathrm{m}}$. The models for predicting the entropy of fusion, $\Delta S_{m}$, were also reviewed since the value of the fusion entropy $\left(\Delta S_{m}\right)$ is equal to the ratio of the fusion enthalpy $\left(\Delta \mathrm{H}_{\mathrm{m}}\right)$ to the melting point $\left(\mathrm{T}_{\mathrm{m}}\right)$, based on thermodynamics as explained below.

For quasi-equilibrium conditions during melting, the Gibbs free energy of a pure specie in the solid state $\left(G^{s}\right)$ is equal to that in the liquid state $\left(G^{l}\right)$. The terms $G^{s}$ and $G^{l}$ are defined in Equations 2 and 3 respectively.

$$
\mathrm{G}^{\mathrm{s}}=\mathrm{H}^{\mathrm{s}}-\mathrm{TS}^{\mathrm{s}}
$$

where $\mathrm{H}^{\mathrm{s}}$ is the enthalpy of a substance in the solid state, $\mathrm{T}$ is the temperature, and $\mathrm{Ss}^{\mathrm{s}}$ is the entropy of a substance in the solid state.

$$
\mathrm{G}^{\mathrm{l}}=\mathrm{H}^{\mathrm{l}}-\mathrm{TS}
$$

where $\mathrm{H}^{\mathrm{l}}$ is the enthalpy of a substance in the liquid state, $\mathrm{T}$ is the temperature, and $\mathrm{S}^{l}$ is the entropy of a substance in the liquid state. Since the value of $G^{s}$ is equal to $G^{l}$ at the melting point, $T_{m}$, combining Equations 2 and 3 yields Equation 4.

$$
\mathrm{H}^{\mathrm{l}}-\mathrm{H}^{\mathrm{s}}=\mathrm{T}_{\mathrm{m}}\left(\mathrm{S}^{\mathrm{l}}-\mathrm{S}^{\mathrm{s}}\right)
$$

The term "Hl- $\mathrm{Hs}^{\mathrm{s}}$ is the difference of the enthalpy between the solid state and the liquid state, which is the enthalpy of fusion, $\Delta \mathrm{H}_{\mathrm{m}}$. The term "Sl-Ss" is the difference of the entropy between the solid state and the liquid state, which is the entropy of fusion, $\Delta \mathrm{S}_{\mathrm{m}}$. Equation 4 can be rewritten to yield Equation 5 .

$$
\Delta \mathrm{S}_{\mathrm{m}}=\Delta \mathrm{H}_{\mathrm{m}} / \mathrm{T}_{\mathrm{m}}
$$

A number of models for predicting the fusion enthalpy or fusion entropy for different types of materials have been proposed. They were either derived 
semi-empirically or quantitatively. These models are reviewed in this section and are summarized in Table 3. Separate columns are provided in Table 3 for the property of material modeled, the method of modeling, and the types of materials modeled. These models are reviewed in the following three subsections. One model for predicting $\Delta \mathrm{S}_{\mathrm{m}}$ of atomic species is described in Section 2.2.1, four models for predicting $\Delta S_{m}$ of organic compounds are described in Section 2.2.2, and two models for predicting $\Delta \mathrm{H}_{\mathrm{m}}$ of aqueous solutions are described in Section 2.2.3.

\subsection{1 $\Delta \mathrm{S}_{\mathrm{m}}$ of Atomic Species}

Perhaps the simplest model for predicting the fusion entropy of atomic species was proposed by Procopiu. (11) He investigated the fusion entropy of 13 metals by computing the ratio of the molar fusion enthalpy to the melting point. The ratio was found to be approximately equal to the gas constant, 1.986 entropy units (e.u. or cal $/ \mathrm{mol}^{\circ} \mathrm{K}$ ), which represents the energy of translation for one degree of freedom of the atoms. The equation that Procopiu used to determine the values of the fusion entropy is shown as Equation 6.

$$
\Delta \mathrm{S}_{\mathrm{m}} \text { (e.u.) }=\left[\Delta \mathrm{H}_{\mathrm{m}}(\mathrm{cal} / \mathrm{g}) * \mathrm{M}(\mathrm{g} / \mathrm{mole})\right] / \mathrm{T}\left({ }^{\circ} \mathrm{K}\right)
$$

where $\Delta \mathrm{S}_{\mathrm{m}}$ is the fusion entropy in entropy units (e.u.),

$\Delta \mathrm{H}_{\mathrm{m}}$ is the fusion enthalpy in calories per gram (cal/g),

$\mathrm{M}$ is the atomic weight ( $\mathrm{g} / \mathrm{mole})$, and

$\mathrm{T}_{\mathrm{m}}$ is the melting point $\left({ }^{\circ} \mathrm{K}\right)$. 
Table 3. Summary of Models for Predicting $\Delta \mathrm{S}_{\mathrm{m}}$ and $\Delta \mathrm{H}_{\mathrm{m}}$

\begin{tabular}{lcll}
\hline Proposed by & Property & Methodology & Type of Materials \\
\hline Procopiu (1948) & $\Delta \mathrm{S}_{\mathrm{m}}$ & Semi-empirical & Atomic Species \\
Walden (1908) & $\Delta \mathrm{S}_{\mathrm{m}}$ & Semi-empirical & Organic \\
Pirsch (1937) & $\Delta \mathrm{S}_{\mathrm{m}}$ & Semi-empirical & Organic \\
Procopiu (1948) & $\Delta \mathrm{S}_{\mathrm{m}}$ & Semi-empirical & Organic \\
Chickos (1991) & $\Delta \mathrm{S}_{\mathrm{m}}$ & Quantitative & Organic \\
Rule of Mixtures* & $\Delta \mathrm{H}_{\mathrm{m}}$ & Quantitative & Aqueous Solution \\
Horvath (1985) & $\Delta \mathrm{H}_{\mathrm{m}}$ & Quantitative & Aqueous Solution \\
& & & \\
\hline
\end{tabular}

* It was not possible to determine who first proposed the Rule of Mixtures. 
The term " $\Delta H_{m}{ }^{*} M$ " is the molar fusion enthalpy. The results obtained by Procopiu are shown in Table 4. ${ }^{(11)}$ The values of $\Delta \mathrm{H}_{\mathrm{m}}$ and $\mathrm{T}_{\mathrm{m}}$ used by Procopiu were from the published literature.

According to this model, the enthalpy of fusion is dependent only on the melting point of the particular specie.

\subsection{2 $\Delta \mathrm{S}_{\mathrm{m}}$ of Organic Compounds}

Four models, either based on semi-empirical investigations or quantitative treatment, for predicting the $\Delta S_{\mathrm{m}}$ of organic compounds have been proposed. These are described below.

\subsubsection{Semi-empirical Model by Walden}

Walden ${ }^{(12)}$ investigated a number of organic materials in order to find the relationship between the molar fusion enthalpy and the melting point. By computing the ratio of the molar fusion enthalpy to the melting point, he found that the fusion entropy ranges from 12.5 e.u. to 14.8 e.u., with an average of 13.5 e.u.. Table 5 shows the values of fusion entropy that were determined by Walden. ${ }^{(12)}$ The reported values of the fusion enthalpy in units of "cal/g" are contained in the fourth column of Table 5. The values of the molar fusion enthalpy were calculated by the product of the molecular weight (second column) and the fusion enthalpy in units of "cal/g" (fourth column), and are listed in the fifth column. The sixth column shows the calculated values of the fusion entropy in e.u.. 
Table 4. $\Delta \mathrm{S}_{\mathrm{m}}$ of 13 Atomic Species Determined by Procopiu (after Ref. 11)

\begin{tabular}{lccccc}
\hline \multirow{2}{*}{ Metal } & \multirow{2}{*}{ Atomic wt. } & \multirow{2}{*}{ Melting Point } & \multicolumn{2}{c}{$\Delta \mathrm{H}_{\mathrm{m}}$} & \multirow{2}{*}{$\Delta \mathrm{S}_{\mathrm{m}}$} \\
\cline { 5 - 5 } & $\mathrm{M}(\mathrm{g} / \mathrm{mol})$ & $\mathrm{T}_{\mathrm{m}}(\mathrm{K})$ & $\mathrm{cal} / \mathrm{g}$ & $\mathrm{cal} / \mathrm{mol}$ & \\
& & & & & \\
\hline $\mathrm{Na}$ & 23.0 & 370 & 31.7 & 729.1 & 1.97 \\
$\mathrm{~K}$ & 39.1 & 335 & 15.7 & 613.9 & 1.83 \\
$\mathrm{Cu}$ & 63.6 & 1356 & 41.6 & 2645.8 & 1.95 \\
$\mathrm{Ag}$ & 107.9 & 1234 & 21.07 & 2273.5 & 1.84 \\
$\mathrm{Cd}$ & 112.4 & 594 & 10.8 & 1213.9 & 2.04 \\
$\mathrm{~Pb}$ & 207.2 & 600 & 5.86 & 1214.2 & 2.02 \\
$\mathrm{Al}$ & 27.0 & 931 & 76.8 & 2073.6 & 2.23 \\
$\mathrm{Fe}$ & 55.8 & 1535 & 59.0 & 3292.2 & 2.14 \\
$\mathrm{Au}$ & 197.2 & 1337 & 15.8 & 3115.8 & 2.33 \\
$\mathrm{Hg}$ & 200.6 & 234 & 2.77 & 555.7 & 2.37 \\
$\mathrm{Ni}$ & 58.7 & 1708 & 73.8 & 4332.1 & 2.54 \\
$\mathrm{Zn}$ & 65.4 & 692.5 & 28.3 & 1850.1 & 2.67 \\
$\mathrm{Pt}$ & 195.2 & 2028 & 27.2 & 5309.4 & 2.62 \\
& & & & & \\
\hline
\end{tabular}


Table 5. $\Delta \mathrm{S}_{\mathrm{m}}$ of 31 Organic Materials, as Determined by Walden (after Ref. 12)

\begin{tabular}{|c|c|c|c|c|c|}
\hline \multirow[t]{2}{*}{ Material } & \multirow{2}{*}{$\begin{array}{l}\text { Mol. wt. } \\
\text { (g/mol) }\end{array}$} & \multirow{2}{*}{$\begin{array}{l}\text { Melting } \\
\text { Point } \\
\text { (K) }\end{array}$} & \multicolumn{2}{|c|}{$\Delta \mathrm{H}_{\mathrm{m}}$} & \multirow{2}{*}{$\begin{array}{l}\Delta \mathrm{S}_{\mathrm{m}} \\
\text { (e.u.) }\end{array}$} \\
\hline & & & $\overline{(\mathrm{cal} / \mathrm{g})}$ & $(\mathrm{cal} / \mathrm{mol})$ & \\
\hline $\mathrm{C}_{10} \mathrm{H}_{4} \mathrm{Br}_{2}$ & 236 & 358 & 20.6 & 4862 & 13.6 \\
\hline $\mathrm{C}_{6} \mathrm{H}_{4} \mathrm{Cl}_{2}$ & 147 & 325.5 & 29.9 & 4395 & 13.5 \\
\hline $\mathrm{C}_{6} \mathrm{H}_{4} \mathrm{ClBr}$ & 191.5 & 340 & 25.1 & 4807 & 14.1 \\
\hline $\mathrm{C}_{6} \mathrm{H}_{4} \mathrm{ClNH}_{2}$ & 127.5 & 342 & 37.2 & 4743 & 13.9 \\
\hline $\mathrm{C}_{10} \mathrm{H}_{7} \mathrm{NO}_{2}$ & 173 & 329 & 25.3 & 4377 & 13.3 \\
\hline $\mathrm{C}_{10} \mathrm{H}_{7} \mathrm{Br}$ & 207 & 332 & 17.8 & 3685 & 12.7 \\
\hline $\mathrm{C}_{7} \mathrm{H}_{7} \mathrm{Cl}$ & 126.5 & 280 & 28.0 & 3542 & 12.7 \\
\hline $\mathrm{C}_{7} \mathrm{H}_{7} \mathrm{Br}$ & 171 & 299.9 & 21.9 & 3745 & 12.5 \\
\hline $\mathrm{C}_{7} \mathrm{H}_{7} \mathrm{~J}$ & 216 & 307 & 18.8 & 4061 & 13.2 \\
\hline$\left(\mathrm{C}_{6} \mathrm{H}_{5}\right)_{2} \mathrm{NH}$ & 169 & 326 & 26.3 & 4445 & 13.6 \\
\hline $\mathrm{C}_{7} \mathrm{H}_{7} \mathrm{NH}_{2}$ & 107 & 311.9 & 39.0 & 4173 & 13.4 \\
\hline $\mathrm{C}_{6} \mathrm{H}_{5} \mathrm{NH}_{2}$ & 93 & 266 & 39.9 & 3711 & 13.9 \\
\hline $\mathrm{C}_{6} \mathrm{H}_{4}\left(\mathrm{CH}_{3}\right)_{2}$ & 106 & 289 & 38.8 & 4113 & 14.2 \\
\hline $\mathrm{C}_{10} \mathrm{H}_{8}$ & 128 & 353 & 35.7 & 4570 & 12.9 \\
\hline$\left(\mathrm{C}_{6} \mathrm{H}_{5}\right)_{2}$ & 154 & 343.2 & 29.4 & 4528 & 13.2 \\
\hline$\left(\mathrm{C}_{6} \mathrm{H}_{5}\right)_{2} \mathrm{CH}_{2}$ & 168 & 299.3 & 25.2 & 4234 & 14.1 \\
\hline$\left(\mathrm{C}_{6} \mathrm{H}_{5}\right)_{3} \mathrm{CH}$ & 244 & 366 & 21.5 & 5246 & 14.3 \\
\hline $\mathrm{C}_{6} \mathrm{H}_{4}\left(\mathrm{NO}_{2}\right)_{2}$ & 168 & 363 & 29.0 & 4872 & 13.4 \\
\hline $\mathrm{C}_{6} \mathrm{H}_{5} \mathrm{NO}_{2}$ & 123 & 278.3 & 30.1 & 3702 & 13.3 \\
\hline $\mathrm{C}_{6} \mathrm{H}_{4}\left(\mathrm{C}_{3} \mathrm{H}_{5}\right)\left(\mathrm{OCH}_{3}\right)$ & 148 & 295.5 & 27.3 & 4040 & 13.7 \\
\hline $\mathrm{C}_{6} \mathrm{H}_{5} \mathrm{COCH}_{3}$ & 122 & 292.5 & 30.3 & 3697 & 12.6 \\
\hline$\left(\mathrm{C}_{6} \mathrm{H}_{5}\right)_{2} \mathrm{CO}$ & 182 & 321 & 23.7 & 4313 & 13.4 \\
\hline $\mathrm{C}_{7} \mathrm{H}_{7} \mathrm{COOH}$ & 136 & 350 & 32.0 & 4352 & 12.5 \\
\hline $\mathrm{C}_{6} \mathrm{H}_{4}(\mathrm{OH}) \mathrm{COOC}_{10} \mathrm{H}_{7}$ & 264 & 366 & 18.0 & 4752 & 13.0 \\
\hline
\end{tabular}


Table 5. $\Delta \mathrm{S}_{\mathrm{m}}$ of 31 Organic Materials, as Determined by Walden (after Ref. 12) (continued)

\begin{tabular}{|c|c|c|c|c|c|}
\hline \multirow[t]{2}{*}{ Material } & \multirow{2}{*}{$\begin{array}{l}\text { Mol. wt. } \\
(\mathrm{g} / \mathrm{mol})\end{array}$} & \multirow{2}{*}{$\begin{array}{l}\text { Melting } \\
\text { Point } \\
\text { (K) }\end{array}$} & \multicolumn{2}{|c|}{$\Delta \mathrm{H}_{\mathrm{m}}$} & \multirow{2}{*}{$\begin{array}{l}\Delta \mathrm{S}_{\mathrm{m}} \\
\text { (e.u.) }\end{array}$} \\
\hline & & & $\overline{(\mathrm{cal} / \mathrm{g})}$ & $(\mathrm{cal} / \mathrm{mol})$ & \\
\hline $\mathrm{C}_{6} \mathrm{H}_{4}\left(\mathrm{OCH}_{3}\right)_{2}$ & 138 & 295.5 & 27.3 & 3767 & 12.8 \\
\hline $\mathrm{CH}_{3} \mathrm{C}_{6} \mathrm{H}_{2}\left(\mathrm{NO}_{2}\right)_{3}$ & 227 & 352 & 21.5 & 4881 & 13.9 \\
\hline $\mathrm{CH}_{3} \mathrm{C}_{6} \mathrm{H}_{3}\left(\mathrm{NO}_{2}\right)_{3}$ & 182 & 343 & 26.4 & 4805 & 14.0 \\
\hline $\mathrm{C}_{14} \mathrm{H}_{10}$ & 178 & 486 & 40.5 & 7209 & 14.8 \\
\hline $\mathrm{C}_{6} \mathrm{H}_{5} \mathrm{NHC}_{7} \mathrm{H}_{7}$ & 183 & 309 & 21.9 & 4008 & 13.0 \\
\hline$\left(\mathrm{C}_{6} \mathrm{H}_{4}\right)_{2} \mathrm{NH}$ & 167 & 509 & 42.1 & 7031 & 13.8 \\
\hline $\mathrm{N}_{2} \mathrm{O}_{4}$ & 92 & 262.05 & 37.2 & 3422 & 13.1 \\
\hline
\end{tabular}




\subsubsection{Semi-empirical Model by Pirsch}

Pirsch considered the value of fusion entropy to be related to the structure of the molecule, particularly the symmetry of the molecule. (13) Therefore he classified the organic molecules into 3 groups: spherical molecules, ring-shaped molecules, and irregular molecules, in order of decreasing symmetry. He found the fusion entropy to be about 3 e.u. for spherical molecules (e.g., $\left.\mathrm{CH}_{4}, \mathrm{CCl}_{4},\left(\mathrm{CH}_{3}\right)_{6} \mathrm{C}_{2}, \mathrm{Cl}_{3} \mathrm{CCO}_{2} \mathrm{H},\left(\mathrm{CH}_{3}\right)_{3} \mathrm{COH}\right)$, 13 e.u. for ring-shaped molecules (e.g., $\mathrm{C}_{6} \mathrm{H}_{6}$, cyclic compounds), and greater than 20 e.u. for irregular-shaped molecules or chains (e.g., alkanes).(14)

There may be two reasons to account for the smaller value of the fusion entropy, namely 3 e.u. for spherical molecules. First, the ratio of the surface area to the volume of the molecule is the smallest in the case of spherical molecules, and this results in the lowest free energy or inter-molecular interaction. Second, the spherical molecules are symmetric and therefore do not possess the dipole moments to enhance the inter-molecular interaction.

\subsubsection{Semi-empirical Model by Procopiu}

Procopiu found that for a number of organic materials the value of the fusion entropy was approximately equal to the number of atoms in the molecule. This represents the energy for 1 degree of freedom of kinetic energy for each atom. (15)

He formulated Equation 7 to predict the fusion entropy of organic compounds.

$$
\Delta \mathrm{S}_{\mathrm{m}}=\mathrm{n} *(1 / 2 * \mathrm{R})=\mathrm{n} *(1 / 2 * 1.986)=\mathrm{n}
$$


where $R$ is the gas constant ( 1.986 e.u.), and $n$ is the number of atoms in the molecules. The term " $1 / 2 * R$ " is related to one degree of freedom contributed from each atom. For organic materials containing $n$ atoms, the entropy is therefore " $n^{*}(1 / 2 * R)$ ".

\subsubsection{Quantitative Model by Chickos}

James S. Chickos ${ }^{(16)}$ used the group additivity theory for estimating the fusion entropies of organic compounds, namely hydrocarbons and hydrocarbon derivatives. This includes both monofunctional and multifunctional groups. The group additivity theory is based upon the assumption that the fusion entropy is a group property and can be estimated from the additivity of the contributions of each constituent part, provided that the structural environment of each group is taken into account. Fusion entropies are then summed from both carbon group contributions and functional group contributions.

The equations proposed by Chickos for predicting the fusion entropies of different categories of hydrocarbons are as follows:

(1) For acyclic and aromatic hydrocarbons,

$$
\Delta \mathrm{S}_{\mathrm{m}}=\Sigma(\mathrm{ni})(\mathrm{Ci})(\mathrm{Gi})
$$

where ni refers to the number of identical groups in the molecule, and $\mathrm{Ci}$ and Gi are group coefficients and group values respectively.

(2) For cyclic hydrocarbons,

$$
\Delta \mathrm{S}_{\mathrm{m}}=[8.41+1.025(\mathrm{n}-3)]+\sum(\mathrm{ni})(\mathrm{Ci})(\mathrm{Gi})
$$


where $\mathrm{n}$ is the size of the ring.

(3) For polycyclic hydrocarbons,

$$
\Delta \mathrm{S}_{\mathrm{m}}=[8.41 \mathrm{~N}+1.025(\mathrm{R}-3 \mathrm{~N})]+\sum(\mathrm{ni})(\mathrm{Ci})(\mathrm{Gi})
$$

where $N$ is the number of rings, and $R$ is the total number of ring atoms.

The equations for predicting fusion entropies for hydrocarbon derivatives bearing functional groups were proposed as follows:

(1) For acyclic and aromatic hydrocarbon derivatives,

$$
\Delta \mathrm{S}_{\mathrm{m}}=\sum(\mathrm{ni})(\mathrm{Ci})(\mathrm{Gi})+\sum(\mathrm{nj})(\mathrm{Cj})(\mathrm{Gj})+\sum(\mathrm{nk})(\mathrm{Ck})(\mathrm{Gk})
$$

where $n i$ is the number of carbon atoms without a functional group, $\mathrm{nj}$ is the number of carbon atoms attached to the functional group, nk is the number of functional groups, $\mathrm{Gi}$ and $\mathrm{Gj}$ are group values from carbon group contributions, Gk are group values from functional group contributions, and $\mathrm{Ci} / \mathrm{Cj}$ and $\mathrm{Ck}$ are group coefficients for carbon groups and functional groups respectively.

(2) For cyclic hydrocarbon derivatives,

$$
\begin{aligned}
\Delta \mathrm{S}_{\mathrm{m}} & =[8.41+1.025(\mathrm{n}-3)]+\sum(\mathrm{ni})(\mathrm{Ci})(\mathrm{Gi})+\sum(\mathrm{nj})(\mathrm{Cj})(\mathrm{Gj}) \\
& +\sum(\mathrm{nk})(\mathrm{Ck})(\mathrm{Gk})
\end{aligned}
$$

where $\mathrm{n}$ is the size of the ring.

(3) For polycyclic hydrocarbons, 


$$
\begin{aligned}
\Delta \mathrm{S}_{\mathrm{m}} & =[8.41 \mathrm{~N}+1.025(\mathrm{R}-3 \mathrm{~N})]+\sum(\mathrm{ni})(\mathrm{Ci})(\mathrm{Gi})+\sum(\mathrm{nj})(\mathrm{Cj})(\mathrm{Gj}) \\
& +\sum(\mathrm{nk})(\mathrm{Ck})(\mathrm{Gk})
\end{aligned}
$$

where $\mathrm{N}$ is the number of rings, and $\mathrm{R}$ is the total number of ring atoms.

Table 6 is a list of entropy contributions from the carbon groups. ${ }^{(16)}$ Each carbon group, in terms of different structural environments (primary, secondary, etc.) and hybridizations ( $\mathrm{sp}^{2}, \mathrm{sp}^{3}$, etc.), as listed in the first column, contributes a different amount towards the fusion entropy as listed in the third column $\left(G_{i}\right)$. The group coefficients $\left(C_{j}\right)$, as shown in the fifth column, are used as correction factors for those carbons bearing functional groups.

Table 7 is a listing of the entropy contribution from functional groups. (16) Each functional group will also contribute a certain amount towards the fusion entropy, as listed in the second column $\left(\mathrm{G}_{\mathrm{k}}\right)$. The group coefficients $\left(C_{k}\right)$, as shown from the fourth to sixth columns, are used as correction factors when more than one functional group appears.

A total of 649 organic compounds were used by Chickos to evaluate the group values $\left(\mathrm{G}_{\mathrm{i}}, \mathrm{G}_{\mathrm{k}}\right)$ and group coefficients $\left(\mathrm{C}_{\mathrm{i}}, \mathrm{C}_{\mathrm{j}}, \mathrm{C}_{\mathrm{k}}\right)$ shown in Tables 6 and 7. This was done by regression analysis. The fusion entropies of these 649 materials had been compiled from 29 different sources. The model proposed by Chickos gave a quantitative treatment of fusion entropy and has been the most extensive means for analyzing the value of $\Delta S_{m}$ of organic materials thus far. The absolute average percent deviation of this model for predicting $\Delta S_{\mathrm{m}}$ of hydrocarbons from the experimentally measured values was reported to be $12.1 \%$ by Chickos ${ }^{(17)}$ and this accounts for the reliability of the group additivity theory for the predictions of $\Delta \mathrm{S}_{\mathrm{m}}$. 


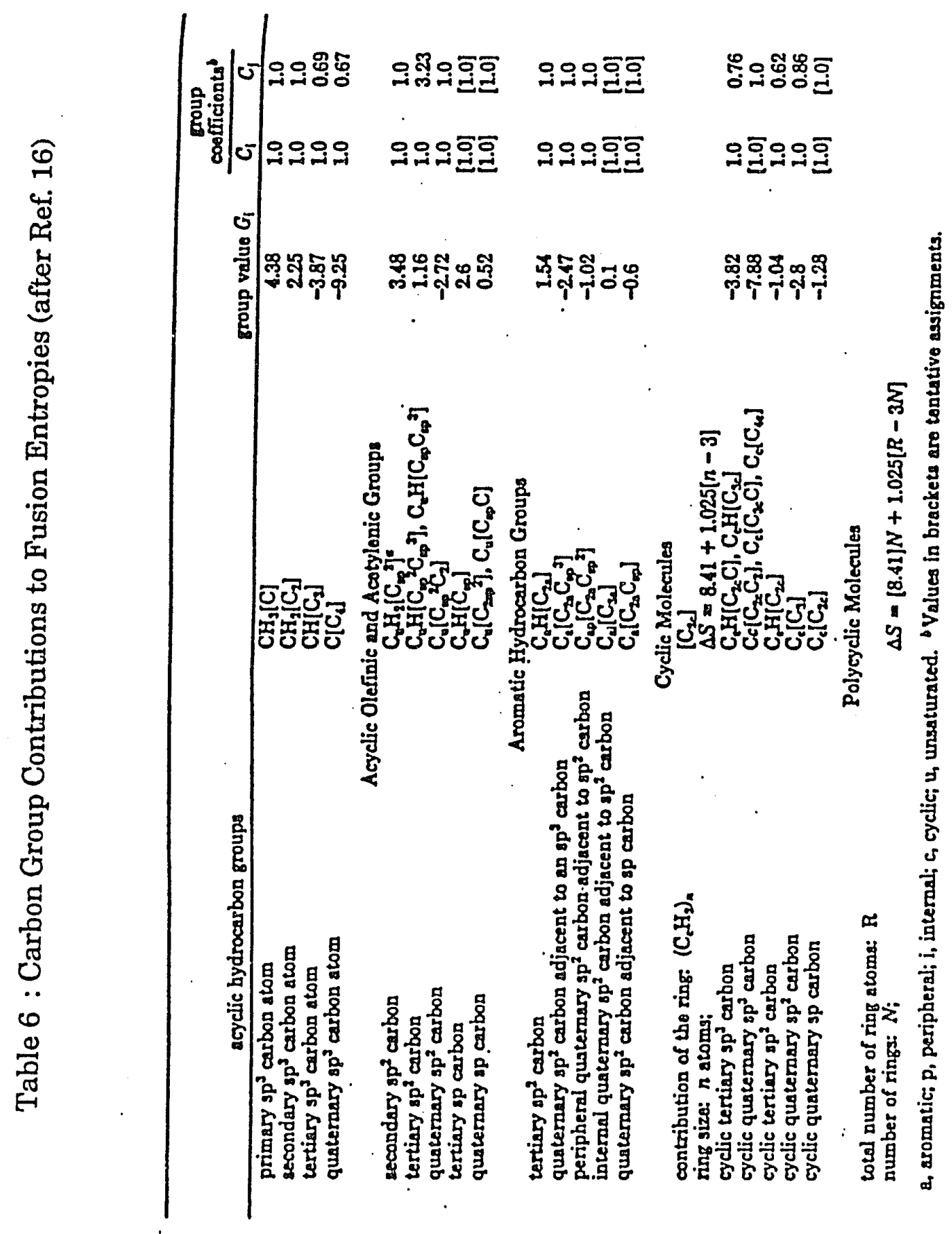


Table 7. Functional Group Contributions to Fusion Entropies (after Ref. 16)

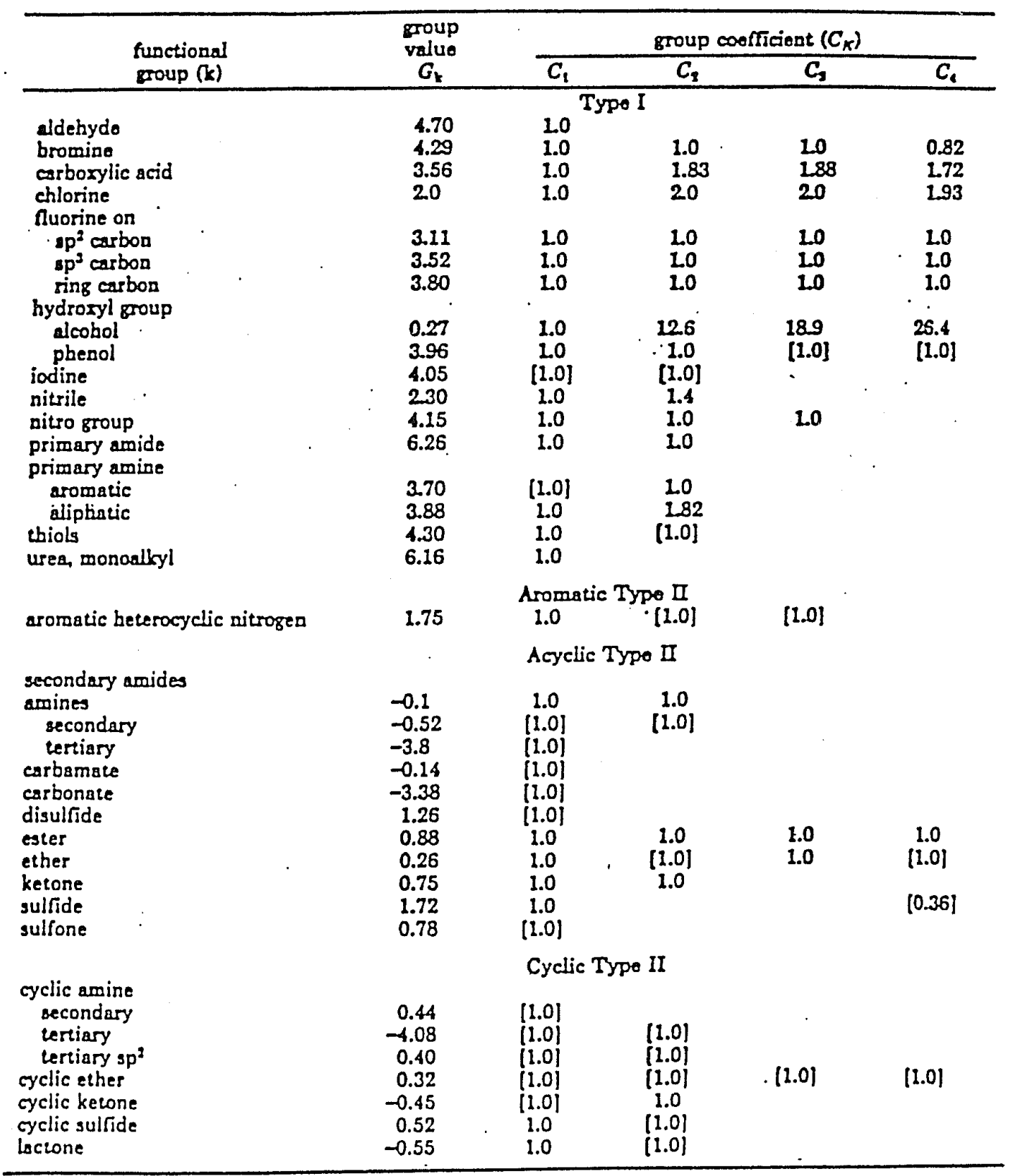




\subsubsection{Fusion Enthalpy of Aqueous Solutions}

Two models for predicting the fusion enthalpy of aqueous solutions were identified, namely, the Rule of Mixtures and Horvath's model which is a model for dilute solutions.

\subsubsection{The Rule of Mixtures}

The Rule of Mixtures is commonly used to determine the enthalpy of fusion of a binary system which shows ideal behavior. The equation for predicting fusion enthalpies of ideal solutions is as follows:

$$
\Delta \mathrm{H}_{\mathrm{m}} \text { (ideal solution) }=\mathrm{X}_{\mathrm{a}} \Delta \mathrm{H}_{\mathrm{a}}+\mathrm{X}_{\mathrm{b}} \Delta \mathrm{H}_{\mathrm{b}}
$$

where $\Delta \mathrm{H}_{\mathrm{a}}$ and $\Delta \mathrm{H}_{\mathrm{b}}$ are the fusion enthalpies for components $\mathrm{a}$ and $\mathrm{b}$ respectively, and $X_{a}$ and $X_{b}$ are the respective molar fractions of components $a$ and $b$.

For predicting fusion enthalpies of aqueous solutions, Equation 14 can be rewritten as follows :

$$
\Delta \mathrm{H}_{\mathrm{m}} \text { (aqueous solutions) }=\mathrm{X}_{\mathrm{a}} \Delta \mathrm{H}_{\mathrm{a}}+\mathrm{X}_{\mathrm{H} 2 \mathrm{O}} \Delta \mathrm{H}_{\mathrm{H} 2 \mathrm{O}}
$$

where $\mathrm{X}_{\mathrm{a}}$ and $\mathrm{X}_{\mathrm{H} 2 \mathrm{O}}$ are the molar fraction of solute " $\mathrm{a}$ " and water respectively, and $\Delta \mathrm{H}_{\mathrm{a}}$ and $\Delta \mathrm{H}_{\mathrm{H} 2 \mathrm{O}}$ are the fusion enthalpy of solute "a" and water respectively.

\subsubsection{Horvath's Model}

A.L.Horvath ${ }^{(18)}$ proposed the following equation for computing the melting point of a dilute solution:

$$
\mathrm{T}_{\mathrm{m}}=\left(\mathrm{T}_{\mathrm{m}} 0\right) /\left(1+\mathrm{RT}_{\mathrm{m}} 0 * \mathrm{~N}_{2} \div \Delta \mathrm{H}_{\mathrm{m}}+\mathrm{N}_{1}\right)
$$


where $T_{m}$ is the melting point $(K)$ of the solution, $\mathrm{T}_{\mathrm{m}}{ }^{0}$ is the melting point $(\mathrm{K})$ of the pure solvent, $\Delta \mathrm{H}_{\mathrm{m}}$ is the molar enthalpy of fusion (cal/mole) of the solution, and $\mathrm{N}_{1}$ and $\mathrm{N}_{2}$ are the number of moles of solvent and solute respectively.

The results and the origin of this equation were not addressed by the author. Therefore this equation was rederived from a thermodynamic viewpoint, and is shown in Appendix A.

For the purpose of predicting the fusion enthalpies of aqueous solutions Equation 16 can be rewritten as follows:

$$
\Delta \mathrm{H}_{\mathrm{m}}=\mathrm{R}^{*} \mathrm{~T}_{\mathrm{m}} 0 *\left(\mathrm{~N}_{2} / \mathrm{N}_{1}\right) *\left[\mathrm{~T}_{\mathrm{m}} /\left(\mathrm{T}_{\mathrm{m}} 0-\mathrm{T}_{\mathrm{m}}\right)\right]
$$

where $T_{m}{ }^{0}$ is the melting point of pure water, $273 \mathrm{~K}$, and $T_{m}$ is the melting point of the aqueous solution. Thus, by measuring the melting point of an aqueous solution, it would be possible to compute the $\Delta \mathrm{H}_{\mathrm{m}}$ for that particular solution.

All the seven models described in this chapter were tested for their accuracy. The four semi-empirical models were tested using data available from the published literatures. The three quantitative models, namely Chickos's model, the Rule of Mixtures, and Horvath's model, were tested against experimental data. The experimental methodology employed in this investigation is described in Chapter 3. 


\section{CHAPTER 3 \\ INVESTIGATION METHODOLOGY}

This chapter presents the methodology for investigating the value of the enthalpy of fusion. Both a theoretical and an experimental approach were taken in this research. A theoretical investigation of the $\Delta \mathrm{H}_{\mathrm{m}}$ from the models is needed in order to make future experimental work easier. The existing models, as described in Chapter 2, were employed to calculate the theoretical $\Delta \mathrm{H}_{\mathrm{m}}$. These models included Chickos's model applied to organic compounds, and both the Rule of Mixtures and Horvath's model applied to aqueous solutions. An experimental investigation of $\Delta \mathrm{H}_{\mathrm{m}}$ was also needed, considering the fact that literature values of $\Delta \mathrm{H}_{\mathrm{m}}$ are occasionally unreliable for organic compounds, and frequently unavailable for aqueous solutions. Experiments were conducted to test the validity of the findings from the theoretical models. The experimental methodology employed in this study is described in Section 3.2 .

\subsection{Theoretical}

The candidate FHS materials are either organic compounds or aqueous solutions, as shown in Table 1. Therefore the fusion enthalpies of organic compounds and aqueous solutions were modeled in this project.

\subsubsection{Organic Compounds}

A total of 4 models, namely Walden's model, Pirsch's model, Procopiu's model, and Chickos's model, for predicting $\Delta \mathrm{S}_{\mathrm{m}}$ of organic compounds were 
found from the literature. Based on a limited number of organic materials, Walden found the $\Delta S_{m}$ to have a constant value of 13.5 e.u.. However, due to the lack of sound theoretical reasoning, it is doubtful that this statement will hold true for all the thousands of organic materials that exist today. Pirsch categorized the organic compounds into three groups and considered each material in the same group to have the same value of fusion entropy. This characterization is also too broad to quantify the fusion entropies of all organic compounds. Procopiu considered the value of $\Delta S_{m}$ to be approximately equal to the number of atoms. According to this, any two molecules with the same number of atoms are expected to have the same value of fusion entropy, which would be unlikely. These three models are all too general and are unlikely to accurately predict fusion entropy of organic materials. In this investigation, they were tested against data available from the literature ${ }^{(19)}$ to determine their validity, but were not employed for modeling purposes due to the lack of sound theoretical reasoning.

Chickos used the group additivity theory and regression analysis to characterize organic materials into different structural environments, hybridizations, and functional groups. The absolute average percentage deviation between the calculated fusion entropy and experimental values was reported by Chickos to be $12.1 \%$ for hydrocarbons. ${ }^{(17)}$ Based on his reported accuracy, the group additivity theory for predicting $\Delta \mathrm{S}_{\mathrm{m}}$ of organic materials appears to be reliable. As can be seen from Tables 6 and 7, Chickos's model is a very specific and quantitative model, compared to the other three models. Therefore this model was chosen for modeling and testing against the experimental data. 
To predict $\Delta \mathrm{H}_{\mathrm{m}}$ of organic materials from Chickos's model, the following equation was used:

$$
\Delta \mathrm{H}_{\mathrm{m}}=\mathrm{T}_{\mathrm{m}} * \Delta \mathrm{S}_{\mathrm{m}}
$$

where $T_{m}$ is the melting point which was determined experimentally, and $\Delta \mathrm{S}_{\mathrm{m}}$ is the fusion entropy which was determined from Equations 8 through 13 , according to the applicable category. The values of the entropy contribution from both carbon groups and functional groups were obtained from Tables 6 and 7.

\subsubsection{Aqueous Solutions}

Two models for predicting $\Delta \mathrm{H}_{\mathrm{m}}$ of aqueous solutions were found from the literature, the Rule of Mixtures and Horvath's model. The validity of these two models had not been investigated previously due to the fact that experimental values of $\Delta \mathrm{H}_{\mathrm{m}}$ for aqueous solutions have been unavailable.

Based on the Rule of Mixtures, the $\Delta \mathrm{H}_{\mathrm{m}}$ of aqueous solutions is given by Equation 15:

$$
\Delta \mathrm{H}_{\mathrm{m}} \text { (aqueous solutions) }=\mathrm{X}_{\mathrm{a}} \Delta \mathrm{H}_{\mathrm{a}}+\mathrm{X}_{\mathrm{H} 2 \mathrm{O}} \Delta \mathrm{H}_{\mathrm{H} 2 \mathrm{O}}
$$

where $\Delta \mathrm{H}_{\mathrm{a}}$ and $\Delta \mathrm{H}_{\mathrm{H} 2 \mathrm{O}}$ are the fusion enthalpies of solute "a" and water respectively, and $\mathrm{X}_{\mathrm{a}}$ and $\mathrm{X}_{\mathrm{H} 2 \mathrm{O}}$ are molar fractions of solute "a" and water respectively. The values of $\mathrm{X}_{\mathrm{a}}$ and $\mathrm{X}_{\mathrm{H} 2 \mathrm{O}}$ are determined from the original compositions. The values of $\Delta \mathrm{H}_{\mathrm{a}}$ and $\Delta \mathrm{H}_{\mathrm{H} 2 \mathrm{O}}$ were obtained from the published literature. $(6,19)$ These are listed in Appendix B.

Based on Horvath's model, the $\Delta \mathrm{H}_{\mathrm{m}}$ of aqueous solutions is given by Equation 17.

$$
\Delta \mathrm{H}_{\mathrm{m}}=\mathrm{R}^{*} \mathrm{~T}_{\mathrm{m}} 0 *\left(\mathrm{~N}_{2} / \mathrm{N}_{1}\right) *\left[\mathrm{~T}_{\mathrm{m}} /\left(\mathrm{T}_{\mathrm{m}}{ }^{0}-\mathrm{T}_{\mathrm{m}}\right)\right]
$$


where $T_{m}$ is the melting point $(K)$ of the solution which was determined experimentally, $\mathrm{T}_{\mathrm{m}}{ }^{0}$ is the melting point $(\mathrm{K})$ of pure water $273^{\circ} \mathrm{K}$, and $\mathrm{N}_{1}$ and $\mathrm{N}_{2}$ are the number of moles of water and the dissociated solute ions, respectively, determined from the original compositions.

\subsection{Experimental}

Experimental values of fusion enthalpy are needed as a standard to test the reliability of the models, as proposed in Section 3.1, for predicting the values of fusion enthalpy. The materials for which the values of $\Delta \mathrm{H}_{\mathrm{m}}$ and $\mathrm{T}_{\mathrm{m}}$ were measured are presented in Section 3.2.1. The experimental methodology for obtaining the values of fusion enthalpies is described in Section 3.2.2.

\subsubsection{Materials}

The materials that were chosen for experimental verification of $\Delta \mathrm{H}_{\mathrm{m}}$ and $T_{m}$ are listed in Tables 8 and 9 . Those listed in Table 8 constitute the organic compounds, and those listed in Table 9 constitute the aqueous solutions. Those materials identified by an "* " in Tables 8 and 9 , are candidate FHS materials identified by Selvaduray and Lomax. The cooling capacity was determined only for candidate FHS materials that yielded an experimental $\mathrm{T}_{\mathrm{m}}$ between $-13^{\circ} \mathrm{C}$ to $5^{\circ} \mathrm{C}$. All materials were purchased from Aldrich Chemical Company and all aqueous solutions were prepared using de-ionized water. 
Table 8. Organic Compounds Selected for $\Delta \mathrm{H}_{\mathrm{m}}$ and $\mathrm{T}_{\mathrm{m}}$ Measurements Material Purity

\begin{tabular}{lr}
\hline Glycerol triacetate* & $100 \%$ \\
Triethylene glycol* & $99 \%$ \\
Benzene,hexafluoro* & $100 \%$ \\
Heptanoic acid* $^{*}$ 2-methyl-2-butanol* $^{*}$ & $99 \%$ \\
2,3-Butanedione* & $99 \%$ \\
Benzoic acid,2-fluoro* & $99 \%$ \\
Cyclohexanol,2-methyl(trans)* & $97 \%$ \\
Cyclohexanol,4-methyl(cis)* & $99 \%$ \\
Tert-Butyl hydroperoxide* & $98 \%$ \\
Benzene,1,4-difluoro* & $100 \%$ \\
Cyclohexanone,2-methyl* & $99 \%$ \\
Cinnamonitrile* & $99 \%$ \\
Cyclooctatetraene* & $97 \%$ \\
4-Methoxybenzaldehyde* & $98 \%$ \\
Benzyl alcohol* & $98 \%$ \\
Indene* & $99 \%$ \\
Cyclohexane,1,2-dibromo* & $99 \%$ \\
Benzene* & $99 \%$ \\
Biphenyl,2-methyl* & $98 \%$ \\
Naphthalene,1-iodo* & $99 \%$ \\
1,2-dihydronaphthalene* & $99 \%$ \\
Biphenyl,3-methyl* & $98 \%$ \\
Piperidene* & $95 \%$ \\
& $99 \%$ \\
\hline
\end{tabular}

* Candidate FHS materials identified by Selvaduray and Lomax 
Table 9. Aqueous Solutions Selected for $\Delta \mathrm{H}_{\mathrm{m}}$ and $\mathrm{T}_{\mathrm{m}}$ Measurements

\begin{tabular}{|c|c|c|}
\hline Materials & Concentration & Purity \\
\hline \multirow[t]{4}{*}{ Magnesium chloride } & $1.0 \%$ & $98 \%$ \\
\hline & $5.0 \%$ & $98 \%$ \\
\hline & $10.0 \%$ & $98 \%$ \\
\hline & $15.0 \%$ & $98 \%$ \\
\hline \multirow[t]{4}{*}{ Lithium bromide } & $1.0 \%$ & $99 \%$ \\
\hline & $5.0 \%$ & $99 \%$ \\
\hline & $10.0 \%$ & $99 \%$ \\
\hline & $15.0 \%$ & $99 \%$ \\
\hline \multirow[t]{3}{*}{ Lithium chloride } & $1.0 \%$ & $99 \%$ \\
\hline & $4.0 \% *$ & $99 \%$ \\
\hline & $12.0 \%$ & $99 \%$ \\
\hline \multirow[t]{3}{*}{ Calcium chloride } & $8.0 \%$ & $97 \%$ \\
\hline & $12.0 \%$ & $97 \%$ \\
\hline & $15.0 \%$ & $97 \%$ \\
\hline \multirow[t]{2}{*}{ Sodium chloride } & $7.0 \% *$ & $98 \%$ \\
\hline & $15.0 \%$ & $98 \%$ \\
\hline Potassium chloride & $9.0 \% *$ & $99 \%$ \\
\hline Sodium bromide & $11.0 \% *$ & $99 \%$ \\
\hline Potassium chromate & $18.0 \% *$ & $98 \%$ \\
\hline Potassium bromide & $13.0 \% *$ & $99 \%$ \\
\hline Sodium nitrate & $10.0 \% *$ & $98 \%$ \\
\hline Potassium iodide & $16.0 \% *$ & $99 \%$ \\
\hline Cesium chloride & $19.0 \% *$ & $99 \%$ \\
\hline Sodium hydroxide & $4.5 \% *$ & $97 \%$ \\
\hline Silver nitrate & $16.0 \% *$ & $99 \%$ \\
\hline Potassium nitrate & $10.0 \% *$ & $100 \%$ \\
\hline
\end{tabular}

* Candidate FHS materials identified by Selvaduray and Lomax 
Table 9. Aqueous Solutions Selected for $\Delta \mathrm{H}_{\mathrm{m}}$ and $\mathrm{T}_{\mathrm{m}}$ Measurements (continued)

\begin{tabular}{lcc}
\hline Materials & Concentration & Purity \\
\hline Potassium sulfate & $5.0 \%^{*}$ & $99 \%$ \\
Potassium hydroxide & $6.0 \%^{*}$ & $99 \%$ \\
Potassium dichromate & $2.5 \%^{*}$ & $99 \%$ \\
Formic acid & $2.0 \%$ & $96 \%$ \\
& $10.0 \%^{*}$ & $96 \%$ \\
& $32.0 \%$ & $96 \%$ \\
Acetic acid & $2.0 \%$ & $99.8 \%$ \\
& $13.0 \%^{*}$ & $99.8 \%$ \\
& $20.0 \%$ & $99.8 \%$ \\
Ethylene glycol & $2.0 \%$ & $99 \%$ \\
& $12.0 \%^{*}$ & $99 \%$ \\
Ethanol & $28.0 \%$ & $99 \%$ \\
& $9.5 \%^{*}$ & $100 \%$ \\
Glycerol & $24.0 \%$ & $100 \%$ \\
& $16.0 \%^{*}$ & $99.5 \%$ \\
& $40.0 \%$ & $99.5 \%$ \\
\hline
\end{tabular}

* Candidate FHS materials identified by Selvaduray and Lomax 


\subsubsection{Equipment and Experimental Methodology}

A Perkin-Elmer Differential Scanning Calorimeter, Model DSC-4, was used to determine the fusion enthalpies, melting temperatures, and heat capacities. The experimental setup, the principle of measurement, the operating procedures, and the interpretations of the curve from the DSC scans are described below.

\subsubsection{Experimental Setup}

The Differential Scanning Calorimeter and the System 4 Microprocessor Controller, both made by Perkin-Elmer Corporation, were used in this study and are shown in Figure 4. The accessories for the equipment are the sample sealer, the sample pan holder, and a box of aluminum pans and pan covers. These are shown in Figure 5 from left to right, respectively. Figure 6 is a photograph of both the aluminum pan and pan cover, illustrating relative sizes. The sample holder and the reference holder, which are located inside the Differential Scanning Calorimeter, were also photographed in order to show where the material investigated was located, and are shown in Figure 7. During experiments, the material under investigation is placed into the sample holder while an empty pan as a reference is placed into the reference holder. 


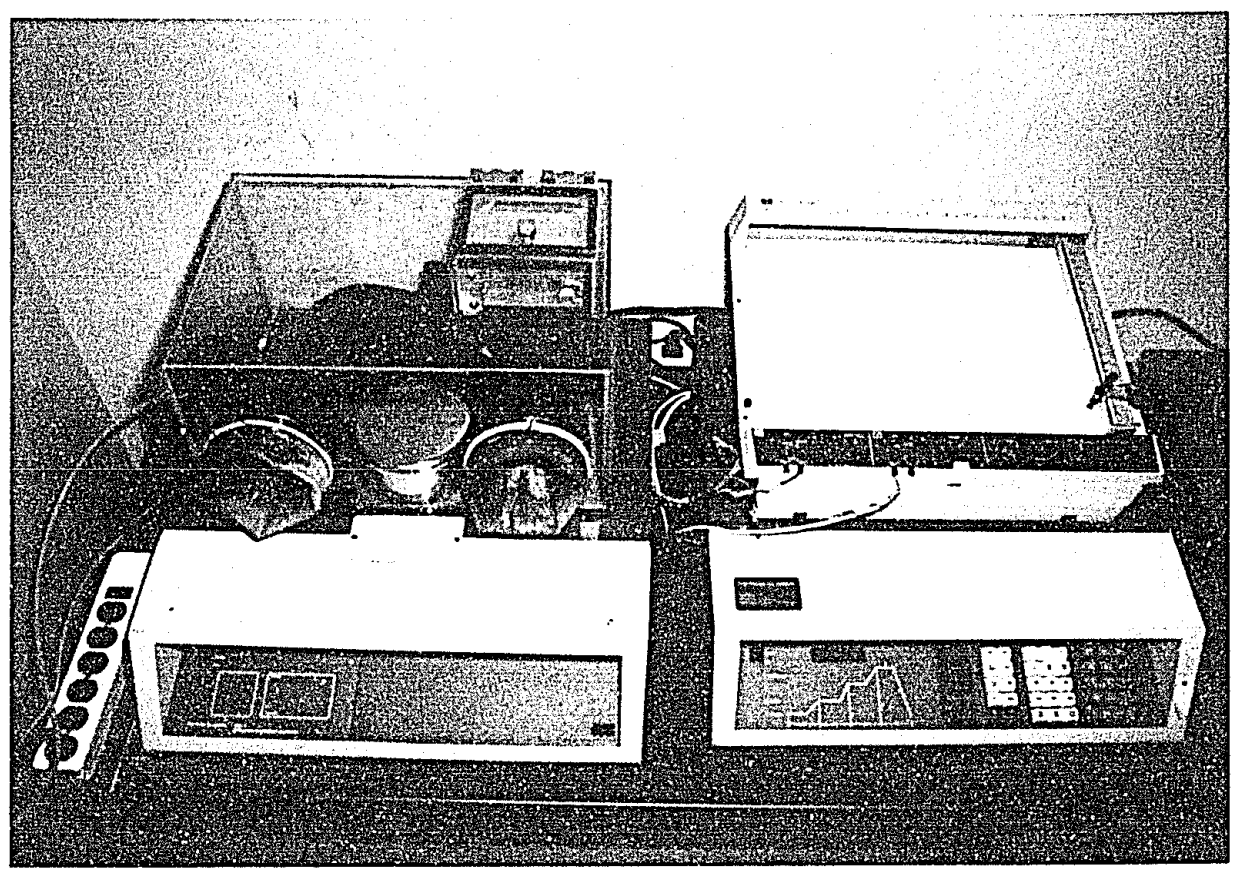

Figure 4. View of the DSC and the System 4 Microprocessor Controller

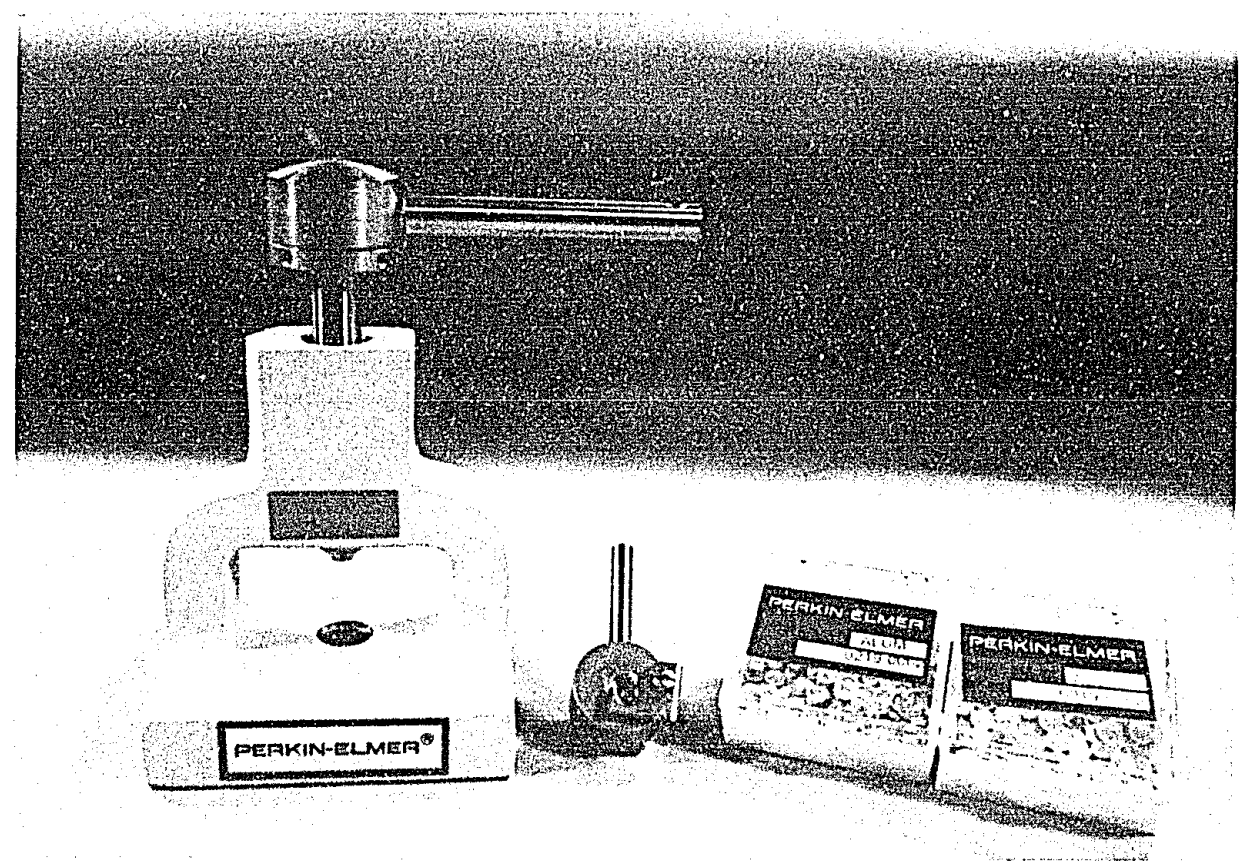

Figure 5. View of the Accessories for the Equipment 


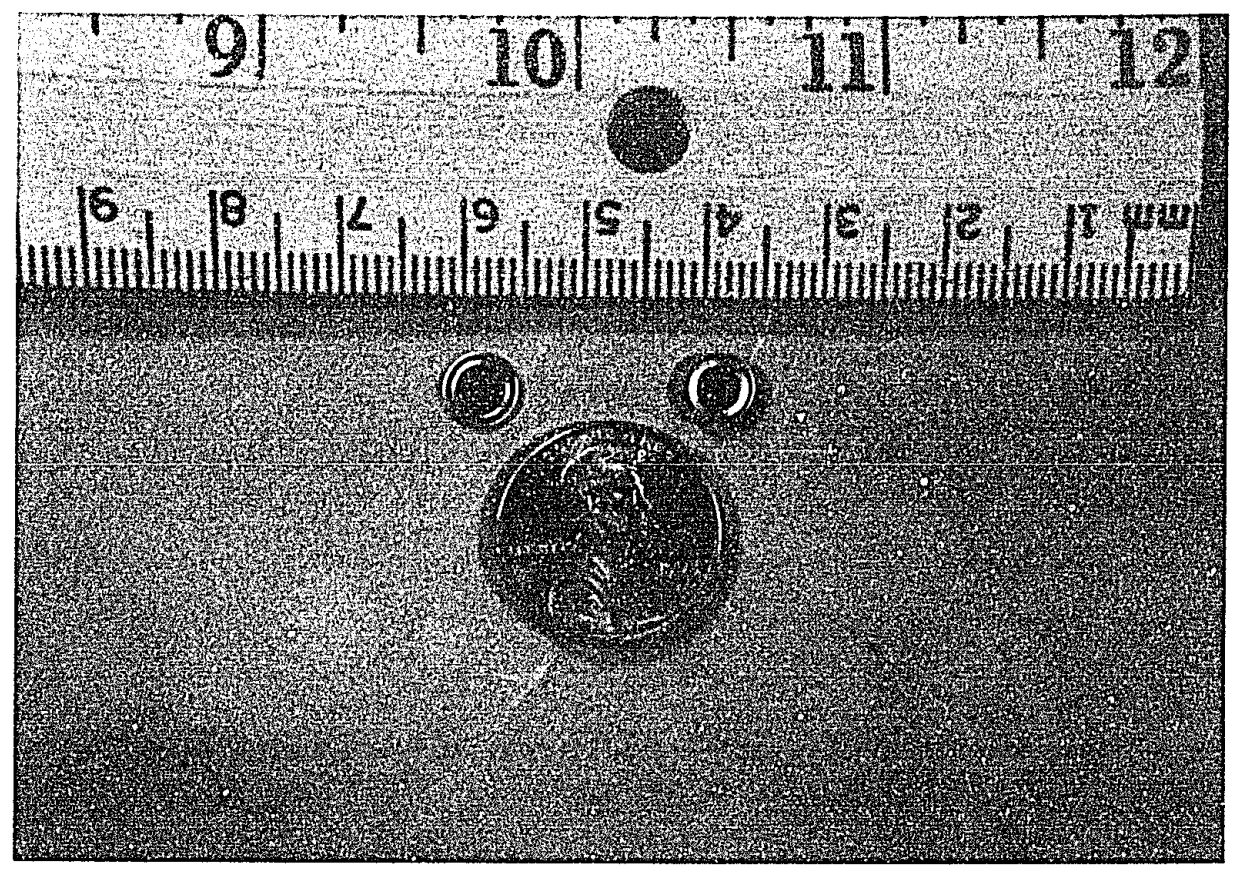

Figure 6. View of an Aluminum Pan and Pan Cover Illustrating Relative Sizes

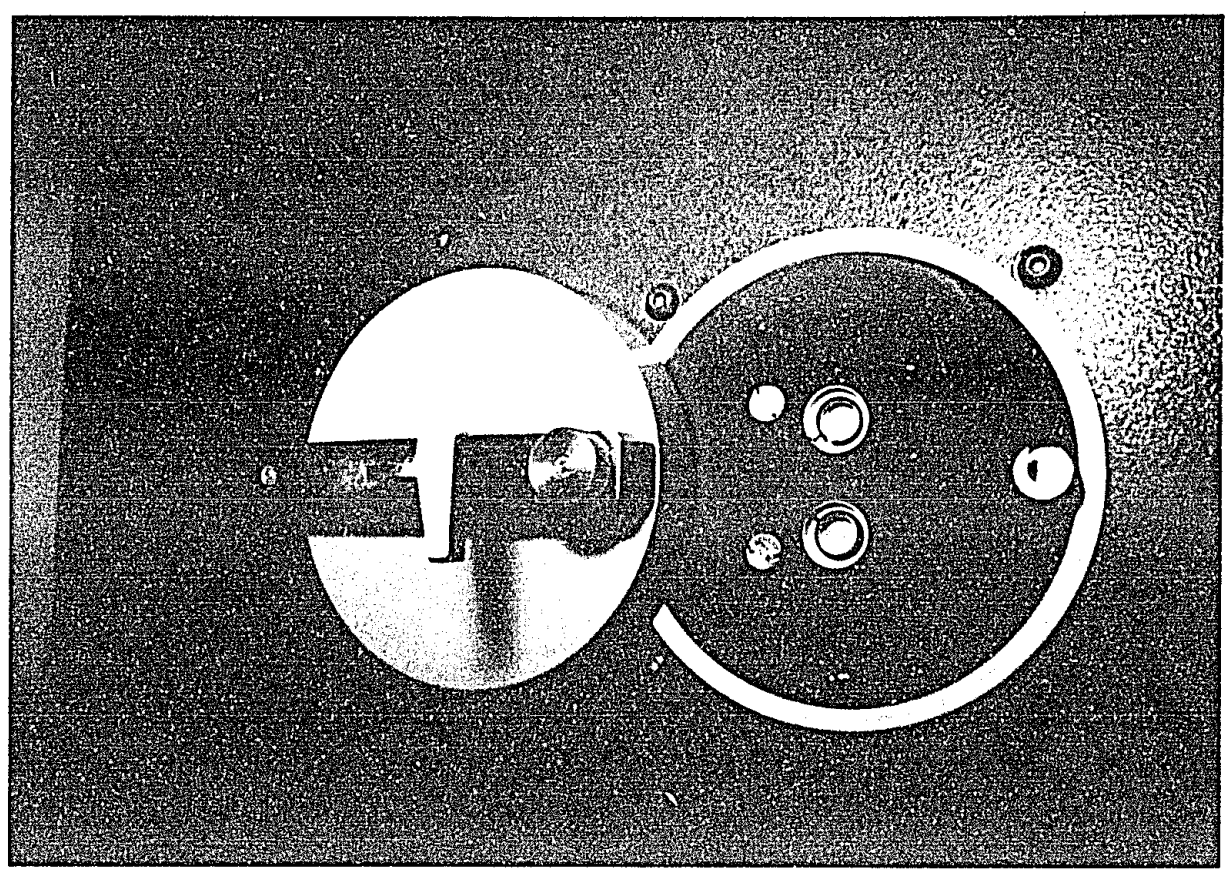

Figure 7. View of the Sample Chamber Including the Sample Holder (Circle in the Bottom) and the Reference Holder (Circle in the Top) 


\subsubsection{Principles of Measurement}

The arrangement of the DSC in Figure 8 is presented to explain the functioning of a Differential Scanning Calorimeter. The sample material and reference material (an empty pan) are placed in identical environments. Resistance thermometers are used to detect the temperature in both holders. During experiments, the material investigated is placed in the sample holder while the reference holder contains only an empty pan. The temperatures of the two holders are maintained at the same level by two heaters, one for each holder. The difference in energy required to maintain the two holders at identical temperatures is a measure of the thermal property of the material being investigated.

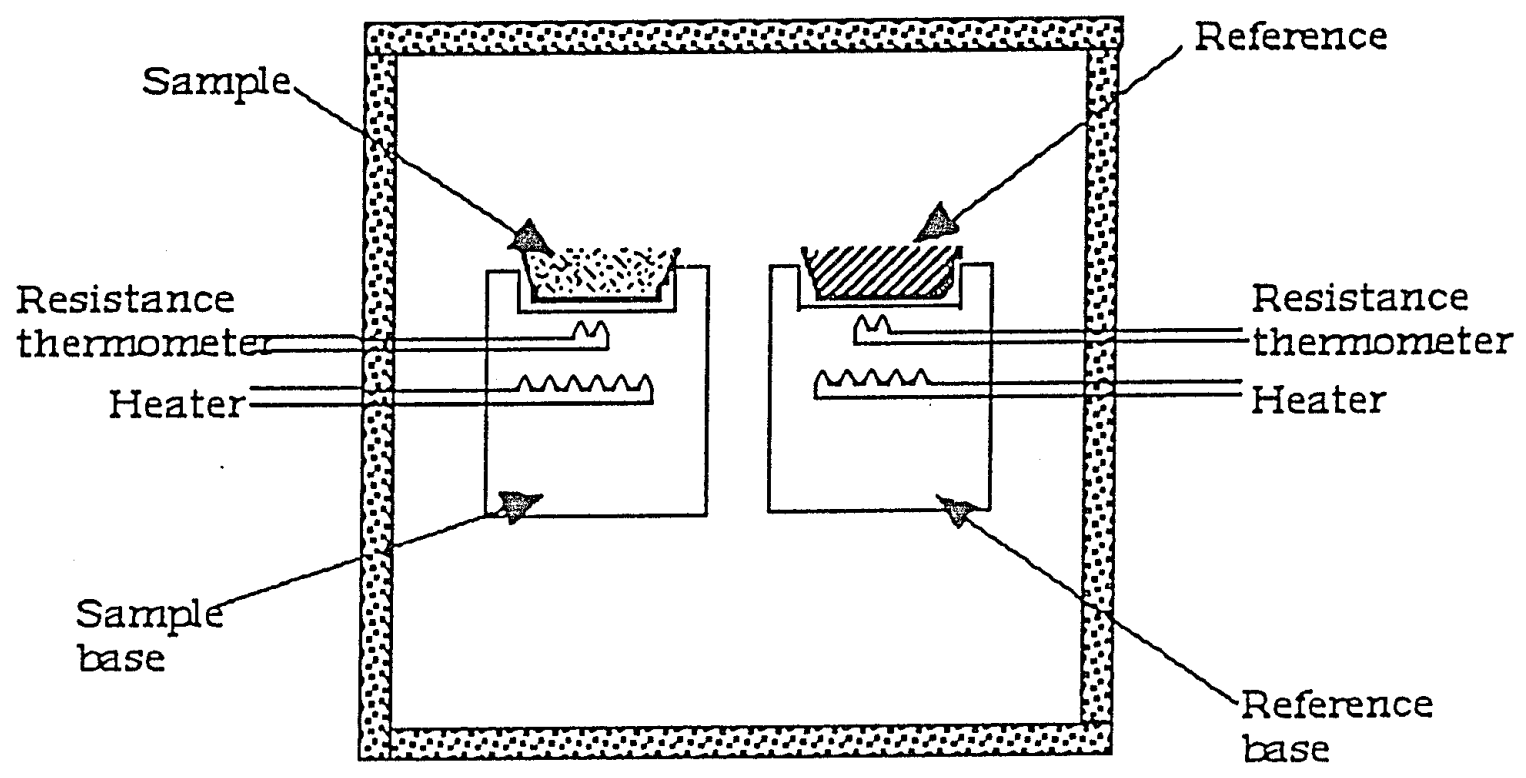

Figure 8. Experimental Arrangement of DSC 


\subsubsection{Procedure for Operating the DSC}

In order to verify accurate functioning of the DSC, calibration runs were first done with de-ionized water and indium. To prepare a de-ionized water sample pan for calibrating the DSC, four stages should be followed. These four stages are illustrated by means of the four photographs shown in Figures $9 \mathrm{a}, 9 \mathrm{~b}, 9 \mathrm{c}$, and $9 \mathrm{~d}$. Figure 9a shows the pan being placed on top of the sample pan holder. Figure 9b shows how de-ionized water was dropped into the pan. Figure 9c shows a pan cover being placed on the pan. Figure $9 \mathrm{~d}$ shows the use of a sample sealer to seal the pan and pan cover. After the initial calibration of the instrument is finished, the procedure for operating the DSC are as follows.

The first step is to purge the sample chamber with nitrogen gas to remove the moisture inside the chamber. Moisture becomes a condensate during cooling and affects the accuracy of the results from the experiment.

The second step is to calibrate the ordinate (energy). This is to make certain that the $\mathrm{Y}$-axis displacement in the chart recorder (heat flow rate), coincides with the preset programmed value of energy supply rate. As suggested by the operation manual, the calibration was performed at $50^{\circ} \mathrm{C}$.

The third step is to cool the instrument down to $-50^{\circ} \mathrm{C}$. Dry ice, which sublimes at $-78.6^{\circ} \mathrm{C},(20)$ was used as a coolant.

The fourth step is to optimize the flatness of the baseline. The baseline ought to be horizontal if the environment of the two holders is identical. However, the slope of the baseline may become positive or negative due to slight differences between the construction of the sample holder cover and the reference holder cover. The purpose of baseline optimization is to retain a 


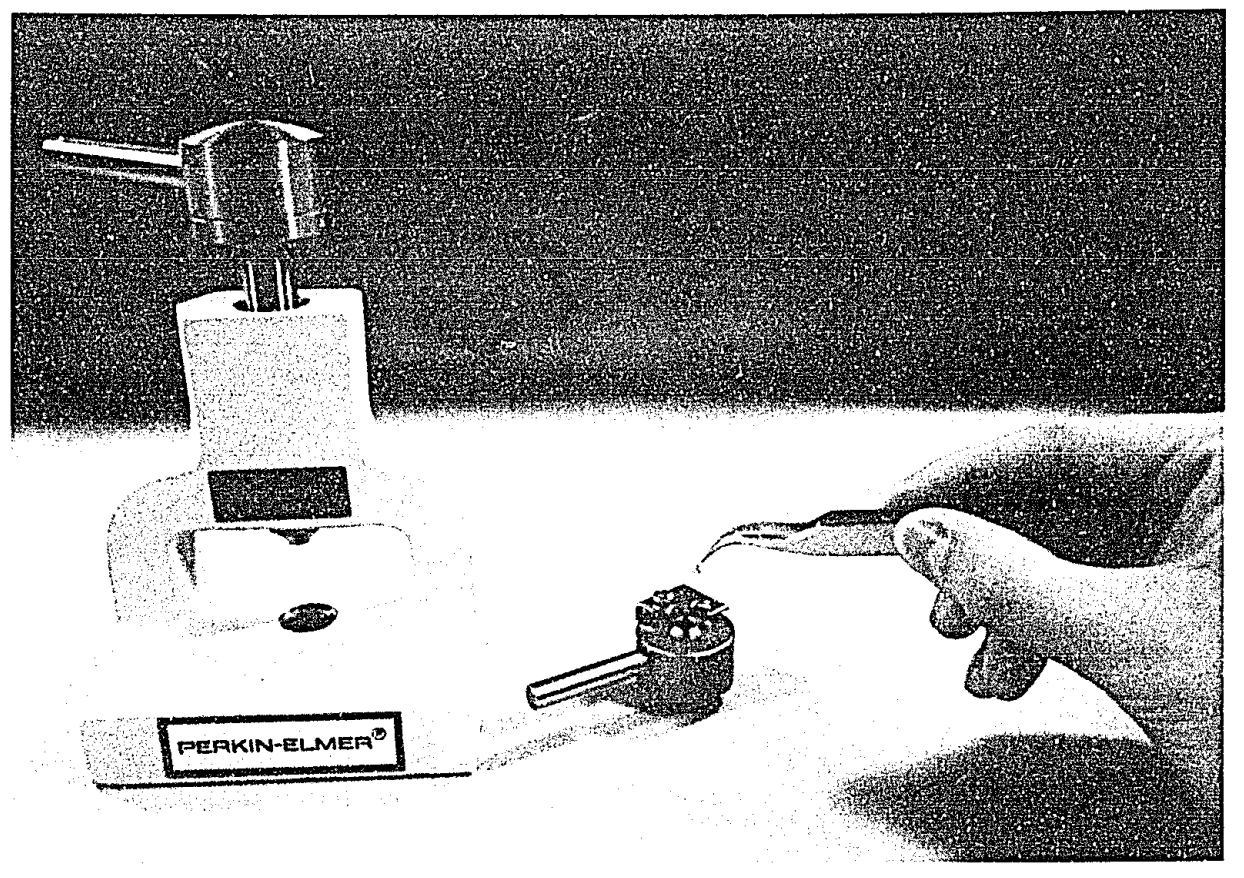

Figure 9a. The Process for Preparing a Sample Pan (Stage one)

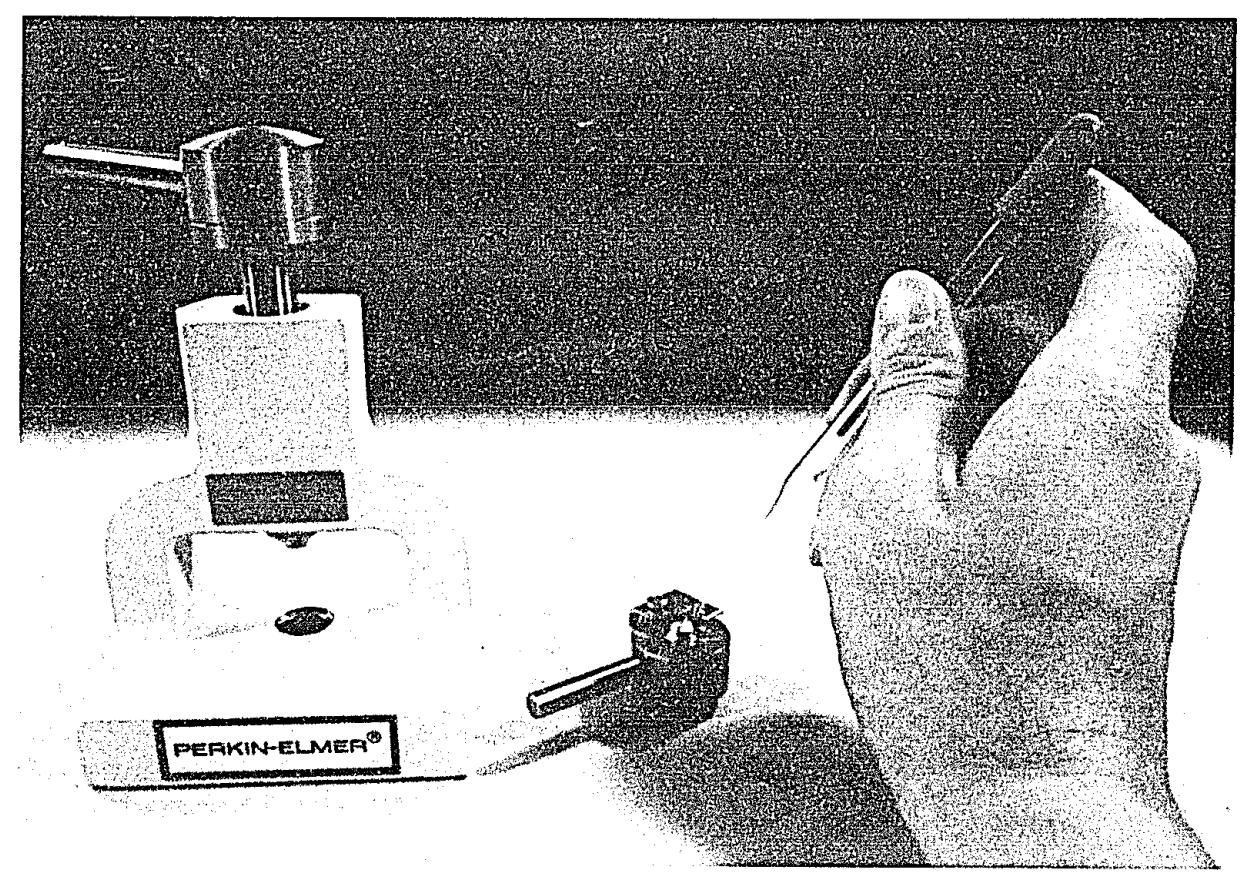

Figure 9b. The Process of Preparing a Sample Pan (Stage two) 


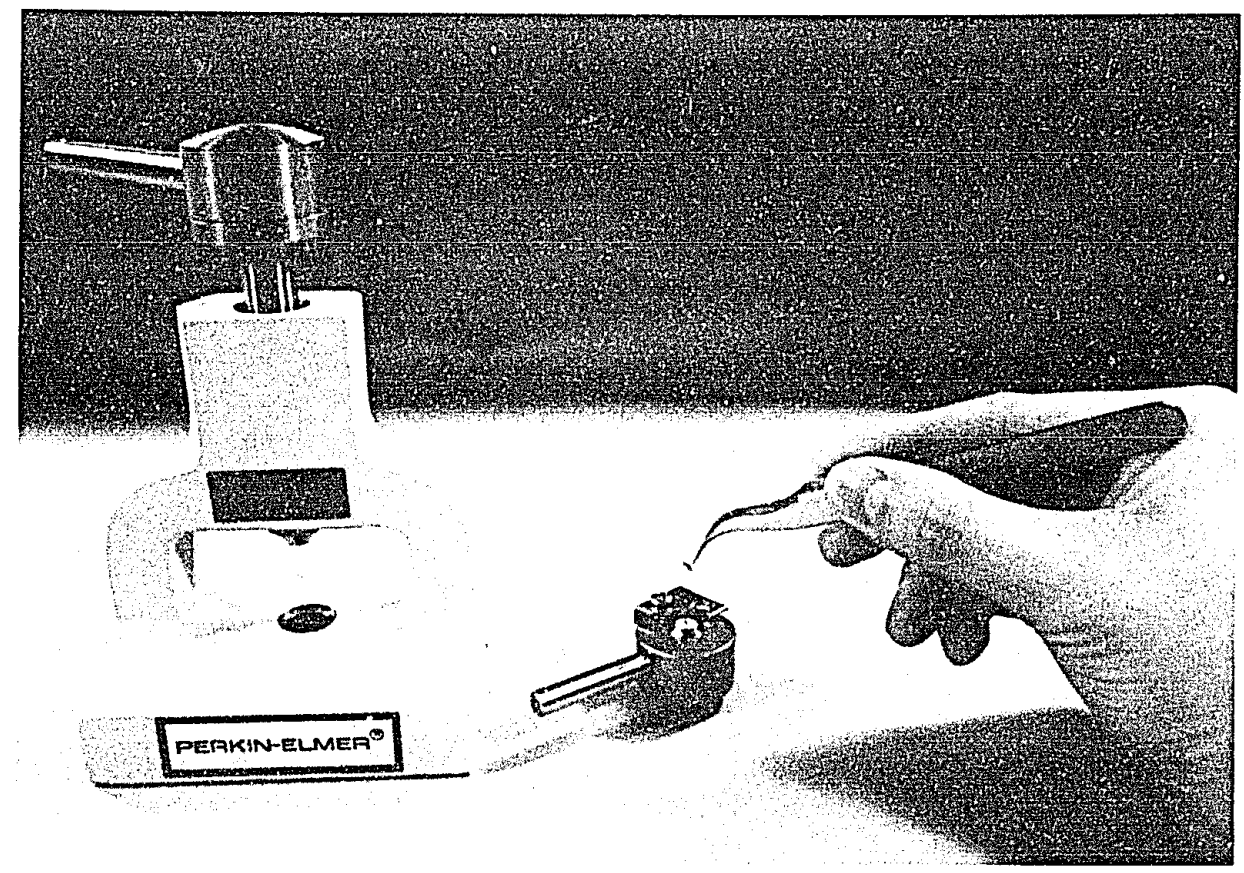

Figure 9c. The Process for Preparing a Sample Pan (Stage three)
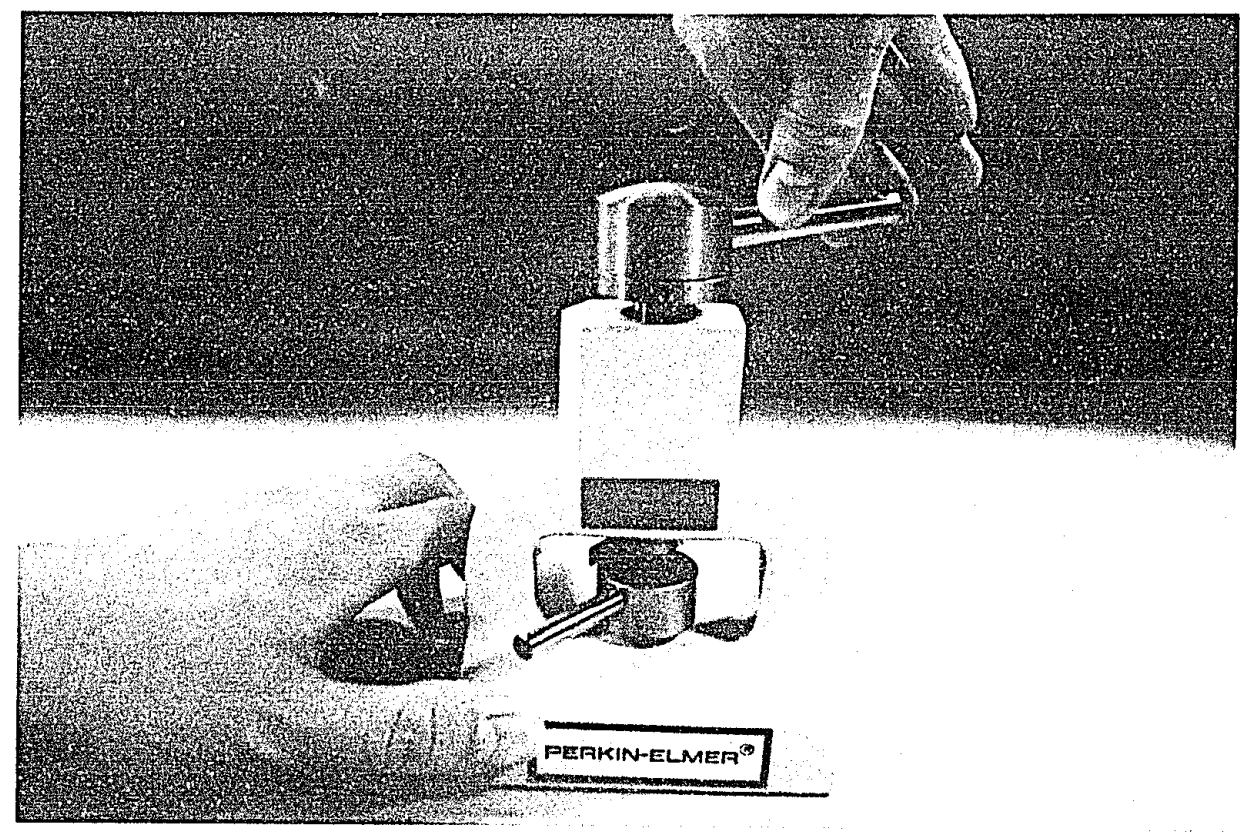

Figure 9d. The Process for Preparing a Sample Pan (Stage four) 
horizontal baseline by adjusting the heat flow rate. This step is performed over a temperature range of $-50^{\circ} \mathrm{C}$ to $30^{\circ} \mathrm{C}$, with both holders empty.

The fifth step is to prepare the sample materials for investigation. First a pan and pan cover are weighed using a microbalance accurate to 0.0001 grams. Both the pan and pan cover are made of aluminum. A pan cover should be used to avoid the loss of weight of volatile material, due to evaporation during scanning. The material investigated, with an approximate weight of several milligrams, is then dropped into the pan and covered with the pan cover. The pan cover and sample pan are then sealed together in the sample sealer to ensure the air-tightness between them and then weighed. The process of preparing a sample pan was illustrated by means of the four photographs in Figures 9a through 9d. After weighing, this sample pan is placed into the sample holder shown in Figure 7. The same weighing and sealing procedure is followed to prepare an empty pan for the reference holder.

The sixth step is to set up the parameters of scanning, including heating rate, initial temperature, and final temperature. The materials investigated were scanned from $-50^{\circ} \mathrm{C}$ to $30^{\circ} \mathrm{C}$ at a heating rate of $2^{\circ} \mathrm{C} / \mathrm{min}$. The maximum allowable heating rate is a function of the weight of the material. Heavier materials require a slower heating rate to complete the phase transition. The relationship between maximum allowable heating rate and the weight of material was investigated. The data for water is shown in Appendix C. From these measurements it was determined that a heating rate of $2^{\circ} \mathrm{C} / \mathrm{min}$ would be slow enough to be insensitive to the sample weight. After scanning, the sample pan is weighed to determine if any evaporation had occured. If the 
evaporation is greater than $2 \%$, then a new sample should be made up, and the measurement repeated.

The last step is to scan an empty pan in order to determine the heat capacity of the material being measured. This is done by placing an empty pan in both holders and using the same procedure as that for the scanning of the material investigated.

\subsubsection{Appearance of DSC Curve}

Figure 10 shows a typical DSC scan. The $\mathrm{X}$ axis is the temperature scale and the $\mathrm{Y}$ axis is the heat flow rate. The curve from the DSC scan appears to be "peak-like." This is explained in the following paragraph.

In the case of a solid-liquid transition, the heat flow rate is expected to reach a maximum which corresponds to the absorption of the latent heat of melting. Therefore, the graph obtained should theoretically be "delta-shaped" or "pulse-shaped," meaning that the phase transition happens at a specific temperature (melting point). However, owing to the delay in heat transfer from the bottom layer of the material (inside the sample pan) to the top, the curve is "peak-like" instead of "pulse-shaped."

\subsubsection{Determination of $T_{m}, \Delta H_{m}, C p, s$ and $C p, 1$}

Figure 10 illustrates how data concerning $T_{m}, \Delta H_{m}, C p, s$, and $C p, l$ is obtained from a Differential Scanning Calorimeter scan. The tangent line $\mathrm{AA}^{\prime}$ of the sample curve intersects the sample solid baseline BB' and the sample liquid baseline $C C^{\prime}$ at points $M$ and $N$. The melting temperature, $T_{m}$, 


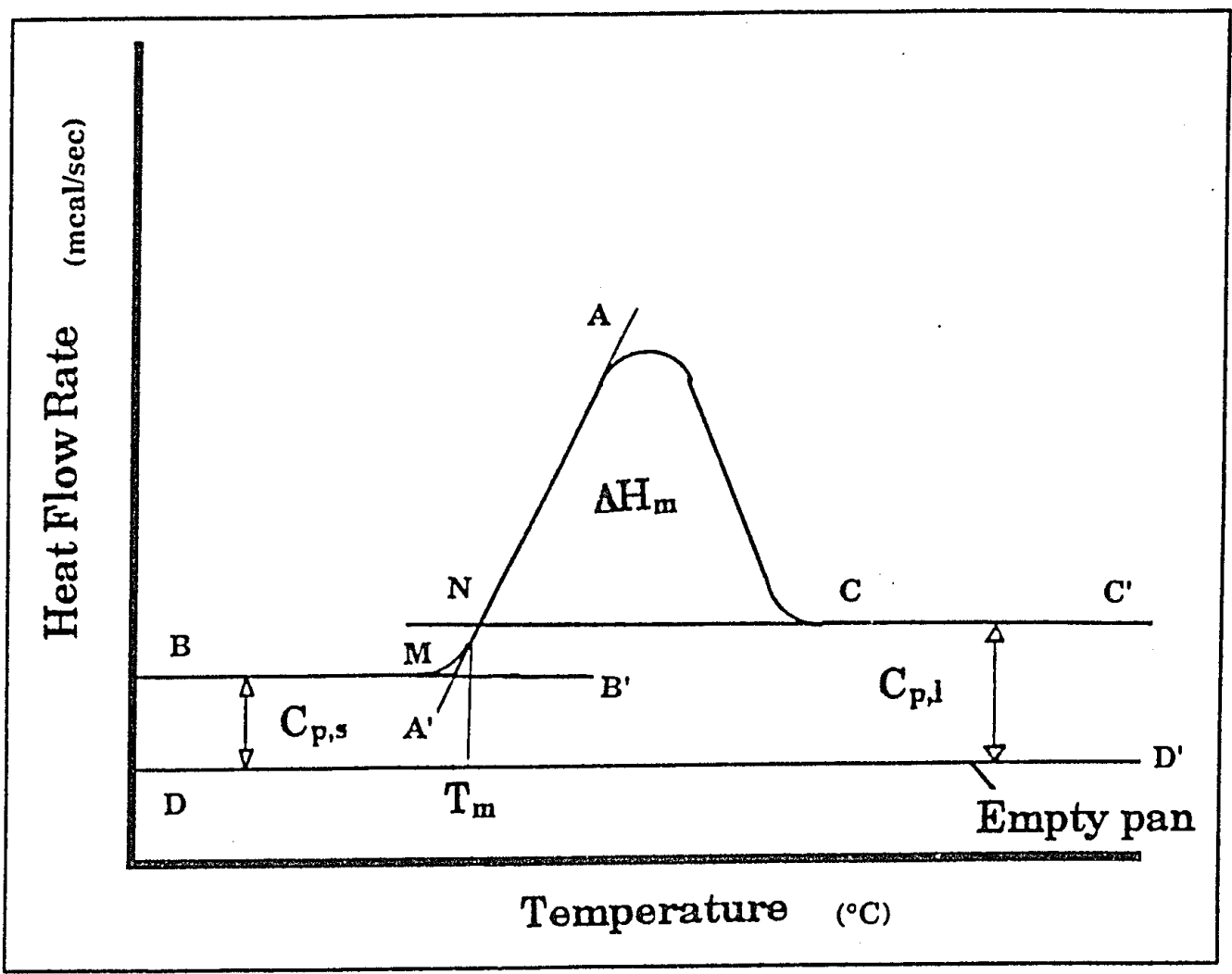

Fig 10. DSC Scan Plot 
is determined by locating the mid-point of the segment MN, as shown in Figure 10.

The fusion enthalpy, $\Delta \mathrm{H}_{\mathrm{m}}$ is determined using Equation 18.

$$
\Delta \mathrm{H}_{\mathrm{m}}=\left[(\mathrm{R} * \mathrm{~A}) /\left(\mathrm{W}^{*} \mathrm{~S}\right)\right]^{*} \mathrm{~K}^{\prime}
$$

where $\Delta \mathrm{H}_{\mathrm{m}}$ is the fusion enthalpy of the material in calories per gram,

$R$ is the range sensitivity in $\mathrm{mcal} / \mathrm{sec}$-inch,

$A$ is the area of the peak ( $\triangle \mathrm{NAC}$ ) in square inches,

$\mathrm{W}$ is the weight of the material in milligrams,

$\mathrm{S}$ is the recorder chart speed in inch/sec, and

$\mathrm{K}^{\prime}$ is the instrument constant.

The value of $\mathrm{K}^{\prime}$ is obtained from the calibration of indium (In) and is determined using Equation 19.

$$
\mathrm{K}^{\prime}=\left(\Delta \mathrm{H}_{\mathrm{m}}(\mathrm{ref}) /\left[\left(\mathrm{R}^{*} \mathrm{~A}\right) /\left(\mathrm{W}^{*} \mathrm{~S}\right)\right]\right.
$$

where $\Delta \mathrm{H}_{\mathrm{m}}$ (ref) is the enthalpy of fusion of indium from the reference (Perkin-Elmer Catalogue). R, A, W, and $\mathrm{S}$ are the same parameters as those described in Equation 18. A detailed sample calculation for determining $\Delta \mathrm{H}_{\mathrm{m}}$ of water is shown in Appendix D.

The $\mathrm{Cp}, \mathrm{s}$ and $\mathrm{Cp}, \mathrm{l}$ data is obtained by comparison with experiments conducted with empty pans. The value of $\mathrm{Cp}, \mathrm{s}$ is determined by Equation 20 .

$$
\mathrm{Cp}, \mathrm{s}=(\mathrm{dH} / \mathrm{dt}) /[(\mathrm{dT} / \mathrm{dt})(\mathrm{W})]
$$

where $\mathrm{dH} / \mathrm{dt}$ is the heat flow rate, determined by measuring the distance between the empty baseline (DD') and the sample's baseline in the solid state $\left(B B^{\prime}\right), d T / d t$ is the heating rate, and $W$ is the weight of the sample.

The value of $\mathrm{Cp}, 1$ is determined by Equation 21 .

$$
\mathrm{Cp}, \mathrm{l}=(\mathrm{dH} / \mathrm{dt}) /(\mathrm{dT} / \mathrm{dt})(\mathrm{W})
$$


where $\mathrm{dH} / \mathrm{dt}$ is the heat flow rate, determined by measuring the distance between the empty baseline (DD') and the sample's baseline in the liquid state (CC'), dT/dt is the heating rate, and $\mathrm{W}$ is the weight of the sample.

The experimental values of fusion enthalpy determined according to the procedure documented in this chapter were used to evaluate the three quantitative models: Chickos's model, the Rule of Mixtures, and Horvath's model. These results are presented in Chapter 4. 


\section{CHAPTER 4 RESULTS AND DISCUSSION}

This chapter presents the results of the evaluation of the seven existing models described in Chapter 2. The four semi-empirical models for predicting fusion entropy, as described in Section 2.2, were tested using available published literature data. The results are presented, along with a discussion of their validity, in Section 4.1. The experimental data including the values of melting point, enthalpy of fusion, and heat capacity is presented in Section 4.2. The three quantitative models for predicting fusion enthalpy, as described in Section 3.1, were tested against the experimental data. The results are presented, along with a discussion of their validity, in Section 4.3.

\subsection{Validity of the Semi-empirical Models}

Four semi-empirical models for predicting $\Delta \mathrm{S}_{\mathrm{m}}$ were tested. The entropy of fusion was calculated based on the models presented in Chapter 2. The results of these calculations are summarized in this section. For ease of understanding, the results for each model are presented seperately. The calculated values were compared with the published literature values and the percentage deviation determined.

\subsubsection{Procopiu's Model for $\Delta \mathbf{S}_{\mathrm{m}}$ of Atomic Species}

Procopiu found that the value of fusion entropy was approximately equal to the gas constant, 1.986 e.u. ( $\left.\mathrm{cal} / \mathrm{mol}^{\circ} \mathrm{K}\right)$, for 13 selected atomic species. To determine if this model is applicable for a wider range of atomic species, a 
total of 59 atomic species were investigated. The results are shown in Figure 11. The $\mathrm{X}$ axis is the melting point and the $\mathrm{Y}$ axis is the fusion enthalpy. The line $\mathrm{OZ}$ corresponds to the constant value of fusion entropy, 1.986 e.u., as predicted by Procopiu. As can be seen from Figure 11, Procopiu's model is reliable for most atomic species.

To further determine the accuracy of this model in applications to different groups, these 59 atomic species were arranged according to the Periodic Table and tested individually. The results are shown in Table 10. The third column contains the $\Delta S_{\mathrm{m}}$ determined by Procopiu's model. The $\Delta \mathrm{S}_{\mathrm{m}}$ values in the fourth column were obtained by dividing the $\Delta \mathrm{H}_{\mathrm{m}}$ values reported in the literature ${ }^{(6)}$ by the melting point. The fifth column contains the absolute percent value of the deviation between the calculated values and the values determined from the literature.

As can be seen from Table 10, Procopiu's model has an accuracy within $35 \%$ for most atomic species except $\mathrm{Ga}, \mathrm{Si}, \mathrm{Ge}, \mathrm{Sn}, \mathrm{As}, \mathrm{Sb}, \mathrm{Bi}, \mathrm{Ne}, \mathrm{Ar}, \mathrm{Xe}, \mathrm{La}$, $\mathrm{Pr}, \mathrm{Nd}$, and Pm. The elements $\mathrm{Si}, \mathrm{Ge}, \mathrm{Sn}$ belong to the IVA group. The elements $\mathrm{As}, \mathrm{Sb}, \mathrm{Bi}$ belong to the VA group. The elements $\mathrm{Ne}, \mathrm{Ar}, \mathrm{Xe}$ belong to the VIIIA group. The elements La, Pr, Nd, Pm belong to the Lanthanides. Procopiu's model seems quite reliable when applied to materials in the IA, IIA, IB, IIB, IIIB, IVB, VB, VIB, VIIB, and VIII groups. Within the constraints of this project it was not possible to pursue the reasons that might explain this behavior. 


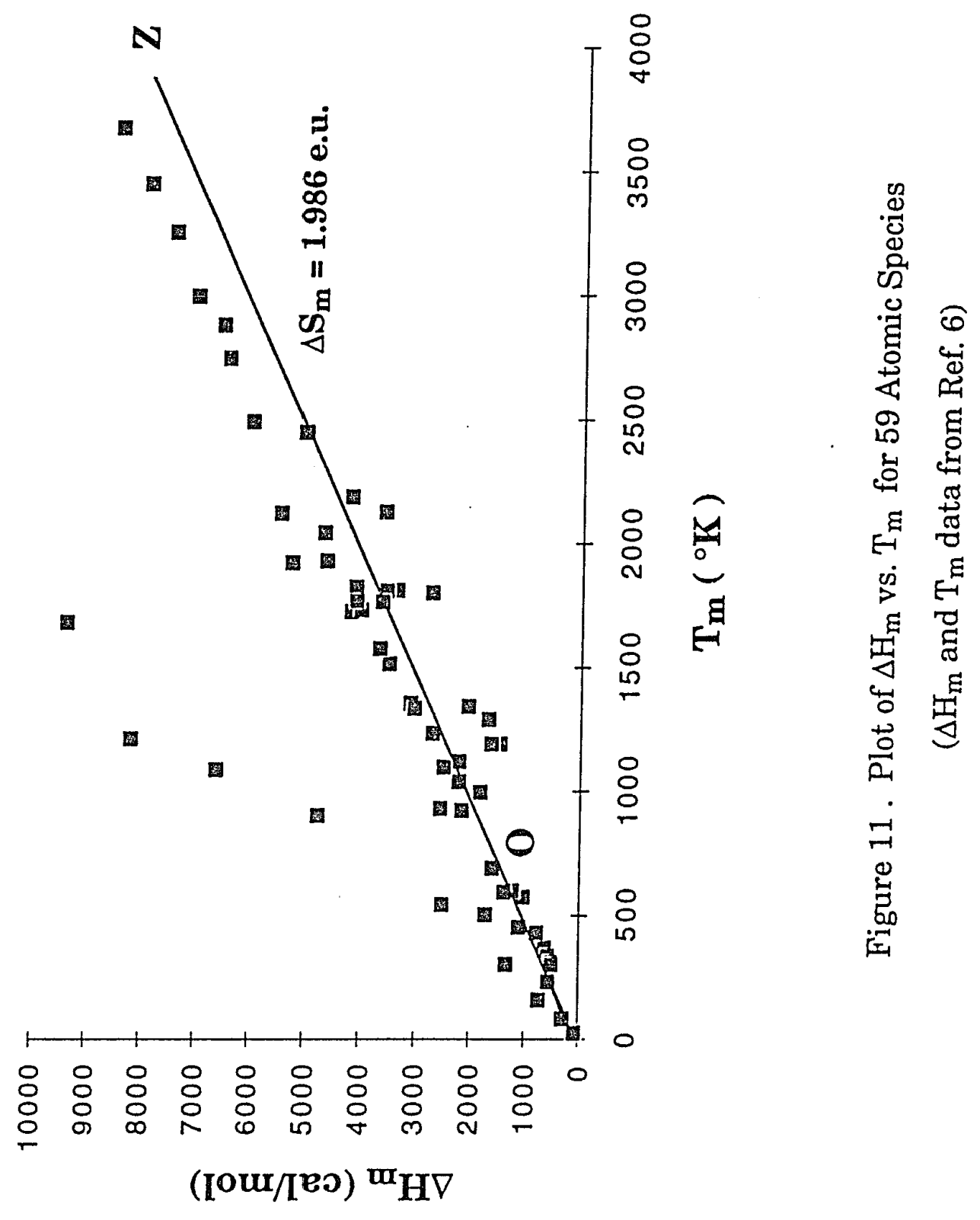


Table 10. Test of Procopiu's Model for $\Delta \mathrm{S}_{\mathrm{m}}$ of Atomic Species

\begin{tabular}{|c|c|c|c|c|}
\hline $\begin{array}{l}\text { Atomic } \\
\text { Species }\end{array}$ & $\begin{array}{l}\text { Periodic Table } \\
\text { Group }\end{array}$ & $\begin{array}{c}\Delta \mathrm{S}_{\mathrm{m}} \text { (e.u.) } \\
\text { (by Procopiu) }\end{array}$ & $\begin{array}{c}\Delta \mathrm{S}_{\mathrm{m}}(\text { e.u. }) \\
\text { (from literature } \\
(6) \text { ) }\end{array}$ & $1 \%$ deviation 1 \\
\hline $\mathrm{Li}$ & IA & 1.986 & 2.43 & $18 \%$ \\
\hline $\mathrm{Na}$ & IA & 1.986 & 1.70 & $17 \%$ \\
\hline $\mathrm{K}$ & IA & 1.986 & 1.71 & $16 \%$ \\
\hline $\mathrm{Rb}$ & IA & 1.986 & 1.68 & $18 \%$ \\
\hline $\mathrm{Cs}$ & IA & 1.986 & 1.66 & $20 \%$ \\
\hline $\mathrm{Mg}$ & IIA & 1.986 & 2.34 & $15 \%$ \\
\hline $\mathrm{Ca}$ & IIA & 1.986 & 1.98 & $0 \%$ \\
\hline $\mathrm{Sr}$ & IIA & 1.986 & 2.13 & $7 \%$ \\
\hline $\mathrm{Ba}$ & IIA & 1.986 & 1.83 & $9 \%$ \\
\hline$B$ & IIIA & 1.986 & 2.06 & $4 \%$ \\
\hline $\mathrm{Al}$ & IIIA & 1.986 & 2.74 & $28 \%$ \\
\hline $\mathrm{Ga}$ & IIIA & 1.986 & 4.41 & $55 \%$ \\
\hline In & IIIA & 1.986 & 1.82 & $9 \%$ \\
\hline $\mathrm{Tl}$ & IIIA & 1.986 & 1.79 & $11 \%$ \\
\hline $\mathrm{Si}$ & IVA & 1.986 & 5.57 & $64 \%$ \\
\hline $\mathrm{Ge}$ & IVA & 1.986 & 6.74 & $71 \%$ \\
\hline $\mathrm{Sn}$ & IVA & 1.986 & 3.40 & $42 \%$ \\
\hline $\mathrm{Pb}$ & IVA & 1.986 & 2.04 & $3 \%$ \\
\hline As & VA & 1.986 & 6.07 & $67 \%$ \\
\hline $\mathrm{Sb}$ & VA & 1.986 & 5.28 & $62 \%$ \\
\hline $\mathrm{Bi}$ & VA & 1.986 & 4.60 & $57 \%$ \\
\hline $\mathrm{Ne}$ & VIIIA & 1.986 & 3.17 & $37 \%$ \\
\hline $\mathrm{Ar}$ & VIIIA & 1.986 & 3.50 & $43 \%$ \\
\hline $\mathrm{Xe}$ & VIIIA & 1.986 & 4.58 & $57 \%$ \\
\hline $\mathrm{Cu}$ & IB & 1.986 & 2.29 & $13 \%$ \\
\hline $\mathrm{Ag}$ & IB & 1.986 & 2.19 & $9 \%$ \\
\hline $\mathrm{Au}$ & IB & 1.986 & 2.27 & $13 \%$ \\
\hline
\end{tabular}


Table 10. Test of Procopiu's Model for $\Delta \mathbf{S}_{\mathrm{m}}$ of Atomic Species (continued)

\begin{tabular}{|c|c|c|c|c|}
\hline $\begin{array}{l}\text { Atomic } \\
\text { Species }\end{array}$ & $\begin{array}{l}\text { Periodic Table } \\
\text { Group }\end{array}$ & $\begin{array}{c}\Delta \mathrm{S}_{\mathrm{m}} \text { (e.u.) } \\
\text { (by Procopiu) }\end{array}$ & $\begin{array}{c}\Delta \mathrm{S}_{\mathrm{m}}(\mathrm{e} . \mathrm{u} .) \\
(\text { from literature } \\
(6))\end{array}$ & |\% deviation 1 \\
\hline $\mathrm{Zn}$ & IIB & 1.986 & 2.30 & $14 \%$ \\
\hline $\mathrm{Cd}$ & IIB & 1.986 & 2.33 & $15 \%$ \\
\hline $\mathrm{Hg}$ & IIB & 1.986 & 2.38 & $17 \%$ \\
\hline $\mathrm{Sc}$ & IIIB & 1.986 & 1.86 & $7 \%$ \\
\hline$Y$ & IIIB & 1.986 & 1.52 & $31 \%$ \\
\hline $\mathrm{Ti}$ & IVB & 1.986 & 2.41 & $18 \%$ \\
\hline $\mathrm{Zr}$ & IVB & 1.986 & 2.58 & $23 \%$ \\
\hline $\mathrm{Hf}$ & IVB & 1.986 & 2.41 & $18 \%$ \\
\hline V & $\mathrm{VB}$ & 1.986 & 1.92 & $3 \%$ \\
\hline $\mathrm{Nb}$ & VB & 1.986 & 2.35 & $15 \%$ \\
\hline $\mathrm{Ta}$ & VB & 1.986 & 2.29 & $13 \%$ \\
\hline $\mathrm{Cr}$ & VIB & 1.986 & 1.69 & $18 \%$ \\
\hline Mo & VIB & 1.986 & 2.28 & $13 \%$ \\
\hline W & VIB & 1.986 & 2.30 & $14 \%$ \\
\hline $\mathrm{Mn}$ & VIIB & 1.986 & 2.31 & $14 \%$ \\
\hline $\operatorname{Re}$ & VIIB & 1.986 & 2.30 & $14 \%$ \\
\hline $\mathrm{Fe}$ & VIII & 1.986 & 1.97 & $1 \%$ \\
\hline Co & VIII & 1.986 & 2.06 & $4 \%$ \\
\hline $\mathrm{Ni}$ & VIII & 1.986 & 2.43 & $18 \%$ \\
\hline $\mathrm{Pd}$ & VIII & 1.986 & 2.25 & $12 \%$ \\
\hline $\mathrm{Pt}$ & VIII & 1.986 & 2.30 & $14 \%$ \\
\hline Os & VIII & 1.986 & 2.35 & $15 \%$ \\
\hline $\mathrm{La}$ & Lanthanides & 1.986 & 1.24 & $60 \%$ \\
\hline $\operatorname{Pr}$ & Lanthanides & 1.986 & 1.37 & $45 \%$ \\
\hline $\mathrm{Nd}$ & Lanthanides & 1.986 & 1.31 & $52 \%$ \\
\hline $\mathrm{Pm}$ & Lanthanides & 1.986 & 1.37 & $45 \%$ \\
\hline
\end{tabular}


Table 10. Test of Procopiu's Model for $\Delta S_{\mathrm{m}}$ of Atomic Species (continued)

\begin{tabular}{lcccc}
\hline $\begin{array}{l}\text { Atomic } \\
\text { Species }\end{array}$ & $\begin{array}{c}\text { Periodic Table } \\
\text { Group }\end{array}$ & $\begin{array}{c}\Delta \mathrm{S}_{\mathrm{m}} \text { (e.u.) } \\
\text { (by Procopiu) }\end{array}$ & $\begin{array}{c}\Delta \mathrm{S}_{\mathrm{m}} \text { (e.u.) } \\
\text { (from literature(6)) }\end{array}$ & I\% deviation I \\
\hline $\mathrm{Sm}$ & Lanthanides & 1.986 & 1.53 & $30 \%$ \\
$\mathrm{Eu}$ & Lanthanides & 1.986 & 2.27 & $13 \%$ \\
$\mathrm{Gd}$ & Lanthanides & 1.986 & 2.33 & $15 \%$ \\
$\mathrm{Ho}$ & Lanthanides & 1.986 & 2.32 & $14 \%$ \\
$\mathrm{Er}$ & Lanthanides & 1.986 & 2.32 & $14 \%$ \\
$\mathrm{Lu}$ & Lanthanides & 1.986 & 2.74 & $28 \%$ \\
\hline
\end{tabular}




\subsubsection{Walden's Model for $\Delta \mathbf{S}_{\mathrm{m}}$ of Organic Compounds}

Walden found the value of $\Delta S_{m}$ to be approximately constant at 13.5 e.u., based on data for 31 organic materials. To determine if this model is applicable for a wider range of organic materials, a total of 572 organic materials were investigated. The values of melting point and fusion enthalpy of these 572 materials had been compiled by William E. Acree, Jr. (19) The graph of their fusion enthalpies versus melting points is shown in Figure 12. To test the reliability of Walden's model, the lines OM, OA, and OB were drawn in Figure 12. These lines correspond to the constant values of fusion entropy 13.5 e.u., 13.5 - $20 \%$ e.u., and $13.5+20 \%$ e.u., respectively. According to Walden's model, each organic material should lie on OM, or at least lie between $O A$ and $O B$, considering $a \pm 20 \%$ deviation of this model. However, a large number of organic materials lie outside this region, as can be seen from Figure 12. Walden's model is therefore not reliable in predicting the fusion entropy of organic materials.

\subsubsection{Pirsch's Model for $\Delta S_{m}$ of Organic Compounds}

Pirsch considered the value of $\Delta S_{\mathrm{m}}$ to be 3 e.u. for spherical molecules, 13 e.u. for ring-shaped molecules, and greater than 20 e.u. for irregular shaped molecules. According to this, materials which belong to the same category and also possess the same chemical formula ought to have the same values of $\Delta \mathrm{S}_{\mathrm{m}}$. A total of fifteen materials, including those with the same chemical formula, from these three categories were selected to test Pirsch's statement. This is shown in Table 11. The second column contains the structural category of the materials. The third column is the fusion entropy 


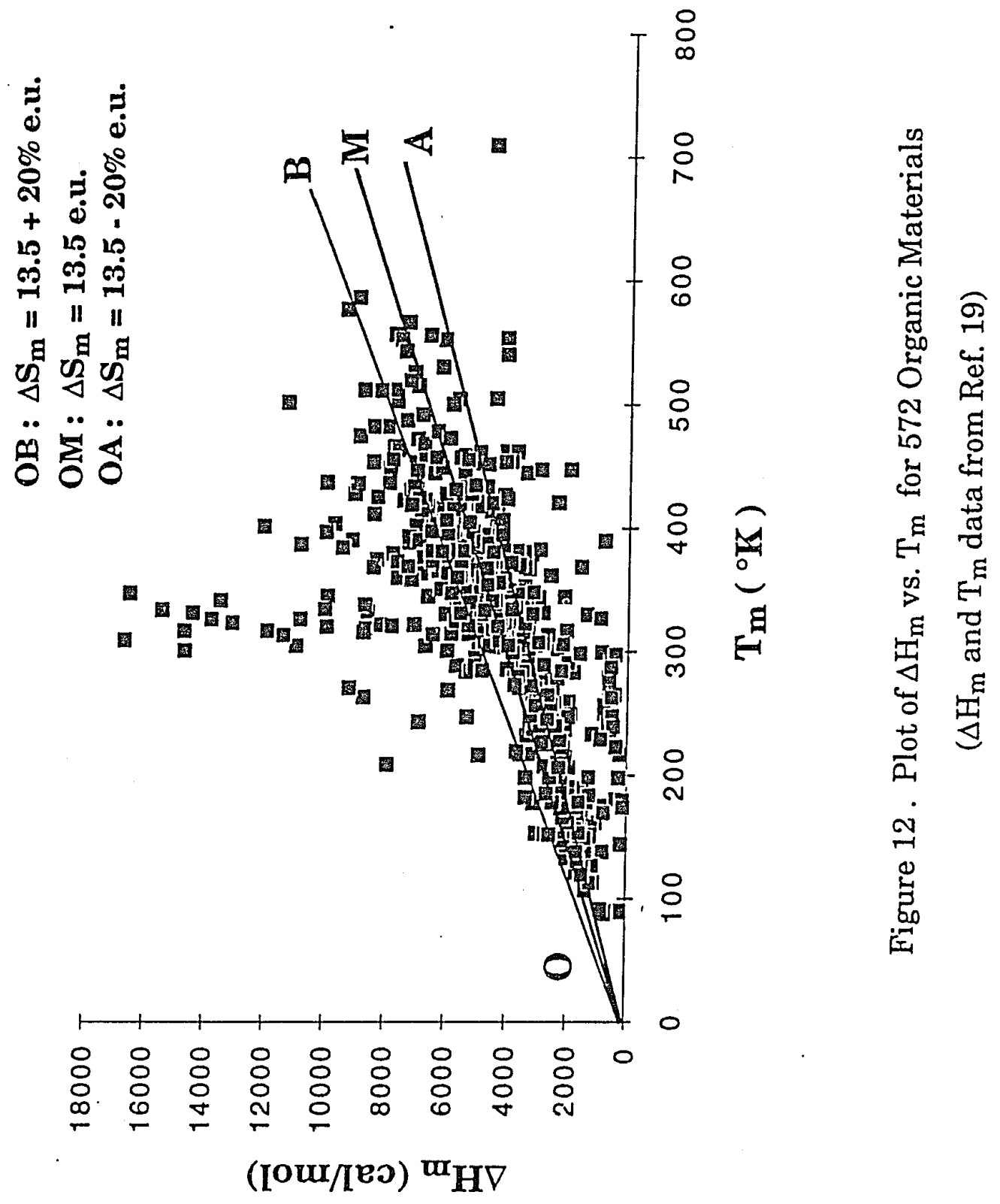


Table 11. Test of Pirsch's Model for $\Delta S_{m}$ of Organic Materials

\begin{tabular}{llll}
\hline Materials & Category & $\begin{array}{c}\Delta \mathrm{S}_{\mathrm{m}}(\text { e.u. }) \\
\text { (by Pirsch) }\end{array}$ & $\begin{array}{c}\Delta \mathrm{S}_{\mathrm{m}} \text { (e.u.) } \\
\text { (literature(19)) }\end{array}$
\end{tabular}

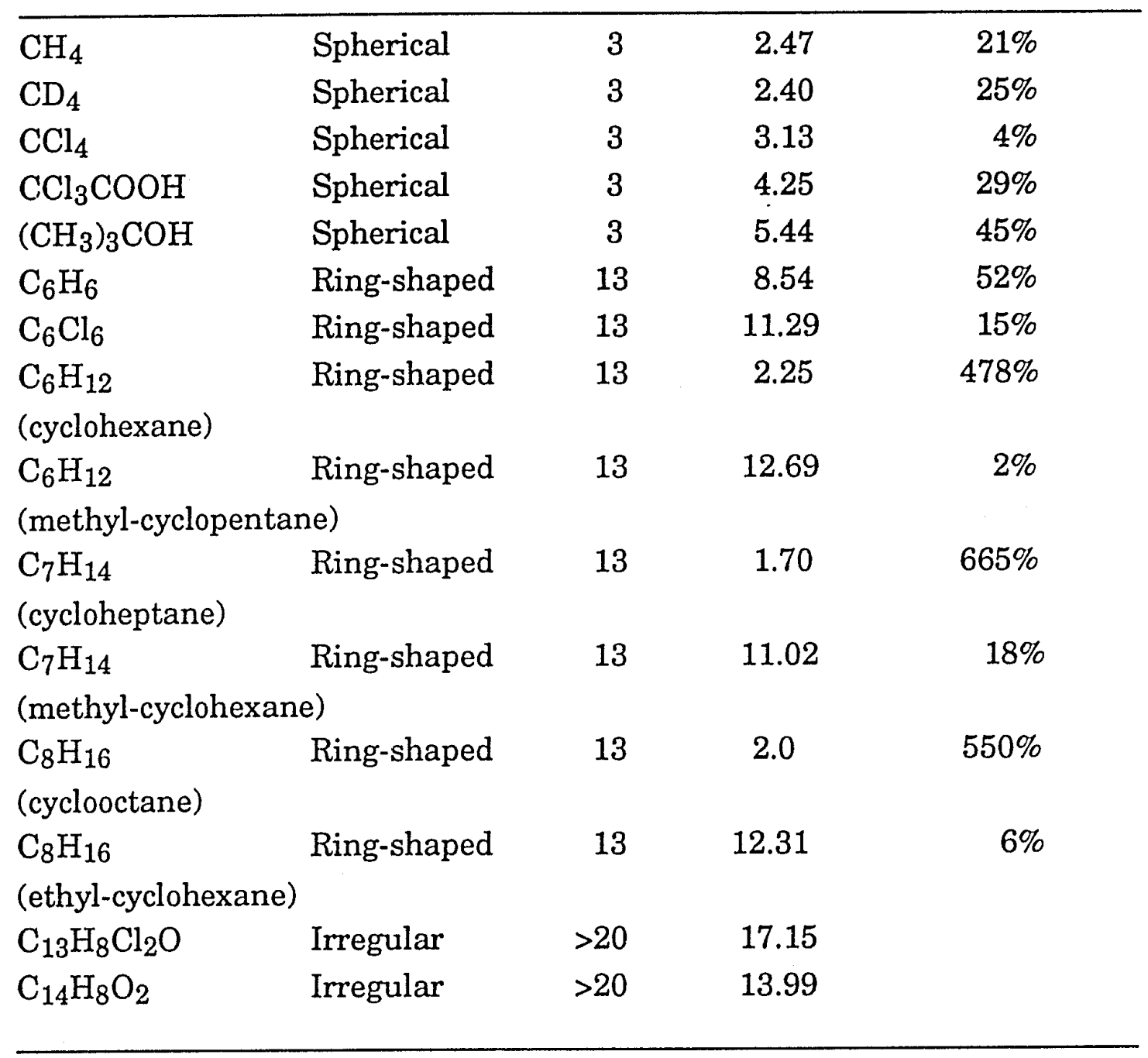


predicted by Pirsch. The fourth column is the fusion entropy obtained from the available literature ${ }^{(19)}$. The absolute percent deviation of Pirsch's model was then calculated, and is listed in the fifth column.

As seen from Table 11, materials in the same category, even with the same chemical formula, do not have the same $\Delta S_{m}$ values as predicted by this model. For example, cyclooctane $\left(\mathrm{C}_{8} \mathrm{H}_{16}\right)$ and ethyl-cyclohexane $\left(\mathrm{C}_{8} \mathrm{H}_{16}\right)$ are not only in the same category (ring-shaped) but also have the same chemical formula and therefore should have the same value for $\Delta S_{m}$, namely 13 e.u.. Actual $\Delta S_{m}$ values for these two compounds are extremely different: 2 e.u. for cyclooctane and 12.3 e.u. for ethyl-cyclohexane. This is contrary to Pirsch's model and may be due to differences in intermolecular force caused by different dipole moments. Cyclooctane has a symmetrical structure and therefore does not have a dipole moment. However, ethyl-cyclohexane is not symmetric and possesses dipole moments which enhance the intermolecular force. The same was found with $\mathrm{C}_{6} \mathrm{H}_{12}$ and $\mathrm{C}_{7} \mathrm{H}_{14}$ compounds. This model resulted in huge deviations of $550 \%, 665 \%$, and $478 \%$ for predicting the fusion entropy of cyclooctane, cycloheptane, and cyclohexane, respectively. The results suggest that Pirsch's model is too general and cannot be used to predict the fusion entropy of organic materials accurately.

\subsubsection{Procopiu's Model for $\Delta S_{m}$ of Organic Compounds}

Procopiu concluded that the fusion entropy of a molecule was equal to the number of atoms in the molecule. From this model, any two molecules with the same number of atoms are expected to have the same value for fusion entropy. Therefore, some materials with the same chemical formula 
were selected for investigation to determine if they have the same values of $\Delta \mathrm{S}_{\mathrm{m}}$, as this model suggests. Ten materials were selected to test Procopiu's model and the results are shown in Table 12. The second column in Table 12 contains the fusion entropy predicted by Procopiu. The third column is the fusion entropy obtained from the compiled source ${ }^{(19)}$ and the fourth column contains the absolute percentage value of the deviation between the calculated values and the values determined from the literature.

As seen from Table 12, materials with the same number of atoms do not have the same fusion entropies as expected from this model. There were huge deviations of $1100 \%, 1135 \%, 700 \%$ for predicting the fusion entropy of cyclooctane, cycloheptane, and cyclohexane, respectively. Discrepancies of $459 \%$ and $1268 \%$ were also found in the case of 2,2-dimethylpropane and 2,2,3,3,-tetramethylpentane. It is thus found that this model does not apply to symmetric molecules or branched molecules. Procopiu's model considers the value of $\Delta S_{m}$ to be dependent solely on the number of atoms, which obviously ignores the effect of any intermolecular forces that exist.

\subsection{Experimental Data}

The melting points, $\mathrm{T}_{\mathrm{m}}$, and fusion enthalpies, $\Delta \mathrm{H}_{\mathrm{m}}$, of materials in Tables 8 and 9 were measured by the Differential Scanning Calorimeter (DSC) and are presented in Table 13. In order to verify the candidate FHS materials identified by Selvaduray and Lomax, the solid heat capacity,

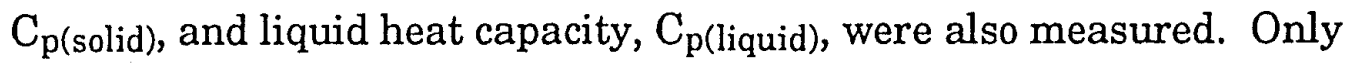
materials that proved to have melting points within $-13^{\circ} \mathrm{C}$ to $5^{\circ} \mathrm{C}$ were

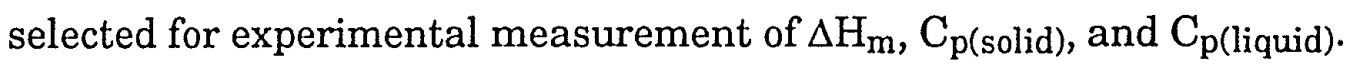


Table 12. Test of Procopiu's Model for $\Delta \mathrm{S}_{\mathrm{m}}$ of Organic Compounds

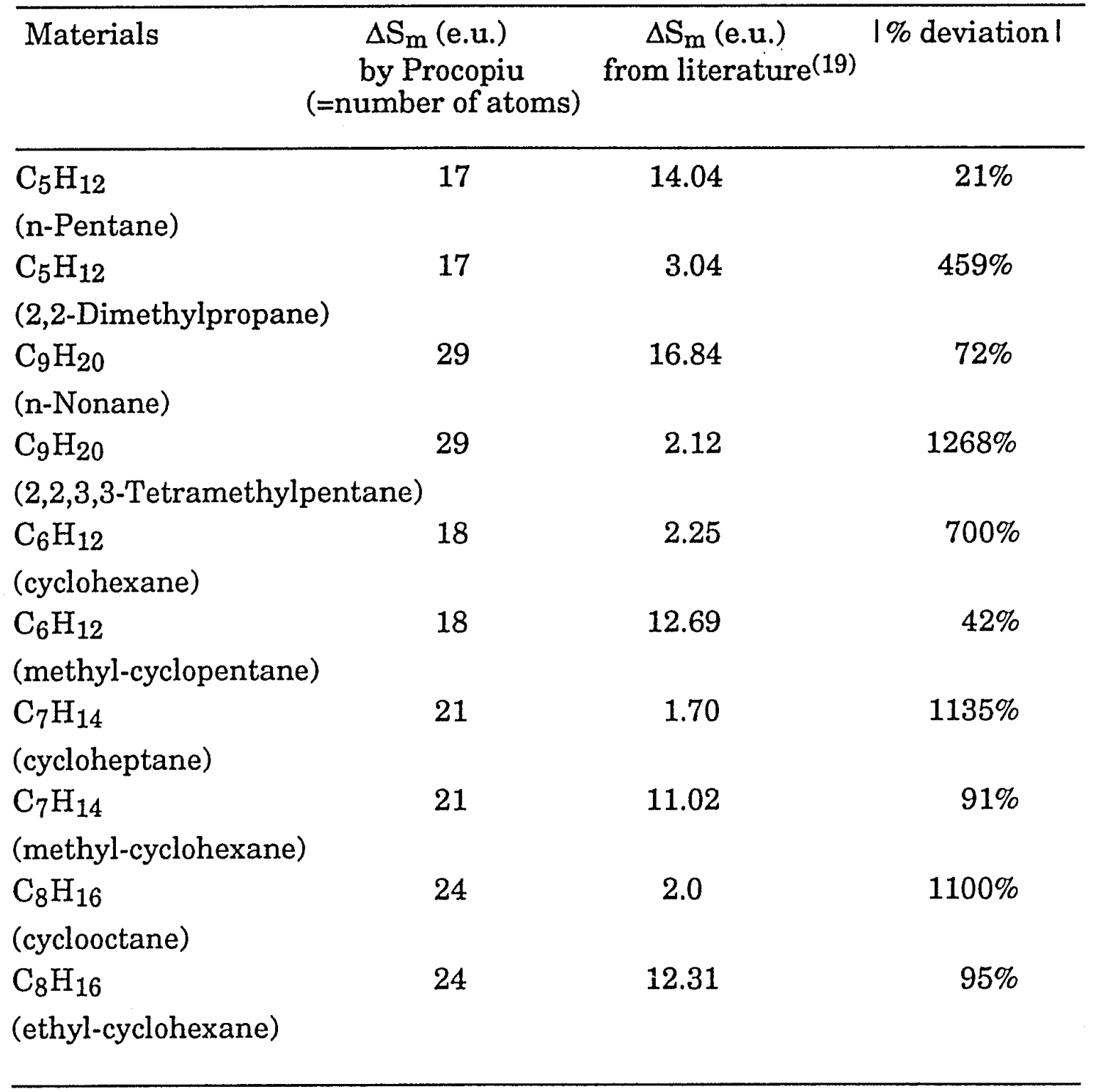


Table 13. Experimental Fusion Enthalpy, Melting Point, and Heat Capacity

\begin{tabular}{|c|c|c|c|c|}
\hline Materials & $\begin{array}{l}\mathrm{T}_{\mathrm{m}} \\
\left({ }^{\circ} \mathrm{C}\right)\end{array}$ & $\underset{(\mathrm{cal} / \mathrm{mol})}{\Delta \mathrm{H}_{\mathrm{m}}}$ & $\begin{array}{c}\mathrm{C}_{\mathrm{p}(\text { solid })} \\
\left(\mathrm{cal} / \mathrm{mol}^{\circ} \mathrm{C}\right)\end{array}$ & $\begin{array}{l}\mathrm{C}_{\mathrm{p} \text { (liquid) }} \\
\left(\mathrm{cal} / \mathrm{mol}^{\circ} \mathrm{C}\right)\end{array}$ \\
\hline Water* & 0.087 & 1451 & 9.4 & 19.1 \\
\hline Indium & 156.0 & 789 & - & - \\
\hline Glycerol triacetate* & $\mathrm{x}$ & $\mathrm{nm}$ & - & - \\
\hline Triethylene giycol* & $\mathrm{x}$ & $\mathrm{nm}$ & - & - \\
\hline Benzene, hexafluoro* & 5.34 & 2893 & - & - \\
\hline Heptanoic acid* & -10.14 & 3679 & 75.6 & 49.5 \\
\hline 2-methyl-2-butanol* & $\mathrm{x}$ & $\mathrm{nm}$ & - & - \\
\hline 2,3-Butanedione* & $\mathrm{x}$ & $\mathrm{nm}$ & - & - \\
\hline \multicolumn{5}{|l|}{ Cyclohexanol, } \\
\hline 2-methyl (trans)* & $\mathrm{x}$ & $\mathrm{nm}$ & - & - \\
\hline \multicolumn{5}{|l|}{ Cyclohexanol, } \\
\hline 4 -methyl (cis)* & -3.96 & 2143 & 34.3 & 52.5 \\
\hline Tert-Butyl hydroperoxide* & $\mathrm{x}$ & $\mathrm{nm}$ & - & - \\
\hline Benzene,1,4-difluoro* & -22.79 & 2671 & - & - \\
\hline Cyclohexanone,2-methyl* & -14.14 & 3696 & - & - \\
\hline Cinnamonitrile* & 5.08 & 2891 & - & - \\
\hline Cyclooctatetraene* & -8.21 & 2425 & 32.3 & 38.5 \\
\hline 4-Methoxybenzaldehyde* & -1.89 & 3782 & 46.9 & 50.3 \\
\hline Benzyl alcohol* & $\mathrm{x}$ & $\mathrm{nm}$ & - & - \\
\hline Indene* & -6.15 & 1754 & 41.8 & 52.3 \\
\hline Cyclohexane,1,2-dibromo* & -4.98 & 2896 & 39.7 & 48.4 \\
\hline Benzene* & $\mathrm{x}$ & $\mathrm{nm}$ & - & - \\
\hline Biphenyl,2-methyl* & -0.48 & 2865 & 42.1 & 69.0 \\
\hline Naphthalene,1-iodo* & $\mathrm{x}$ & $\mathrm{nm}$ & - & - \\
\hline 1,2-dihydronaphthalene* & -10.05 & 2450 & 41.0 & 48.2 \\
\hline Biphenyl,3-methyl* & $\mathrm{x}$ & $\mathrm{nm}$ & - & - \\
\hline Piperidene* & -18.46 & 2619 & - & - \\
\hline
\end{tabular}

* Candidate FHS materials identified by Selvaduray and Lomax

$x$ No transformation was detected from $-50^{\circ} \mathrm{C}$ to $30^{\circ} \mathrm{C}$ $\mathrm{nm}$ Not measured 
Table 13. Experimental Fusion Enthalpy, Melting Point, and Heat Capacity (continued)

\begin{tabular}{|c|c|c|c|c|c|}
\hline Materials & Percent & $\begin{array}{l}\mathrm{T}_{\mathrm{m}} \\
\left({ }^{\circ} \mathrm{C}\right)\end{array}$ & $\underset{(\mathrm{cal} / \mathrm{mol})}{\Delta \mathrm{H}_{\mathrm{m}}}$ & $\begin{array}{c}\mathrm{C}_{\mathrm{p}(\mathrm{solid})} \\
\left(\mathrm{cal} / \mathrm{mol}^{\circ} \mathrm{C}\right)\end{array}$ & $\begin{array}{l}\mathrm{C}_{\mathrm{p}(\text { liquid })} \\
\left(\mathrm{cal} / \mathrm{mol}^{\circ} \mathrm{C}\right)\end{array}$ \\
\hline \multirow[t]{4}{*}{ Magnesium chloride } & e $1 \%$ & -0.13 & 1316 & - & - \\
\hline & $5 \%$ & -6.53 & 975 & - & - \\
\hline & $10 \%$ & -14.43 & 565 & - & - \\
\hline & $15 \%$ & -24.94 & 309 & - & - \\
\hline \multirow[t]{4}{*}{ Lithium bromide } & $1 \%$ & -0.217 & 1438 & - & - \\
\hline & $5 \%$ & -5.61 & 1043 & - & - \\
\hline & $10 \%$ & -9.58 & 764 & - & - \\
\hline & $15 \%$ & -16.78 & 609 & - & - \\
\hline \multirow[t]{3}{*}{ Lithium chloride } & $1 \%$ & -1.63 & 1264 & - & - \\
\hline & $4 \% *$ & -7.96 & 925 & 12.0 & 16.8 \\
\hline & $12 \%$ & -24.84 & 331 & - & - \\
\hline \multirow[t]{3}{*}{ Calcium chloride } & $8 \%$ & -4.75 & 1108 & - & - \\
\hline & $12 \%$ & -6.24 & 1018 & - & - \\
\hline & $15 \%$ & -8.22 & 910 & - & - \\
\hline \multirow[t]{2}{*}{ Sodium chloride } & $7 \% *$ & $\begin{array}{l}-20.6\left(\mathrm{~T}_{\mathrm{tr}, 1}\right) \\
-10.2\left(\mathrm{~T}_{\mathrm{tr}, 2}\right)\end{array}$ & 1282 & - & - \\
\hline & $15 \%$ & -20.5 & 1231 & - & - \\
\hline Potassium chloride & $9 \% *$ & -8.55 & 1373 & 8.3 & 14.7 \\
\hline Sodium bromide & $11 \% *$ & $\begin{array}{r}-29.94\left(\mathrm{~T}_{\mathrm{tr}, 1}\right) \\
-9.68\left(\mathrm{~T}_{\mathrm{tr}, 2}\right)\end{array}$ & 1418 & - & - \\
\hline $\begin{array}{r}\text { Potassium } \\
\text { chromate }\end{array}$ & $18 \% *$ & $\begin{array}{c}-10.96\left(\mathrm{~T}_{\mathrm{tr}, 1}\right) \\
-8.7\left(\mathrm{~T}_{\mathrm{tr}, 2}\right)\end{array}$ & 1511 & 6.7 & 18.3 \\
\hline $\begin{array}{l}\text { Potassium } \\
\text { bromide }\end{array}$ & $13 \% *$ & $\begin{array}{l}-12.15\left(\mathrm{~T}_{\mathrm{tr}, 1}\right) \\
-11.04\left(\mathrm{~T}_{\mathrm{tr}, 2}\right)\end{array}$ & 1361 & 7.9 & 18.2 \\
\hline
\end{tabular}

* Candidate FHS materials identified by Selvaduray and Lomax

$\mathrm{T}_{\mathrm{tr}, 1}$ Eutectic temperature

$\mathrm{T}_{\mathrm{tr}, 2}$ Liquidus temperature 
Table 13. Experimental Fusion Enthalpy, Melting Point, and Heat Capacity (continued)

\begin{tabular}{lccccc}
\hline Materials & Percent & $\begin{array}{l}\mathrm{T}_{\mathrm{m}} \\
\left({ }^{\circ} \mathrm{C}\right)\end{array}$ & $\begin{array}{c}\Delta \mathrm{H}_{\mathrm{m}} \\
(\mathrm{cal} / \mathrm{mol})\end{array}$ & $\begin{array}{c}\mathrm{C}_{\mathrm{p}(\mathrm{solid})} \\
\left(\mathrm{cal} / \mathrm{mol}^{\circ} \mathrm{C}\right)\end{array}$ & $\begin{array}{c}\mathrm{C}_{\mathrm{p}}(\mathrm{liquid}) \\
\left(\mathrm{cal} / \mathrm{mol}^{\circ} \mathrm{C}\right)\end{array}$ \\
\hline Sodium nitrate & $10.0 \% *$ & $-16.35\left(\mathrm{~T}_{\mathrm{tr}, 1}\right)$ & 1443 & - & - \\
Potassium iodide & $16.0 \% *$ & $-20.5\left(\mathrm{~T}_{\mathrm{tr}, 2)}\right)$ & & & \\
& & $-8.95\left(\mathrm{~T}_{\mathrm{tr}, 1}\right)$ & 1479 & - & - \\
Cesium chloride & $19.0 \% *$ & $-22.66\left(\mathrm{~T}_{\mathrm{tr}, 1)}\right)$ & 1424 & - & - \\
& & $-10.75\left(\mathrm{~T}_{\mathrm{tr}, 2}\right)$ & & & \\
Sodium hydroxide & $4.5 \% *$ & -7.27 & 737 & 11.1 & 15.7 \\
Silver nitrate & $16.0 \% *$ & $-8.68\left(\mathrm{~T}_{\mathrm{tr}, 1)}\right.$ & 1471 & 7.1 & 18.3 \\
& & $-7.72\left(\mathrm{~T}_{\mathrm{tr}, 2}\right)$ & & & \\
Potassium nitrate & $10.0 \% *$ & -2.41 & 1583 & 6.5 & 17.1 \\
Potassium sulfate & $5.0 \% *$ & -0.81 & 1492 & 7.5 & 17.1 \\
Potassium hydroxide & $6.0 \% *$ & -7.26 & 921 & 13.1 & 10.5 \\
Potassium & & & & & \\
dichromate & $2.5 \% *$ & -0.02 & 1547 & 7.4 & 20.3 \\
Formic acid & $2.0 \%$ & -1.15 & 1259 & - & - \\
& $10.0 \% *$ & -7.53 & 1084 & 11.1 & 15.9 \\
& $32.0 \%$ & -25.07 & 480 & - & - \\
Acetic acid & $2.0 \%$ & -1.21 & 1387 & - & - \\
& $13.0 \% *$ & -8.54 & 1111 & 11.9 & 19.8 \\
& $20.0 \%$ & -10.65 & 939 & - & - \\
Ethylene glycol & $2.0 \%$ & -0.06 & 1386 & - & - \\
& $12.0 \% *$ & -5.52 & 1120 & 14.6 & 23.6 \\
& $28.0 \%$ & -21.64 & 470 & - & - \\
\hline
\end{tabular}

* Candidate FHS materials identified by Selvaduray and Lomax $\mathrm{T}_{\mathrm{tr}, 1}$ Eutectic temperature

$\mathrm{T}_{\mathrm{tr}, 2}$ Liquidus temperature 
Table 13. Experimental Fusion Enthalpy, Melting Point, and Heat Capacity (continued)

\begin{tabular}{lcccrr}
\hline Materials & Percent & $\begin{array}{l}\mathrm{T}_{\mathrm{m}} \\
\left({ }^{\circ} \mathrm{C}\right)\end{array}$ & $\begin{array}{c}\Delta \mathrm{H}_{\mathrm{m}} \\
(\mathrm{cal} / \mathrm{mol})\end{array}$ & $\begin{array}{c}\mathrm{C}_{\mathrm{p}(\text { solid })} \\
\left(\mathrm{cal} / \mathrm{mol}{ }^{\circ} \mathrm{C}\right)\end{array}$ & $\begin{array}{c}\mathrm{C}_{\mathrm{p}(\text { liquid }} \\
\left(\mathrm{cal} / \mathrm{mol}{ }^{\circ} \mathrm{C}\right)\end{array}$ \\
\hline Ethanol & $9.5 \%^{*}$ & -6.72 & 954 & 14.9 & 19.1 \\
& $24.0 \%^{*}$ & -17.6 & 417 & - & - \\
Glycerol & $16.0 \%^{*}$ & -7.95 & 947 & 13.0 & 19.0 \\
& $40.0 \%$ & -24.78 & 406 & - & - \\
\hline
\end{tabular}

* Candidate FHS materials identified by Selvaduray and Lomax 
The accuracy of the apparatus (DSC-4) was determined to be within $2 \%$, based on calibration runs with water and indium. The data used to arrive at this conclusion is shown in Appendix E. Ten organic compounds, as identified with an " $x$ " in the second column of Table 13, did not have solidliquid transitions during the heating process from $-50^{\circ} \mathrm{C}$ to $30^{\circ} \mathrm{C}$. It is probable that their melting points are below $-50^{\circ} \mathrm{C}$.

\subsection{Evaluations of the Models for Predictions of $\Delta \mathbf{H}_{\mathbf{m}}$}

This section contains the results obtained in evaluation of the quantitative models. Evaluation of Chickos's model for predicting fusion enthalpies of organic compounds is presented in Section 4.3.1. The Rule of Mixtures is evaluated in Section 4.3.2, and Horvath's model is evaluated in

Section 4.3.3. For ease of understanding, the results for each model are presented separately. The calculated values were compared with the experimental measurements and the percentage deviation determined.

\subsubsection{Chickos's Model for $\Delta \mathrm{H}_{\mathrm{m}}$ of Organic Materials}

The fusion enthalpies of organic compounds predicted from Chickos's model were compared to those determined from differential scanning calorimetry. The results are shown in Table 14. The second column in Table 14 is the $\Delta \mathrm{H}_{\mathrm{m}}$ calculated according to Chickos's model. The detailed calculations are contained in Appendix $\mathrm{F}$. The $\Delta \mathrm{H}_{\mathrm{m}}$ values in the third column were determined by DSC. The fourth column contains the absolute percent deviation between the calculated values and the values determined experimentally. 
Table 14. Test of Chickos's Model for $\Delta \mathrm{H}_{\mathrm{m}}$ of Organic Materials

\begin{tabular}{lllr}
\hline $\begin{array}{l}\text { Materials } \\
\text { (Organic compounds) }\end{array}$ & $\begin{array}{c}\Delta \mathrm{H}_{\mathrm{m}} \text { (cal/mol) } \\
\text { (by Chickos's model) }\end{array}$ & $\begin{array}{l}\Delta \mathrm{H}_{\mathrm{m}} \text { (cal/mol) } \\
\text { (from DSC) }\end{array}$ & |\%deviation l \\
\hline Benzene,hexafluoro & 3490 & 2893 & $21 \%$ \\
Heptanoic acid & 5044 & 3679 & $37 \%$ \\
Cyclohexanol,4-methyl(cis) & 2532 & 2143 & $18 \%$ \\
Benzene,1.4-difluoro & 2587 & 2671 & $3 \%$ \\
Cyclohexanone,2-methyl & 2378 & 3696 & $36 \%$ \\
Cinnamonitrile & 3862 & 2891 & $34 \%$ \\
Cyclooctatetraene & 1381 & 2425 & $43 \%$ \\
4-methoxybenzaldehyde & 3649 & 3782 & $4 \%$ \\
Indene & 2386 & 1754 & $36 \%$ \\
Cyclohexane,1.2-dibromo & 3822 & 2896 & $31 \%$ \\
Biphenyl,2-methyl & 3742 & 2865 & $30 \%$ \\
1,2-dihydronaphthalene & 3175 & 2450 & $16 \%$ \\
Piperidene & 3035 & 2619 & \\
& & & average deviation $=26.3 \%$ \\
\hline
\end{tabular}


As can be seen from Table 14, the average deviation between the calculated values and measured values was found to be $26.3 \%$.

\subsubsection{The Rule of Mixtures for $\Delta \mathrm{H}_{\mathrm{m}}$ of Aqueous Solutions}

The fusion enthalpies of aqueous solutions, as predicted from the Rule of Mixtures, are compared to those determined from experiments. The results are shown in Table 15. The second column in Table 15 is the $\Delta H_{m}$ predicted by the Rule of Mixtures. The $\Delta \mathrm{H}_{\mathrm{m}}$ values in the third column were determined from differential scanning calorimetry. The fourth column is the absolute percent of the deviation between the calculated values and the values determined experimentally. A sample calculation for determining the $\Delta \mathrm{H}_{\mathrm{m}}$ of $\mathrm{MgCl}_{2}$, according to the Rule of Mixtures, is contained in Appendix G.

The Rule of Mixtures for predicting $\Delta \mathrm{H}_{\mathrm{m}}$ of aqueous solutions was tested and the absolute average deviation was calculated to be $75.9 \%$. However, the values ranged from a high of $434.3 \%$ to a low of $0.1 \%$. As seen from Table 15, the Rule of Mixtures gives accurate predictions of fusion enthalpies for dilute solutions. However, this model appears to become inaccurate when the concentration of the solute is increased. The Rule of Mixtures assumes that the solution is a mixture of pure components and does not take into account the nature of interaction between the constituents. In dilute solutions, this interaction might not be great enough to affect the fusion enthalpies of the solutions. In concentrated solutions, because more solute and solvent (water) molecules are involved, the interactions of constituents become important and play a significant role in determining the fusion enthalpies of solutions. Due to this, a factor concerning the interaction of solute and water will be 
Table 15. Test of the Rule of Mixtures for $\Delta \mathrm{H}_{\mathrm{m}}$ of Aqueous Solutions

\begin{tabular}{lrcrr}
\hline $\begin{array}{l}\text { Materials } \\
\text { (Aqueous Solution) }\end{array}$ & \multicolumn{2}{c}{$\begin{array}{c}\Delta \mathrm{H}_{\mathrm{m}} \text { (cal/mol) } \\
\text { (by Rule of Mixtures) }\end{array}$} & $\begin{array}{c}\Delta \mathrm{H}_{\mathrm{m}}(\mathrm{cal} / \mathrm{mol}) \\
\text { (from DSC) }\end{array}$ & I\%deviation I \\
\hline Magnesium chloride & $1 \%$ & 1449 & 1316 & $10.1 \%$ \\
& $5 \%$ & 1502 & 975 & $54.1 \%$ \\
& $10 \%$ & 1573 & 565 & $178.4 \%$ \\
& $15 \%$ & 1651 & 309 & $434.3 \%$ \\
Lithium bromide & $1 \%$ & 1439 & 1438 & $0.1 \%$ \\
& $5 \%$ & 1452 & 1043 & $39.2 \%$ \\
& $10 \%$ & 1469 & 764 & $92.3 \%$ \\
& $15 \%$ & 1488 & 609 & $144.3 \%$ \\
Lithium chloride & $1 \%$ & 1443 & 1264 & $14.2 \%$ \\
& $4 \%$ & 1466 & 925 & $58.5 \%$ \\
Calcium chloride & $12 \%$ & 1532 & 331 & $362.8 \%$ \\
& $8 \%$ & 1501 & 1108 & $35.5 \%$ \\
& $12 \%$ & 1537 & 1018 & $51.0 \%$ \\
Sodium chloride & $7 \%$ & 1567 & 910 & $72.1 \%$ \\
& $15 \%$ & 1734 & 1282 & $22.2 \%$ \\
Potassium chloride & $9 \%$ & 1552 & 1231 & $40.9 \%$ \\
Sodium bromide & $11 \%$ & 1535 & 1373 & $13.0 \%$ \\
Potassium chromate & $18 \%$ & 1545 & 1418 & $8.3 \%$ \\
Potassium bromide & $13 \%$ & 1515 & 1511 & $2.3 \%$ \\
Sodium nitrate & $10 \%$ & 1490 & 1361 & $11.3 \%$ \\
& & & 1443 & $3.3 \%$ \\
\hline
\end{tabular}


Table 15. Test of the Rule of Mixtures for $\Delta \mathrm{H}_{\mathrm{m}}$ of Aqueous Solutions (continued)

\begin{tabular}{|c|c|c|c|c|}
\hline \multirow{2}{*}{$\begin{array}{l}\text { Materials } \\
\text { (Aqueous Solution) } \\
\text { Potassium iodide }\end{array}$} & \multicolumn{2}{|r|}{$\begin{array}{c}\Delta \mathrm{H}_{\mathrm{m}}(\mathrm{cal} / \mathrm{mol}) \\
\text { (by Rule of Mixtures) }\end{array}$} & \multirow{2}{*}{$\begin{array}{c}\Delta \mathrm{H}_{\mathrm{m}}(\mathrm{cal} / \mathrm{mol}) \\
\text { (from DSC) }\end{array}$} & \multirow{2}{*}{$\frac{\mid \% \text { deviation } \mid}{0.7 \%}$} \\
\hline & $16.0 \%$ & 1490 & & \\
\hline Cesium chloride & $19.0 \%$ & 1489 & 1424 & $4.6 \%$ \\
\hline Sodium hydroxide & $4.5 \%$ & 1448 & 737 & $96.4 \%$ \\
\hline Silver nitrate & $16.0 \%$ & 1462 & 1472 & $0.6 \%$ \\
\hline Potassium nitrate & $10.0 \%$ & 1463 & 1583 & $7.6 \%$ \\
\hline Potassium sulfate & $5.0 \%$ & 1472 & 1492 & $1.3 \%$ \\
\hline \multicolumn{5}{|l|}{ Potassium } \\
\hline hydroxide & $6.0 \%$ & 1447 & 921 & $57.1 \%$ \\
\hline \multicolumn{5}{|l|}{ Potassium } \\
\hline dichromate & $2.5 \%$ & 1448 & 1547 & $6.4 \%$ \\
\hline \multirow[t]{3}{*}{ Formic acid } & $2.0 \%$ & 1448 & 1259 & $15.0 \%$ \\
\hline & $10.0 \%$ & 1503 & 1084 & $38.7 \%$ \\
\hline & $32.0 \%$ & 1685 & 480 & $251.0 \%$ \\
\hline \multirow[t]{3}{*}{ Acetic acid } & $2.0 \%$ & 1444 & 1387 & $4.1 \%$ \\
\hline & $13.0 \%$ & 1493 & 1111 & $34.4 \%$ \\
\hline & $20.0 \%$ & 1528 & 939 & $62.7 \%$ \\
\hline \multirow[t]{3}{*}{ Ethylene glycol } & $2.0 \%$ & 1443 & 1386 & $4.1 \%$ \\
\hline & $12.0 \%$ & 1484 & 1120 & $32.5 \%$ \\
\hline & $28.0 \%$ & 1563 & 470 & $232.5 \%$ \\
\hline \multirow[t]{2}{*}{ Ethanol } & $9.5 \%$ & 1427 & 954 & $49.6 \%$ \\
\hline & $24.0 \%$ & 1410 & 417 & $238.1 \%$ \\
\hline \multirow[t]{2}{*}{ Glycerol } & $16.0 \%$ & 1543 & 947 & $62.9 \%$ \\
\hline & $40.0 \%$ & 1780 & 406 & $338.4 \%$ \\
\hline
\end{tabular}


introduced in the following chapter, to improve the Rule of Mixtures in predicting the fusion enthalpy. The validity of the Rule of Mixtures for predicting fusion enthalpies of aqueous solutions appears to be limited to dilute solutions.

\subsubsection{Horvath's Model for $\Delta \mathbf{H}_{\mathrm{m}}$ of Aqueous Solutions}

The fusion enthalpies of aqueous solutions, as predicted from Horvath's model, were compared to those determined experimentally. The results are shown in Table 16. The second column in Table 16 contains the $\Delta H_{m}$ predicted by Horvath's model. The $\Delta \mathrm{H}_{\mathrm{m}}$ values in the third column were determined from the DSC. The fourth column contains the absolute percent deviation between the calculated values and the values determined experimentally. A sample calculation for determining the $\Delta \mathrm{H}_{\mathrm{m}}$ of $\mathrm{MgCl}_{2}$, according to Horvath's model, is contained in Appendix H.

Horvath's model for predicting $\Delta \mathrm{H}_{\mathrm{m}}$ of aqueous solutions was found to have an average deviation of $142.9 \%$. The results show that wide discrepancies occur in the case of some dilute solutions. These dilute solutions are magnesium chloride (1\%), ethylene glycol (2\%), and potassium dichromate (2.5\%). This might be explained by the following.

Horvath gave Equation 17 below for predicting the fusion enthalpies of dilute solutions.

$$
\Delta \mathrm{H}_{\mathrm{m}}=\mathrm{R}^{*} \mathrm{~T}_{\mathrm{m}} 0 *\left(\mathrm{~N}_{2} / \mathrm{N}_{1}\right) *\left[\mathrm{~T}_{\mathrm{m}} /\left(\mathrm{T}_{\mathrm{m}}{ }^{0}-\mathrm{T}_{\mathrm{m}}\right)\right]
$$

As seen from this equation, the term " $\Delta \mathrm{H}_{\mathrm{m}}$ " is very sensitive to the term " $\mathrm{T}_{\mathrm{m}}{ }^{0}-\mathrm{T}_{\mathrm{m}}$ " especially when " $\mathrm{T}_{\mathrm{m}}{ }^{0}-\mathrm{T}_{\mathrm{m}}$ " is very small. For the case of ethylene glycol (2\%), the value of " $\mathrm{T}_{\mathrm{m}}{ }^{0}-\mathrm{T}_{\mathrm{m}}$ " was measured to be $0.06^{\circ} \mathrm{K}$ and therefore 
Table 16. Test of Horvath's Model for $\Delta \mathrm{H}_{\mathrm{m}}$ of Aqueous Solutions

\begin{tabular}{|c|c|c|c|c|}
\hline \multicolumn{2}{|l|}{$\begin{array}{l}\text { Materials } \\
\text { (Aqueous Solution) }\end{array}$} & $\begin{array}{c}\Delta \mathrm{H}_{\mathrm{m}}(\mathrm{cal} / \mathrm{mol}) \\
\text { (by Horvath's model) }\end{array}$ & $\begin{array}{c}\Delta \mathrm{H}_{\mathrm{m}}(\mathrm{cal} / \mathrm{mol}) \\
\text { (from DSC) }\end{array}$ & $1 \%$ deviation \\
\hline \multirow[t]{4}{*}{ Magnesium chloride } & e $1.0 \%$ & 6524 & 1316 & $395.7 \%$ \\
\hline & $5.0 \%$ & 661 & 975 & $32.2 \%$ \\
\hline & $10.0 \%$ & 613 & 565 & $8.5 \%$ \\
\hline & $15.0 \%$ & 540 & 309 & $74.7 \%$ \\
\hline \multirow[t]{4}{*}{ Lithium bromide } & $1.0 \%$ & 2854 & 1438 & $98.5 \%$ \\
\hline & $5.0 \%$ & 564 & 1043 & $45.9 \%$ \\
\hline & $10.0 \%$ & 687 & 764 & $10.1 \%$ \\
\hline & $15.0 \%$ & 606 & 609 & $0.4 \%$ \\
\hline \multirow[t]{3}{*}{ Lithium chloride } & $1.0 \%$ & 774 & 1264 & $38.8 \%$ \\
\hline & $4.0 \%$ & 639 & 925 & $30.9 \%$ \\
\hline & $12.0 \%$ & 627 & 331 & $89.4 \%$ \\
\hline \multirow[t]{3}{*}{ Calcium chloride } & $8.0 \%$ & 1296 & 1108 & $17.0 \%$ \\
\hline & $12.0 \%$ & 1538 & 1018 & $51.1 \%$ \\
\hline & $15.0 \%$ & 1500 & 910 & $64.8 \%$ \\
\hline Sodium chloride & $15.0 \%$ & 726 & 1231 & $41.0 \%$ \\
\hline Potassium chloride & $9.0 \%$ & 801 & 1373 & $41.7 \%$ \\
\hline Sodium hydroxide & $4.5 \%$ & 837 & 737 & $13.6 \%$ \\
\hline Potassium nitrate & $10.0 \%$ & 2412 & 1583 & $52.4 \%$ \\
\hline Potassium sulfate & $5.0 \%$ & 2974 & 1492 & $99.3 \%$ \\
\hline \multicolumn{5}{|l|}{ Potassium } \\
\hline hydroxide & $6.0 \%$ & 814 & 921 & $11.6 \%$ \\
\hline \multicolumn{5}{|l|}{ Potassium } \\
\hline dichromate & $2.5 \%$ & 34853 & 1547 & $2153.0 \%$ \\
\hline \multirow[t]{3}{*}{ Formic acid } & $2.0 \%$ & 1023 & 1259 & $18.7 \%$ \\
\hline & $10.0 \%$ & 831 & 1084 & $23.3 \%$ \\
\hline & $32.0 \%$ & 987 & 480 & $105.6 \%$ \\
\hline
\end{tabular}


Table 16. Test of Horvath's Model for $\Delta \mathrm{H}_{\mathrm{m}}$ of Aqueous Solutions (continued)

\begin{tabular}{lrrrr}
\hline $\begin{array}{l}\text { Materials } \\
\text { (Aqueous Solution) }\end{array}$ & \multicolumn{1}{c}{$\begin{array}{c}\Delta \mathrm{H}_{\mathrm{m}}(\mathrm{cal} / \mathrm{mol}) \\
\text { (by Horvath's model) }\end{array}$} & $\begin{array}{c}\Delta \mathrm{H}_{\mathrm{m}}(\mathrm{cal} / \mathrm{mol}) \\
\text { (from DSC) }\end{array}$ & |\%deviation I \\
\hline Acetic acid & $2.0 \%$ & 746 & 1387 & $46.2 \%$ \\
& $13.0 \%$ & 752 & 1111 & $32.3 \%$ \\
Ethylene glycol & $20.0 \%$ & 1001 & 939 & $6.6 \%$ \\
& $2.0 \%$ & 14604 & 1386 & $953.7 \%$ \\
& $12.0 \%$ & 1039 & 1120 & $7.2 \%$ \\
Ethanol & $28.0 \%$ & 711 & 470 & $51.3 \%$ \\
& $9.5 \%$ & 881 & 954 & $7.7 \%$ \\
Glycerol & $24.0 \%$ & 971 & 417 & $132.9 \%$ \\
& $16.0 \%$ & 673 & 947 & $28.9 \%$ \\
& $40.0 \%$ & 708 & 406 & $74.4 \%$ \\
\hline
\end{tabular}


the value of " $\Delta \mathrm{H}_{\mathrm{m}}$ " is predicted to be $14604 \mathrm{cal} / \mathrm{mol}$ from Equation 17. If the value of " $\mathrm{T}_{\mathrm{m}}{ }^{0}-\mathrm{T}_{\mathrm{m}}$ " is measured to be $0.26^{\circ} \mathrm{K}$, then the value of " $\Delta \mathrm{H}_{\mathrm{m}}$ " will be predicted to be $3359 \mathrm{cal} / \mathrm{mol}$, which is much closer to the experimental $\Delta \mathrm{H}_{\mathrm{m}}$, $1386 \mathrm{cal} / \mathrm{mol}$. Evaluation of this model would be difficult especially for a very dilute solution due to inevitable experimental errors.

Another limitation of Horvath's model is that it cannot predict fusion enthalpies of solutions that show multiple transitions during solid-liquid transformation, a typical example being those systems that exhibit eutectic behavior.

The two present models, namely the Rule of Mixtures and Horvath's model, for predicting the fusion enthalpy of aqueous solutions appear to be quite unreliable. Based on the data obtained during the course of this investigation, a modified model resulting from this study for predicting the $\Delta \mathrm{H}_{\mathrm{m}}$ of aqueous solutions has been developed and is presented in Chapter 5. 


\section{CHAPTER 5 \\ MODIFIED MIXTURE RULE}

This chapter describes a newly developed model, resulting from this study, for predicting the fusion enthalpy of aqueous solutions. The reliability and applicability of this model are also discussed.

As seen from Chapter 4, the models for predicting fusion enthalpies of aqueous solutions are not reliable. The Rule of Mixtures closely predicts the values of fusion enthalpy for dilute aqueous solutions; however, it becomes inapplicable when the concentration of solute increases. This is due to the lack of information of the interaction between the solute and the water which exists in an aqueous solution. One major interaction of the solute and water results from hydration. The phenomenon of hydration is, therefore, explained here to describe the interaction of solute and water molecule, in an effort to improve the Rule of Mixtures and make it applicable to higher concentrations. This newly developed model has been termed "The Modified Mixture Rule," to distinguish it from the original Rule of Mixtures.

The phenomenon of hydration is described in Section 5.1 since this is necessary for an understanding of the new model. An equation for predicting fusion enthalpies of aqueous solutions is developed in Section 5.2. An evaluation of this model, based on results determined experimentally, is contained in Section 5.3 and the results are discussed in Section 5.4. An application of this model for identifying FHS materials is described in Section 5.5 . 


\subsection{The Phenomenon of Hydration}

For most aqueous solutions that display eutectic behavior, addition of the solute to water results in a stronger solute-water bond than either solutesolute or water-water bonds. This is called "hydration," meaning a bond between the water and the solute. When an ionic solute (electrolyte) is dissolved in water, it dissociates into cations and anions. Each cation and anion will be bonded to a number of water molecules. For each mole of solute, the total number of moles of water bonded to this solute is referred to as its hydration number. Figure 13 shows the phenomenon of hydration when $\mathrm{NaCl}$ is dissolved in water. (21) Because of hydration, the hydrogen bonding of water molecules in the neighborhood of the solute must be broken during solution. The energy for breaking the hydrogen bonds, the hydration energy, is a possible factor to account for the inaccuracy of the Rule of Mixtures when determining the fusion enthalpy of solutions.

Two types of aqueous solutions were identified in Table 1. They were electrolytic aqueous solutions (e.g., $\mathrm{LiCl}$ or $\mathrm{NaCl}$ in $\mathrm{H}_{2} \mathrm{O}$ ) and non-electrolytic aqueous solutions (e.g., formic acid in $\mathrm{H}_{2} \mathrm{O}$ ). Each type of aqueous solution displays a different hydration phenomenon.

Bockris stated that for electrolytic aqueous solutions, hydration can be divided into two parts, called "primary" (close) hydration and "secondary" (distant) hydration. (22) Figure 14 shows the orientations of water dipoles in the presence of an electrolyte.(23) As seen from Figure 14, water dipoles can be divided into 3 regions, corresponding to their different orientations. Primary hydration happens in the inner region where all the water molecules are oriented axially. Secondary hydration happens in the in-between region 


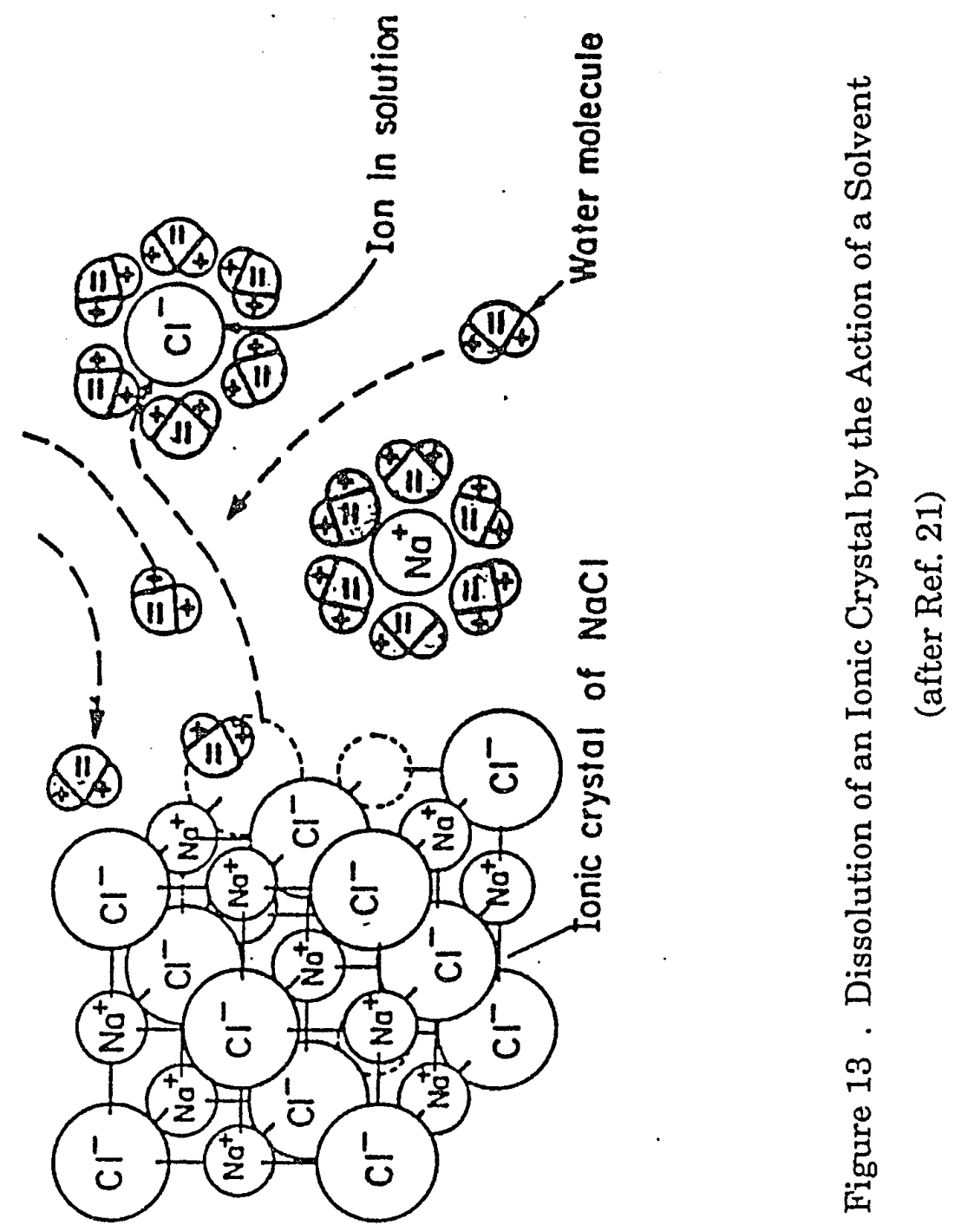




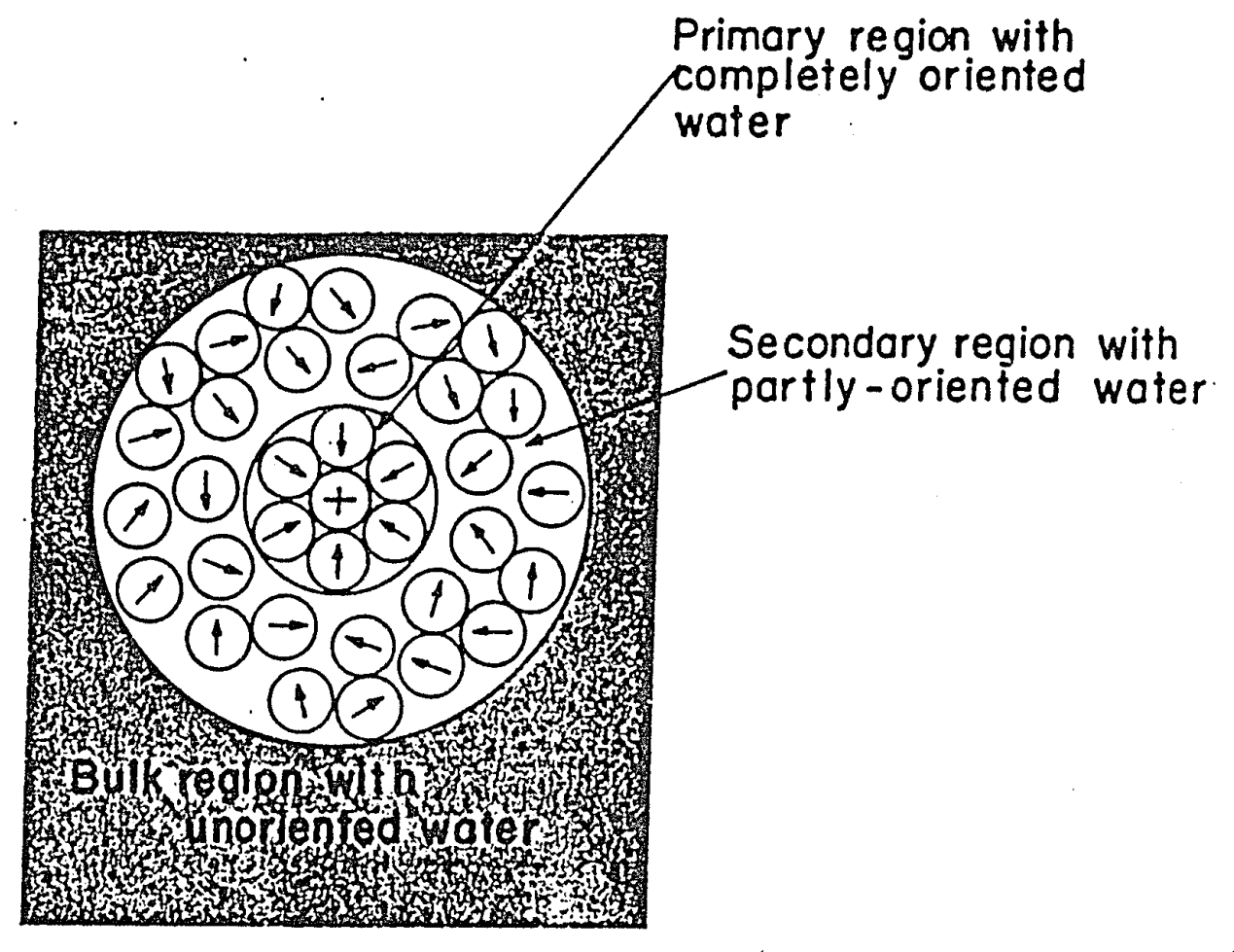

Figure 14. Orientation of Water Dipoles in a Electrolytic Solution (after Ref. 23) 
where the water molecules are partly oriented. Water molecules in the bulk region are not reoriented in the presence of the solute.

Primary hydration consists of the stable combination of the "neighboring" water molecules with the solute ions. Secondary hydration signifies the electrostatic interaction of the solute ions and the water molecule dipoles which are not in the vicinity of the solute. Although the interaction energy of an ion with a single water molecule which is not in its immediate vicinity is very small, the total energy obtained by summation over many molecules reaches a large value, and forms a considerable part of the hydration energy of ions. (24) For electrolytic aqueous solutions, both primary and secondary hydration phenomena should be considered.

Although non-electrolytic solutes do not dissociate into ions when added to water, this type of solution contains polar molecules and possesses local dipole charges to interact with the "neighboring" water molecules and therefore participate in primary hydration. However this type of solution does not display secondary hydration due to the very weak electrostatic interaction of the dipoles of solutes and the distant water molecules as compared to the stronger ion-dipole interaction in the electrolytic aqueous solutions.

\subsection{The Equation for Predicting Fusion Enthalpy}

The Rule of Mixtures, as given by Equation 15, predicts the fusion enthalpy inaccurately due to lack of information on the interaction between the solute and the water that exist in an aqueous solution. One major interaction between the solute and the water arises from the hydration 
behavior of the components. Due to hydration, additional hydrogen bonds must be broken. The energy for breaking the hydrogen bonds, the hydration energy, needs to be considered as a negative term to account for the value of fusion enthalpy. By introducing the factor of hydration energy, Equation 15 was modified to produce Equation 22 in order to improve the accuracy of the Rule of Mixtures in predicting fusion enthalpy of aqueous solutions.

$$
\begin{aligned}
\Delta \mathrm{H}_{\mathrm{m}(\mathrm{aq})} & =\left[\mathrm{X}_{\mathrm{a}} \Delta \mathrm{H}_{\mathrm{a}}+\mathrm{X}_{\mathrm{H} 2 \mathrm{O}} \Delta \mathrm{H}_{\mathrm{H} 2 \mathrm{O}}\right]-[\mathrm{M}] \\
& =\left[\mathrm{X}_{\mathrm{a}} \Delta \mathrm{H}_{\mathrm{a}}+\mathrm{X}_{\mathrm{H} 2 \mathrm{O}} \Delta \mathrm{H}_{\mathrm{H} 2 \mathrm{O}}\right]-\left(\mathrm{X}_{\mathrm{a}}\right) *(\mathrm{~h}) *\left(\mathrm{E}_{\mathrm{H}}\right)
\end{aligned}
$$

where $\quad X_{a}$ is the molar fraction of solute " $a$ ",

$\mathrm{X}_{\mathrm{H} 2 \mathrm{O}}$ is the molar fraction of water,

$\Delta \mathrm{H}_{\mathrm{a}}$ is the fusion enthalpy of solute "a",

$\Delta \mathrm{H}_{\mathrm{H} 2 \mathrm{O}}$ is the fusion enthalpy of water,

$M$ is the hydration energy,

$\mathrm{h}$ is the hydration numbers, and

$E_{H}$ is the energy of hydrogen bonds per mole water.

The term " $M$," the hydration energy, is equivalent to the product of the number of moles of hydrated water $\left(\mathrm{X}_{\mathrm{a}} * \mathrm{~h}\right)$ and the hydrogen bond energy per mole water $\left(E_{H}\right)$. In the case of electrolytic solutions, the term " $h "$ corresponds to the total hydration number (considering both primary and secondary hydration). The values of " $h$ " were available from Robinson ${ }^{(25)}$ and are listed in Appendix I. In the case of non-electrolytic solutions, the term " $h "$ corresponds to the primary hydration number. The values of " $h$ " were available from CRC Handbook of Chemistry and Physics ${ }^{(26)}$ and are listed in Appendix J. The hydrogen bond energy per mole of water is $3.0 \mathrm{kcal} / \mathrm{mol}$, 
according to Nemethy and Scheraga. ${ }^{(27)}$ The values of $\Delta \mathrm{H}_{\mathrm{a}}$ and $\Delta \mathrm{H}_{\mathrm{H} 2 \mathrm{O}}$ were from the published literature ${ }^{(6,19)}$ and are listed in Appendix B.

\subsection{Results}

The fusion enthalpies of aqueous solutions, as predicted by the Modified Mixture Rule, were compared to those obtained experimentally. The percent deviation between the calculated $\Delta \mathrm{H}_{\mathrm{m}}$ and those obtained experimentally were determined and are shown in Table 17. The average deviation was found to be $12.5 \%$, with the values ranging from a high of $58.1 \%$ to a low of $0.3 \%$. A sample calculation for the case of determining $\Delta \mathrm{H}_{\mathrm{m}}$ for $\mathrm{MgCl}_{2}$, according to the Modified Mixture Rule, is presented in Appendix K.

\subsection{Discussion of Results}

The Modified Mixture Rule is a modification of the Rule of Mixtures. To determine if the Modified Mixture Rule is more reliable than the Rule of Mixtures, results from these two models are compared by means of the graphs in Figures 15 and 16. The experimental data of the fusion enthalpy obtained from the DSC were used as the standard for comparison.

Comparisons of the reliability of the two models in predicting the fusion enthalpies of 5 electrolytic solutions, namely, $\mathrm{MgCl}_{2}, \mathrm{LiBr}, \mathrm{LiCl}, \mathrm{CaCl}_{2}$, and $\mathrm{NaCl}$, are shown in Figures 15a through 15e respectively.

Comparisons of the reliability of the two models in predicting the fusion enthalpies of 5 non-electrolytic solutions, namely, formic acid, acetic acid, ethylene glycol, ethanol, and glycerol, are shown in Figures 16a through 16e respectively. 
Table 17. Test of the Modified Mixture Rule for $\Delta \mathrm{H}_{\mathrm{m}}$ of Aqueous Solutions

\begin{tabular}{|c|c|c|c|c|}
\hline Materials & & $\begin{array}{l}\Delta \mathrm{H}_{\mathrm{m}}(\mathrm{cal} / \mathrm{mol}) \\
\text { by Modified } \\
\text { Mixture Rule }\end{array}$ & $\begin{array}{l}\Delta \mathrm{H}_{\mathrm{m}}(\mathrm{cal} / \mathrm{mol}) \\
\text { from DSC }\end{array}$ & |\%deviation | \\
\hline \multirow[t]{4}{*}{ Magnesium chloride } & $1.0 \%$ & 1370 & 1316 & $4.1 \%$ \\
\hline & $5.0 \%$ & 1097 & 975 & $12.5 \%$ \\
\hline & $10.0 \%$ & 727 & 565 & $28.7 \%$ \\
\hline & $15.0 \%$ & 324 & 309 & $4.9 \%$ \\
\hline \multirow[t]{4}{*}{ Lithium bromide } & $1.0 \%$ & 1391 & 1438 & $3.3 \%$ \\
\hline & $5.0 \%$ & 1206 & 1043 & $15.6 \%$ \\
\hline & $10.0 \%$ & 956 & 764 & $25.1 \%$ \\
\hline & $15.0 \%$ & 683 & 609 & $12.2 \%$ \\
\hline \multirow[t]{3}{*}{ Lithium chloride } & $1.0 \%$ & 1353 & 1264 & $7.0 \%$ \\
\hline & $4.0 \%$ & 1096 & 925 & $18.5 \%$ \\
\hline & $12.0 \%$ & 367 & 331 & $10.9 \%$ \\
\hline \multirow[t]{3}{*}{ Calcium chloride } & $8.0 \%$ & 1000 & 1108 & $9.7 \%$ \\
\hline & $12.0 \%$ & 758 & 1018 & $25.5 \%$ \\
\hline & $15.0 \%$ & 564 & 910 & $38.0 \%$ \\
\hline \multirow[t]{2}{*}{ Sodium chloride } & $7.0 \%$ & 1329 & 1282 & $3.7 \%$ \\
\hline & $15.0 \%$ & 1193 & 1231 & $3.1 \%$ \\
\hline Potassium chloride & $9.0 \%$ & 1419 & 1373 & $3.4 \%$ \\
\hline Sodium bromide & $11.0 \%$ & 1269 & 1418 & $10.5 \%$ \\
\hline Potassium bromide & $13.0 \%$ & 1376 & 1361 & $1.1 \%$ \\
\hline Potassium iodide & $16.0 \%$ & 1338 & 1479 & $9.5 \%$ \\
\hline \multirow[t]{3}{*}{ Formic acid } & $2.0 \%$ & 1402 & 1259 & $11.3 \%$ \\
\hline & $10.0 \%$ & 1259 & 1084 & $16.1 \%$ \\
\hline & $32.0 \%$ & 759 & 480 & $58.1 \%$ \\
\hline \multirow[t]{3}{*}{ Acetic acid } & $2.0 \%$ & 1392 & 1387 & $0.3 \%$ \\
\hline & $13.0 \%$ & 1122 & 1111 & $0.9 \%$ \\
\hline & $20.0 \%$ & 922 & 939 & $1.8 \%$ \\
\hline
\end{tabular}


Table 17. Test of the Modified Mixture Rule for $\Delta \mathrm{H}_{\mathrm{m}}$ of Aqueous Solutions (continued)

\begin{tabular}{lrccr}
\hline Materials & \multicolumn{5}{c}{$\begin{array}{c}\Delta \mathrm{H}_{\mathrm{m}} \text { (cal/mol) } \\
\text { by Modified } \\
\text { Mixture Rule }\end{array}$} & $\begin{array}{l}\Delta \mathrm{H}_{\mathrm{m}}(\mathrm{cal} / \mathrm{mol}) \\
\text { from DSC }\end{array}$ & 1\%deviation I \\
\hline Ethylene glycol & $2.0 \%$ & 1390 & 1386 & $0.3 \%$ \\
& $12.0 \%$ & 1139 & 1120 & $1.7 \%$ \\
Ethanol & $28.0 \%$ & 648 & 470 & $37.9 \%$ \\
& $9.5 \%$ & 1074 & 954 & $12.6 \%$ \\
Glycerol & $24.0 \%$ & 440 & 417 & $5.5 \%$ \\
& $16.0 \%$ & 1118 & 947 & $18.1 \%$ \\
& $40.0 \%$ & 415 & 406 & $2.2 \%$ \\
\hline
\end{tabular}




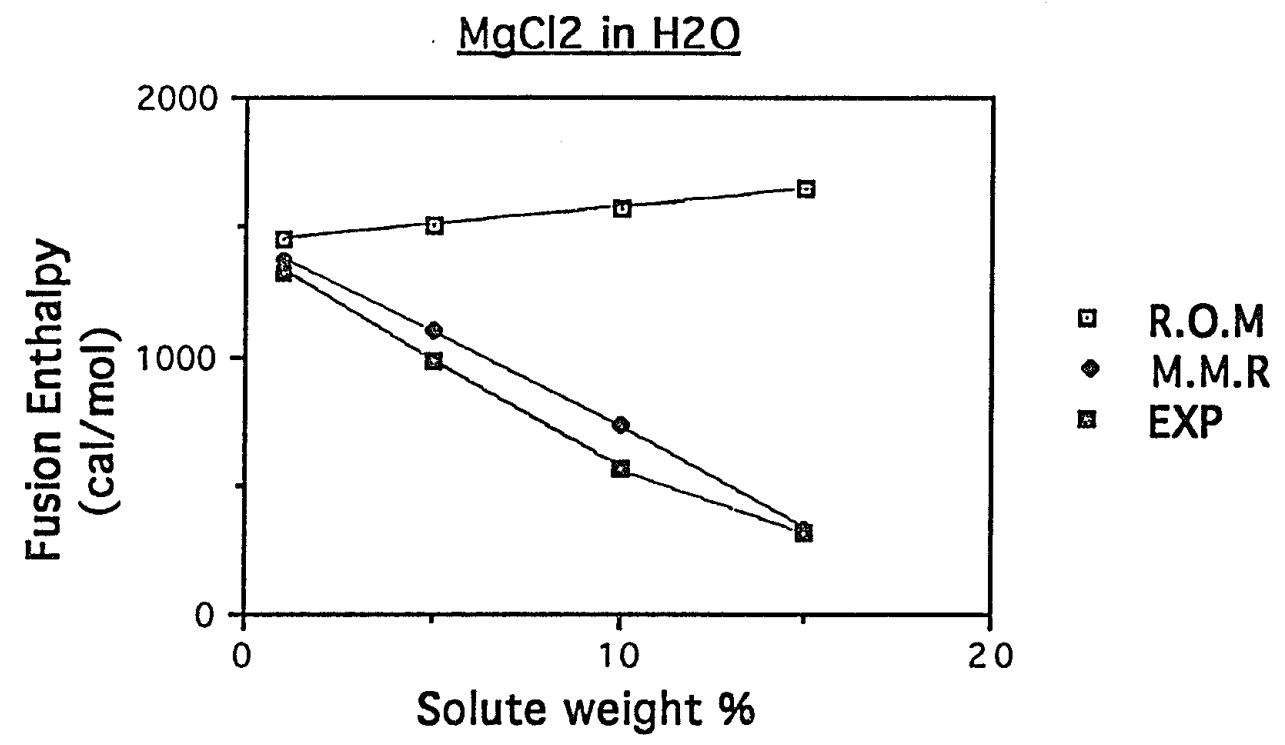

Figure 15a . Comparison of the Rule of Mixtures (R.O.M) and the Modified Mixture Rule (M.M.R) in Predicting $\Delta \mathrm{H}_{\mathrm{m}}$ of $\mathrm{MgCl}_{2}$ Electrolyte Aqueous Solution

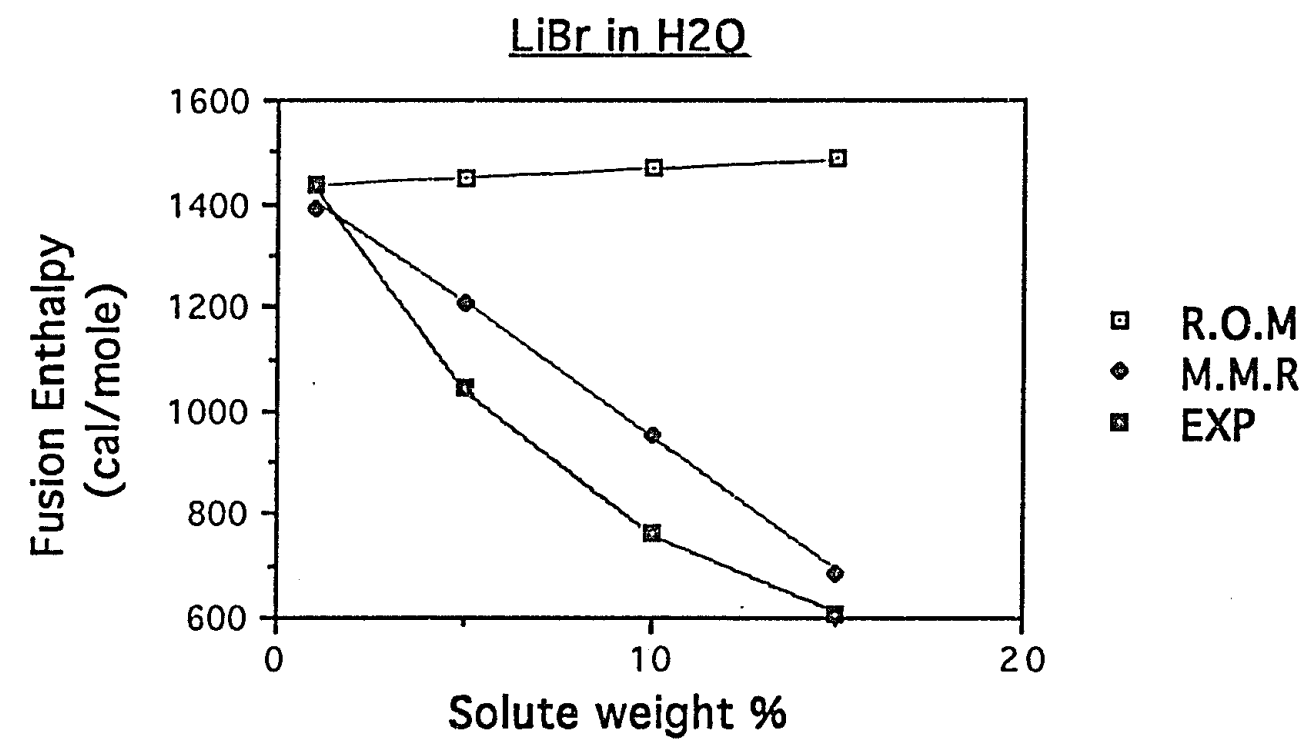

Figure 15b . Comparison of the Rule of Mixtures (R.O.M) and the Modified Mixture Rule (M.M.R) in Predicting $\Delta \mathrm{H}_{\mathrm{m}}$ of $\mathrm{LiBr}$ Electrolyte Aqueous Solution 


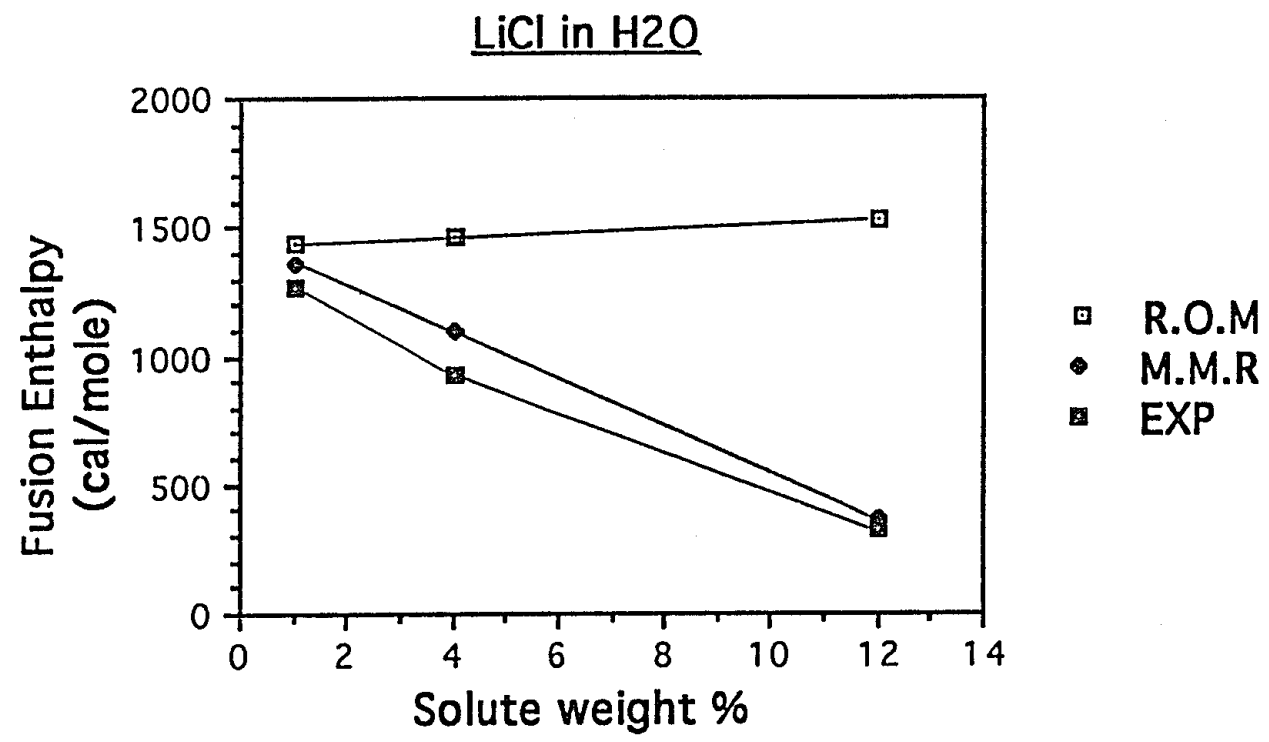

Figure 15c. Comparison of the Rule of Mixtures (R.O.M) and the Modified Mixture Rule (M.M.R) in Predicting $\Delta \mathrm{H}_{\mathrm{m}}$ of $\mathrm{LiCl}$ Electrolyte Aqueous Solution

$\mathrm{CaCl} 2$ in $\mathrm{H} 2 \mathrm{O}$

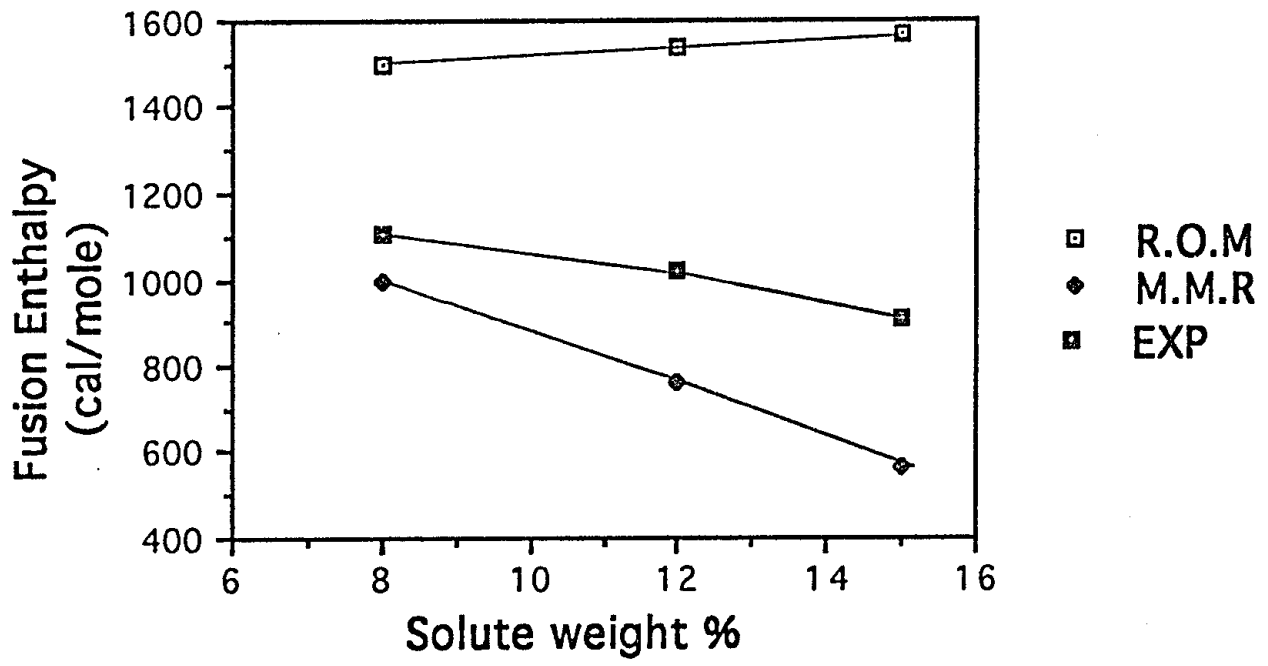

Figure 15d . Comparison of the Rule of Mixtures (R.O.M) and the Modified Mixture Rule (M.M.R) in Predicting $\Delta \mathrm{H}_{\mathrm{m}}$ of $\mathrm{CaCl}_{2}$ Electrolyte Aqueous Solution 


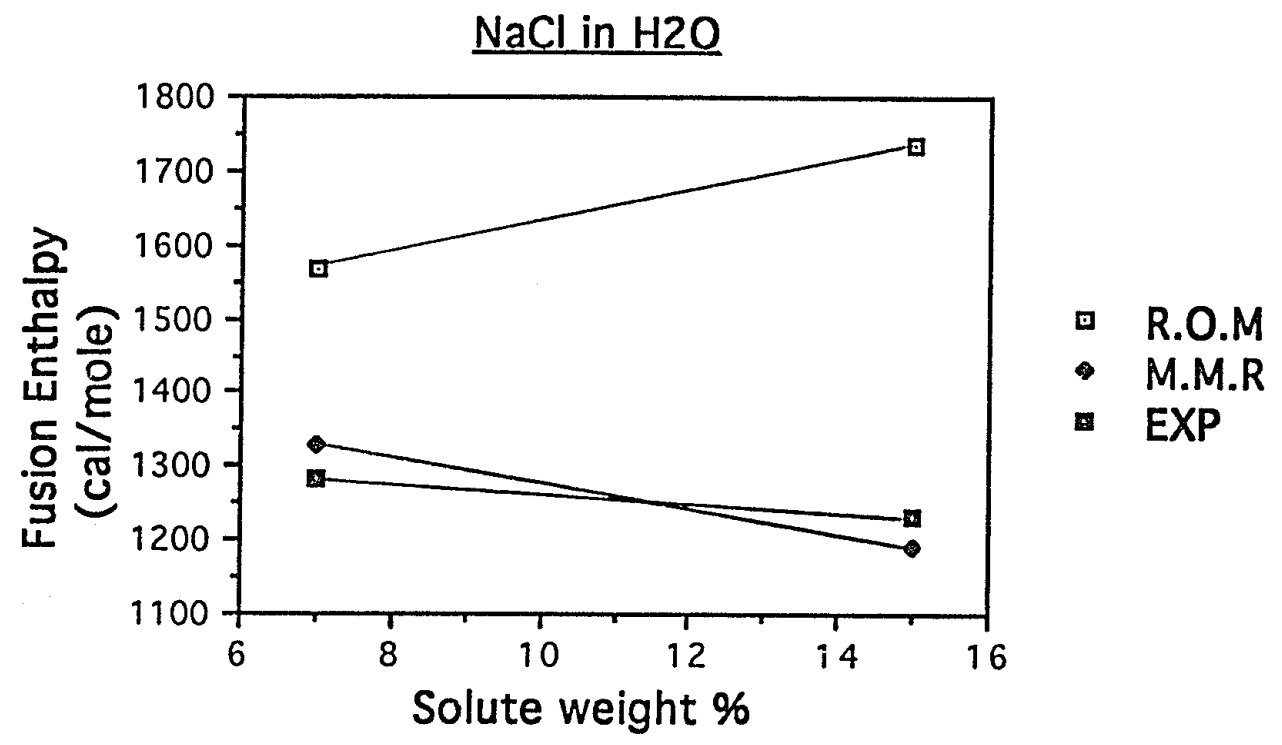

Figure 15e . Comparison of the Rule of Mixtures (R.O.M) and the Modified Mixture Rule (M.M.R) in Predicting $\Delta \mathrm{H}_{\mathrm{m}}$ of $\mathrm{NaCl}$ Electrolyte Aqueous Solution

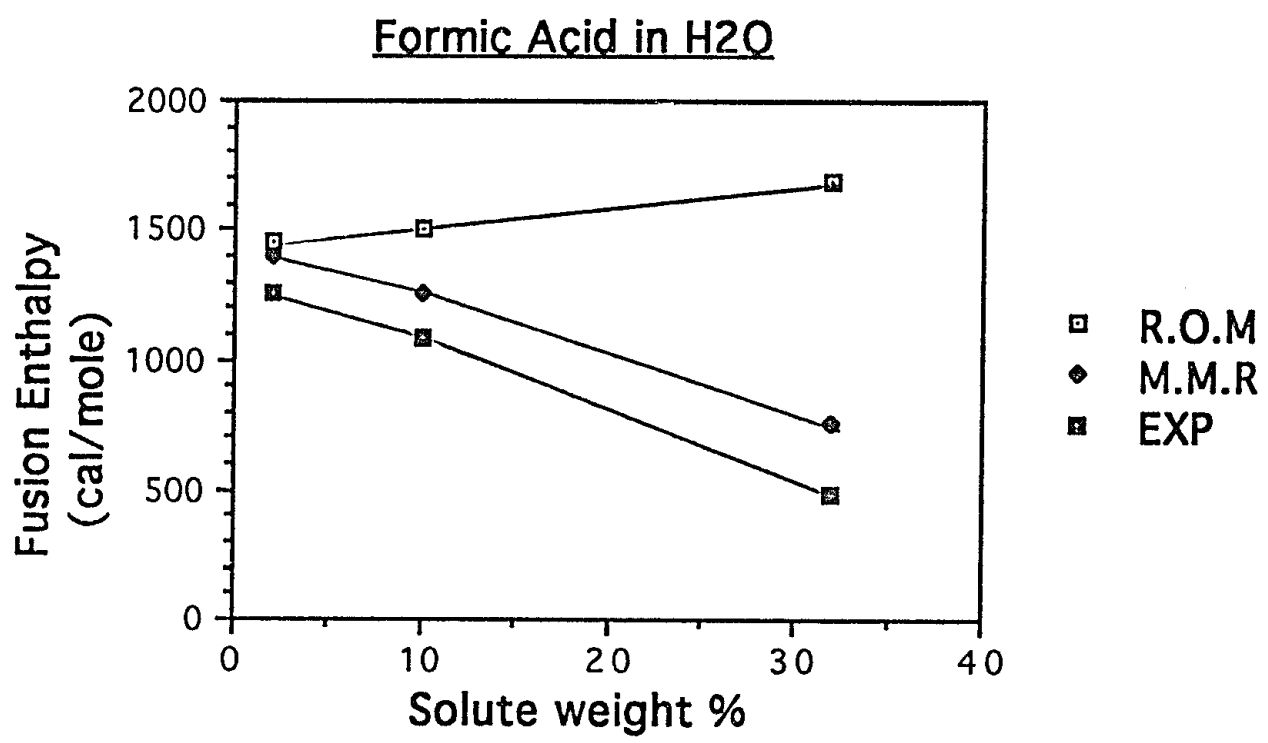

Figure 16a . Comparison of the Rule of Mixtures (R.O.M) and the Modified Mixture Rule (M.M.R) in Predicting $\Delta \mathrm{H}_{\mathrm{m}}$ of Formic Acid Non- electrolyte Aqueous Solution 


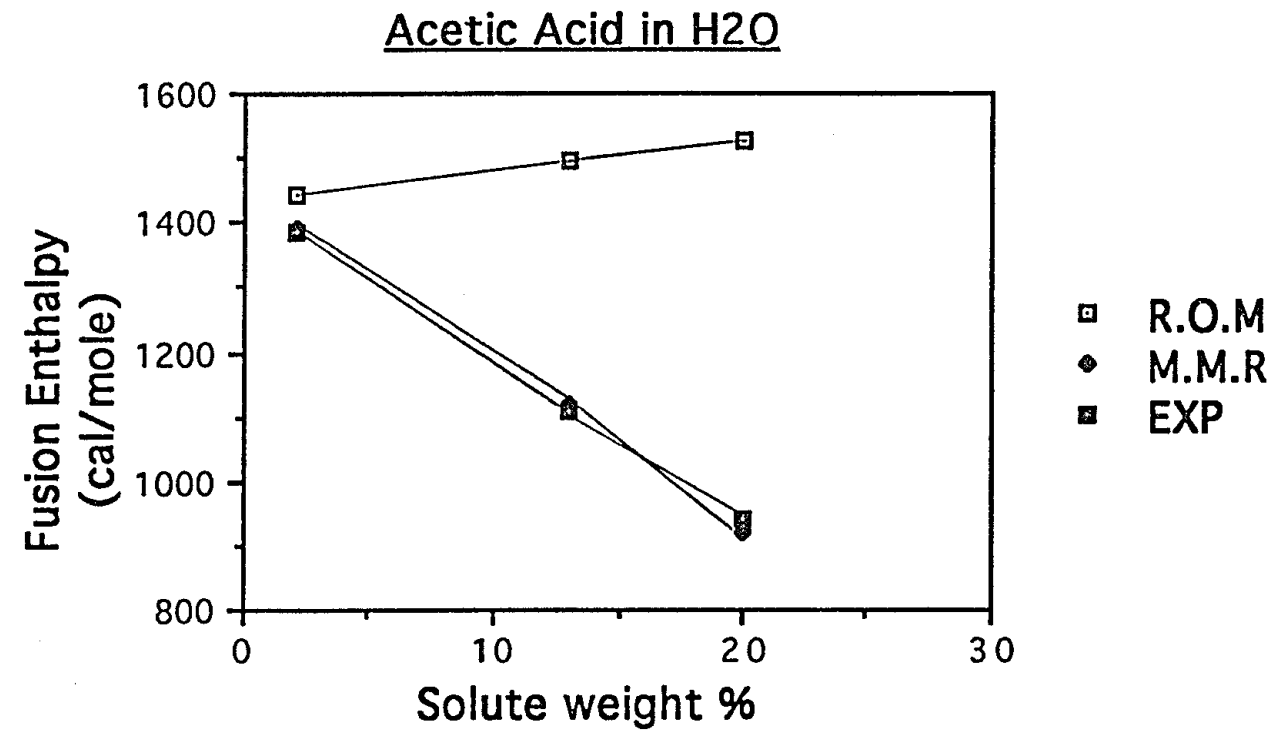

Figure 16b . Comparison of the Rule of Mixtures (R.O.M) and the Modified Mixture Rule (M.M.R) in Predicting $\Delta \mathrm{H}_{\mathrm{m}}$ of Acetic Acid Non- electrolyte Aqueous Solution

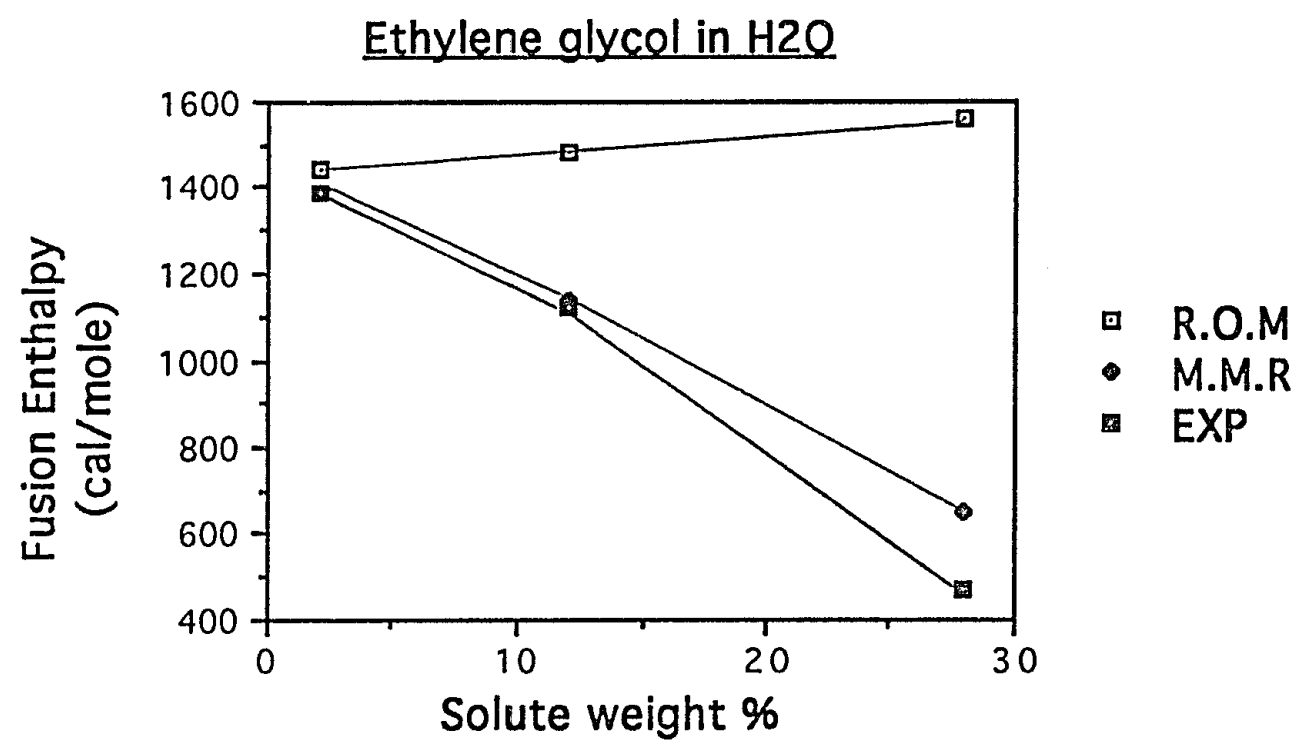

Figure 16c . Comparison of the Rule of Mixtures (R.O.M) and the Modified Mixture Rule (M.M.R) in Predicting $\Delta \mathrm{H}_{\mathrm{m}}$ of Ethylene Glycol Non- electrolyte Aqueous Solution 


\section{Ethanol in $\mathrm{H} 2 \mathrm{O}$}

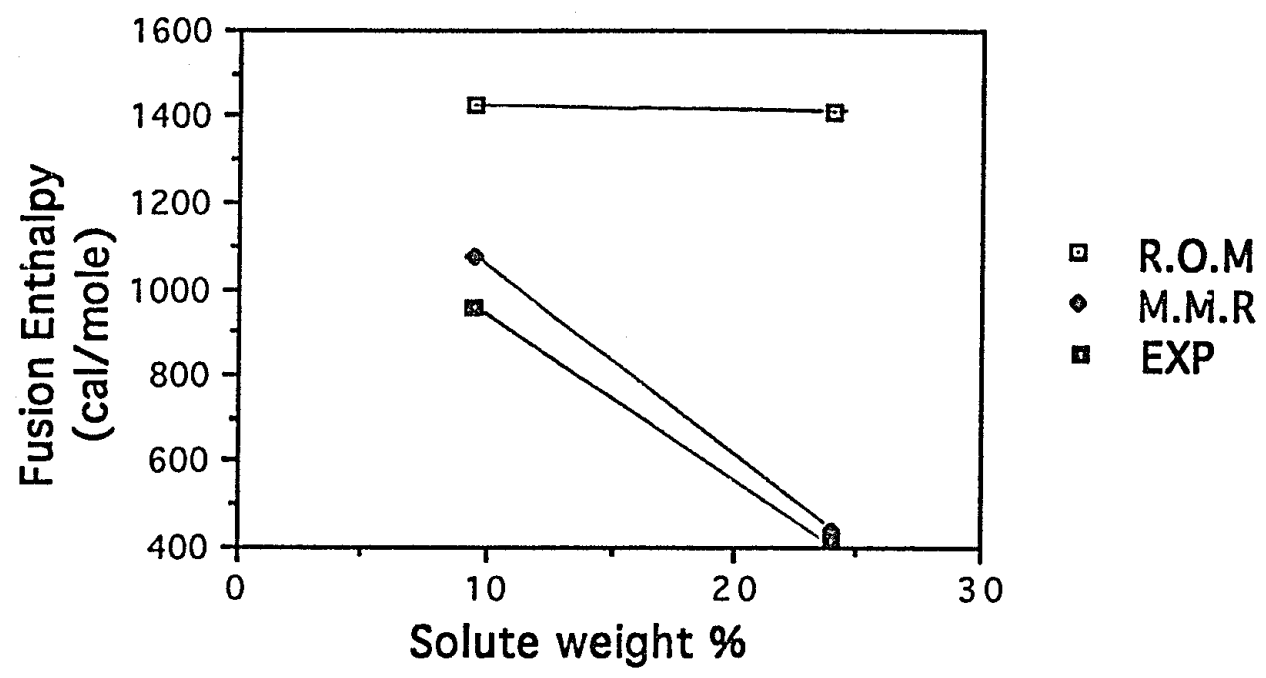

Figure 16d . Comparison of the Rule of Mixtures (R.O.M) and the Modified Mixture Rule (M.M.R) in Predicting $\Delta \mathrm{H}_{\mathrm{m}}$ of Ethanol Non- electrolyte Aqueous Solution

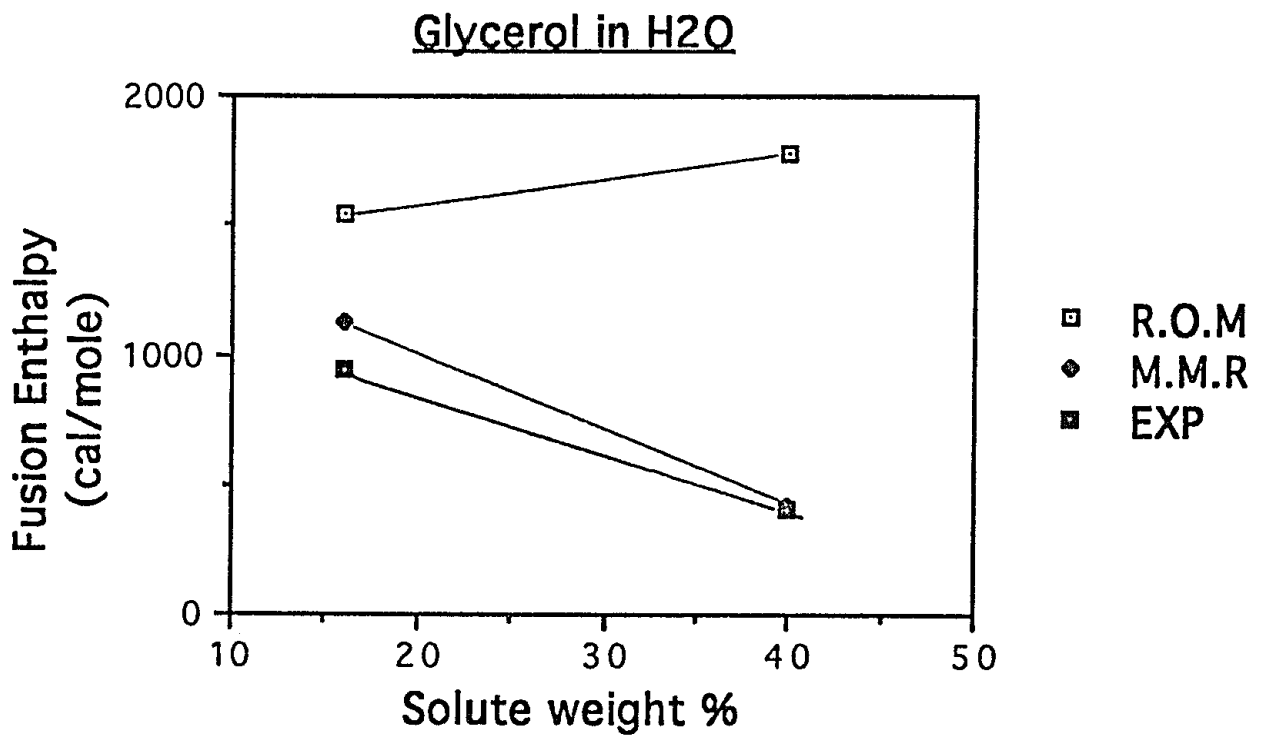

Figure 16e . Comparison of the Rule of Mixtures (R.O.M) and the Modified Mixture Rule (M.M.R) in Predicting $\Delta \mathrm{H}_{\mathrm{m}}$ of Glycerol Non- electrolyte Aqueous Solution 
As can be seen from Figures 15 and 16, the Rule of Mixtures becomes more unreliable as the concentration increases. Modifying the Rule of Mixtures by introducing another parameter, the hydration energy, yields more accurate predictions for fusion enthalpies of concentrated solutions. This supports the assumption that the solute-water interaction plays a significant role in determining the fusion enthalpy.

As can be seen from Table 17, the Modified Mixture Rule is reliable for most aqueous solutions except formic acid at a concentration of $32 \%$. The fusion enthalpy of formic acid is overestimated by $58.1 \%$ according to the Modified Mixture Rule. This might be explained by the following equation for formic acid ionization:

$$
\mathrm{HCOOH}->\mathrm{H}^{+}+\mathrm{COOH}^{-}
$$

Formic acid gives off a proton $\left(\mathrm{H}^{+}\right)$when added to water, resulting in additional hydrogen bonds being broken besides those due to hydration.

It is also possible that the value of the hydrogen bond energy in aqueous solutions may be different from that in pure water and this might account for the residual inaccuracy of this model. Figure 17 shows the possible configurations of $\mathrm{H}_{2} \mathrm{O}$ molecules. (28) For pure water, the $\mathrm{H}_{2} \mathrm{O}$ molecules are arranged in their normal configuration. These molecules are arranged in a bent configuration in the presence of a solute. According to Conway the hydrogen bond energy in water depends both on the angle of the O-H...O bond and the $\mathrm{O}-\mathrm{O}$ bond distance.(28) The angle of the O-H...O bond deviates from $180^{\circ}$ (normal case in pure water) when a solute (ions) is added. LennardJones and Pople proposed that the hydrogen bond energy decreases slowly with deviation of the $\mathrm{O}-\mathrm{H} . . . \mathrm{O}$ bond angle from $180^{\circ}$.(29) The hydrogen bond 


\section{STRETCHED and BENT H-BOND CONFIGURATIONS}
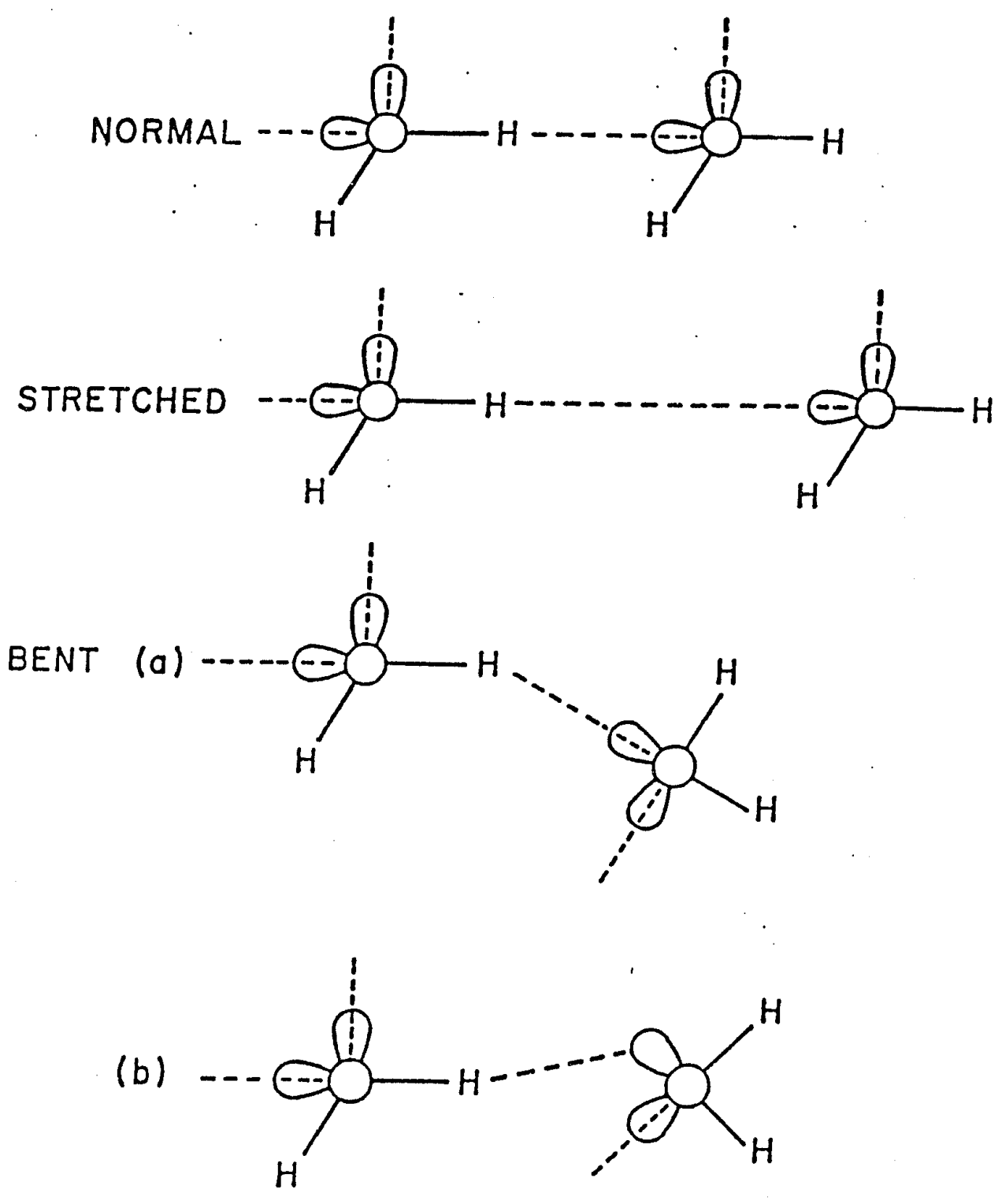

Figure 17. Bent and Stretched H-Bond Configuration in Water (after Ref. 28) 
energy in the solution might be slightly lower than that in pure water (3.0 $\mathrm{kcal} / \mathrm{mol})$. This may affect the accuracy of the Modified Mixture Rule in predicting the value of fusion enthalpy for aqueous solutions.

The validity of this model for predicting fusion enthalpies of aqueous solutions at much higher concentrations could not be determined due to the lack of published data for hydration numbers in highly concentrated solutions. According to Robinson, the hydration numbers are applicable only for those solutions in which the ratio of the number of moles of the hydrated water to that of the total water is less than one-fourth.(30) When more than one-quarter of the total water molecules are bonded to ions, the hydration numbers will begin to decrease owing to the effects of competition between neighboring cations. ${ }^{(30)}$ Different solutes have different degrees of hydration when added to water and therefore lead to different maximum allowable concentrations when applying the Modified Mixture Rule. To find the applicable range of the Modified Mixture Rule, the maximum allowable concentrations for the ten solutions investigated in this project were calculated and are shown in Table 18. The values of the hydration number of the solute in water are in the second column of Table 18. The third column corresponds to the maximum concentration at which $1 / 4$ of the water molecules are hydrated. The detailed calculation is shown in Appendix L.

As seen from Table 18, solutes with higher hydration numbers generally have smaller maximum allowable concentrations for application of the Modified Mixture Rule. 
Table 18. The Maximum Allowable Concentrations of the Solutions in the Application of the Modified Mixture Rule

\begin{tabular}{lcc}
\hline Solute Material & Hydration number & Maximum concentration \\
\hline Formic acid & $1.99^{(26)}$ & $24.3 \%$ \\
Acetic acid & $2.90^{(26)}$ & $22.3 \%$ \\
Ethylene glycol & $3.01^{(26)}$ & $22.3 \%$ \\
Ethanol & $2.94^{(26)}$ & $17.9 \%$ \\
Glycerol & $3.95^{(26)}$ & $24.5 \%$ \\
Magnesium chloride & $13.7^{(25)}$ & $8.8 \%$ \\
Lithium bromide & $7.6^{(25)}$ & $13.7 \%$ \\
Lithium chloride & $7.1^{(25)}$ & $7.7 \%$ \\
Calcium chloride & $12.0^{(25)}$ & $11.4 \%$ \\
Sodium chloride & $3.5^{(25)}$ & $18.8 \%$ \\
& & \\
\hline
\end{tabular}




\subsection{Identification of FHS Materials by the Model}

Experiments showed that the Modified Mixture Rule is reliable. Therefore this model will help identify future FHS materials of the aqueous solution type.

According to Equation 22, future FHS materials of the aqueous solution type should have a value of $\Delta \mathrm{H}_{\mathrm{a}}$ that is greater than $\Delta \mathrm{H}_{\mathrm{H} 2 \mathrm{O}}$, and the value of $\mathrm{h}$ should be very small, or as close to zero as possible.

Solutes with a fusion enthalpy higher than water were first identified from the literature and are listed in Table 19. The second and third column contain the values of the fusion enthalpy obtained from CRC Handbook of Chemistry and Physics ${ }^{(6)}$ and Lange's Handbook of Chemistry(7) respectively. The values of hydration numbers are in the fourth column.

The solutes, $\mathrm{MgCl}_{2}$ and $\mathrm{NaCl}$, have reported values of fusion enthalpy, $\Delta \mathrm{H}_{\mathrm{a}}$, higher than that of water. Experimental results, as can be seen from Figure 15a and 15e, show that both $\mathrm{MgCl}_{2}$ and $\mathrm{NaCl}$ aqueous solutions are not suitable FHS materials because their measured fusion enthalpies are lower than water. This is probably due to the hydration energy which negatively affects the magnitude of the fusion enthalpy. $\mathrm{NiCl}_{2}$ aqueous solution is also unlikely to have a higher fusion enthalpy than water based on this model, because its hydration number is high.

The solutes, $\mathrm{KF}$ and $\mathrm{NaF}$, also have a fusion enthalpy higher than water. However, their hydration numbers were not reported. If their hydration numbers are so low that the hydration energy can be ignored, then the fusion enthalpy of the solution, $\Delta \mathrm{H}_{\mathrm{m}}$ (aq), will be dominated by the term 
Table 19. Solutes with a Fusion Enthalpy Higher than Water

\begin{tabular}{lccc}
\hline Solute & $\begin{array}{c}\Delta \mathrm{H}_{\mathrm{m}}\left(\mathrm{cal} / \mathrm{mol}^{\prime}\right) \\
\text { from CRC handbook }\end{array}$ & $\begin{array}{c}\Delta \mathrm{H}_{\mathrm{m}}(\mathrm{cal} / \mathrm{mol}) \\
\text { from Lange's handbook }\end{array}$ & $\begin{array}{c}\text { Hydration } \\
\text { number }\end{array}$ \\
\hline $\mathrm{MgCl}_{2}$ & 8100 & 10300 & 13.7 \\
$\mathrm{KF}$ & 6500 & 6500 & - \\
$\mathrm{NaCl}$ & 7220 & 6730 & 3.5 \\
$\mathrm{NiCl}_{2}$ & 18470 & 18470 & 13.0 \\
$\mathrm{NaF}$ & 7000 & 7970 & - \\
& & & \\
\hline
\end{tabular}

- Not reported in the literature 
" $\mathrm{X}_{\mathrm{a}} \Delta \mathrm{H}_{\mathrm{a}}$ ", according to Equation 22. In this situation, the fusion enthalpy, $\Delta \mathrm{H}_{\mathrm{m}}$ (aq), is expected to increase when more solute is added to water. Actual results show that as the solute concentration increases, the freezing point decreases due to eutectic behavior. The freezing point may decrease below the lower bound $\left(-13^{\circ} \mathrm{C}\right)$ of the operating temperature of the FHS when a certain concentration of the solute " $\mathrm{X}_{\mathrm{a}}$ " is reached and this may limit the maximum value of the term " $\mathrm{X}_{\mathrm{a}} \Delta \mathrm{H}_{\mathrm{a}}$ " or the fusion enthalpy $\Delta \mathrm{H}_{\mathrm{m}}$ (aq). 


\section{CHAPTER 6}

\section{Verification of Candidate FHS Materials}

One of the main purposes of this project was to experimentally verify the prelimary results of candidate FHS materials as determined by Selvaduray and Lomax. The results are presented in this chapter and summarized in Table 20. The third column contains the calculated values of the total cooling capacity, based on the experimental data reported in Section 4.2. The detailed calculations are contained in Appendix M. The cooling capacity was not measured for those candidate materials whose melting points were found to lie outside the desired operating range of $-13^{\circ} \mathrm{C}$ to $5^{\circ} \mathrm{C}$. The fourth column contains the values of the total cooling capacity reported by Selvaduray and Lomax for purposes of comparison. Since Selvaduray and Lomax reported their cooling capacity values in units of "cal/g" because total weight of the PLSS is a parameter of concern, the cooling capacities in Table 20 are presented using the unit of "cal/g," rather than "cal/mole," as has been done throughout the rest of this thesis.

As can be seen from Table 20, potassium dichromate at a concentration of $2.5 \%$ is the only material which has a melting temperature within $-13^{\circ} \mathrm{C}$ to $5^{\circ} \mathrm{C}$ and the measured cooling capacity greater than water. The increase in cooling capacity, however, is only 2.2 percent greater than water. The cooling capacity of potassium dichromate at a concentration higher than $2.5 \%$ cannot be predicted from the Modified Mixture Rule, due to the lack of the reported hydration number for potassium dichromate. 
Table 20. Verification of Candidate FHS Materials

\begin{tabular}{|c|c|c|c|}
\hline \multirow[t]{2}{*}{ FHS candidate } & \multirow{2}{*}{$\begin{array}{l}\text { Melting Point } \\
\quad\left({ }^{\circ} \mathrm{C}\right)\end{array}$} & \multicolumn{2}{|c|}{ Cooling Capacity (cal/g) } \\
\hline & & Measured & Reported \\
\hline Water & 0.087 & 92.60 & 90.97 \\
\hline Benzene,hexafluoro & 5.34 & - & 1280.07 \\
\hline Heptanoic acid & -10.14 & 35.78 & 1119.59 \\
\hline Cyclohexanol,4-methyl(cis) & -3.96 & 24.99 & 874.47 \\
\hline Benzene,1,4-difluoro & -22.79 & - & 717.29 \\
\hline Cyclohexanone,2-methyl & -14.14 & - & 613.34 \\
\hline Cinnamonitrile & 5.08 & - & 593.50 \\
\hline Cyclooctatetraene & -8.21 & 29.65 & 593.50 \\
\hline 4-Methoxybenzaldehyde & -1.89 & 34.25 & 469.34 \\
\hline Indene & -6.15 & 22.58 & 234.64 \\
\hline Cyclohexane,1,2-dibromo & -4.98 & 15.33 & 160.35 \\
\hline Biphenyl,2-methyl & -0.48 & 22.40 & 153.35 \\
\hline 1,2-dihydronaphthalene & -10.05 & 25.39 & 138.26 \\
\hline Piperidene & -18.46 & - & 97.99 \\
\hline Sodium chloride (7\%) & $\begin{array}{l}-20.6\left(\mathrm{~T}_{\mathrm{tr}, 1}\right) \\
-10.2\left(\mathrm{~T}_{\mathrm{tr}, 2}\right)\end{array}$ & - & 94.31 \\
\hline Potassium chloride $(9 \%)$ & -8.55 & 83.30 & 93.53 \\
\hline Sodium bromide (11\%) & $\begin{array}{r}-29.94\left(\mathrm{~T}_{\mathrm{tr}, 1}\right) \\
-9.68\left(\mathrm{~T}_{\mathrm{tr}, 2}\right)\end{array}$ & - & 93.09 \\
\hline Lithium chloride $(4 \%)$ & -7.96 & 65.26 & 92.95 \\
\hline Potassium chromate $(18 \%)$ & $\begin{array}{r}-10.96\left(\mathrm{~T}_{\mathrm{tr}, 1}\right) \\
-8.7\left(\mathrm{~T}_{\mathrm{tr}, 2}\right)\end{array}$ & 83.22 & 92.87 \\
\hline Potassium bromide(13\%) & $\begin{array}{l}-12.15\left(\mathrm{~T}_{\mathrm{tr}, 1}\right) \\
-11.04\left(\mathrm{~T}_{\mathrm{tr}, 2}\right)\end{array}$ & 82.50 & 92.73 \\
\hline
\end{tabular}

- Not obtained because the heat capacity was not measured $T_{t r, 1}$ Eutectic temperature.

$\mathrm{T}_{\mathrm{tr}, 2}$ Liquidus temperature 
Table 20. Verification of Candidate FHS Materials (continued)

\begin{tabular}{lccc}
\hline FHS candidate & Melting Point & \multicolumn{2}{c}{ Cooling Capacity (cal/g) } \\
\cline { 3 - 4 } & $\left({ }^{\circ} \mathrm{C}\right)$ & Measured & Reported \\
\hline Sodium nitrate(10\%) & $-16.35\left(\mathrm{~T}_{\mathrm{tr}, 1}\right)$ & - & 92.50 \\
& $-8.5\left(\mathrm{~T}_{\mathrm{tr}, 2}\right)$ & & \\
Potassium iodide(16\%) & $-20.82\left(\mathrm{~T}_{\mathrm{tr}, 1}\right)$ & - & 92.46 \\
& $-8.95\left(\mathrm{~T}_{\mathrm{tr}, 2}\right)$ & & \\
Cesium chloride(19\%) & $-22.66\left(\mathrm{~T}_{\mathrm{tr}, 1}\right)$ & - & 92.43 \\
& $-10.75\left(\mathrm{~T}_{\mathrm{tr}, 2}\right)$ & & \\
Sodium hydroxide(4.5\%) & -7.27 & 53.76 & 92.34 \\
Silver nitrate(16\%) & $-8.68\left(\mathrm{~T}_{\mathrm{tr}, 1}\right)$ & 82.91 & 91.90 \\
& $-7.72\left(\mathrm{~T}_{\mathrm{tr}, 2}\right)$ & & \\
Potassium nitrate(10\%) & -2.41 & 90.64 & 91.82 \\
Potassium sulfate(5\%) & -0.81 & 89.37 & 91.82 \\
Potassium hydroxide $(6 \%)$ & -7.26 & 59.97 & 91.28 \\
Potassium dichromate $(2.5 \%)$ & -0.02 & 94.65 & 91.26 \\
Formic acid(10\%) & -7.53 & 70.12 & 92.64 \\
Acetic acid(13\%) & -8.54 & 72.33 & 92.24 \\
Ethylene glycol(12\%) & -5.52 & 75.05 & 92.17 \\
Ethanol(9.5\%) & -6.72 & 66.54 & 91.35 \\
Glycerol(16\%) & -7.95 & 60.90 & 92.51 \\
\hline
\end{tabular}

- Not obtained because the heat capacity was not measured $\mathrm{T}_{\mathrm{tr}, 1}$ Eutectic temperature

$\mathrm{T}_{\mathrm{tr}, 2}$ Liquidus temperature 


\section{CHAPTER 7 \\ CONCLUSION}

The results presented in the previous chapters have led to several conclusions, including verification of candidate FHS materials and evaluation of models for predicting fusion enthalpies of both organic compounds and aqueous solutions. These models will help identify future FHS materials for space suit applications.

From experimental verification of melting points and cooling capacities of candidate FHS materials, potassium dichromate at a concentration of $2.5 \%$, meets both the first criterion $\left(-13^{\circ} \mathrm{C}<\mathrm{T}_{\mathrm{m}}<5^{\circ} \mathrm{C}\right)$, and the second $\left(\Delta \mathrm{H}_{\text {tot }}>\Delta \mathrm{H}_{\text {tot }}(\mathrm{H} 2 \mathrm{O})\right)$. To determine if potassium dichromate $(2.5 \%)$ is suitable for space suit applications, other criteria as mentioned in Section 1.5 need to be further employed in evaluating this material in the future. Ten of the candidate FHS materials, as identified with an " $\mathrm{x}$ " in Table 13, did not display a solid-liquid transition between $-50^{\circ} \mathrm{C}$ to $30^{\circ} \mathrm{C}$, based on differential scanning calorimetry. These ten materials need to be further investigated to verify their melting points. The rest of the candidate FHS materials are not suitable for space suit applications because they do not meet the first and second criteria.

The existing models for predicting the fusion enthalpy were evaluated against experimental data. The model proposed by Chickos for predicting the fusion enthalpies of 13 organic compounds was found to have an average percent deviation of $26.3 \%$ from the experimentally measured values. The accuracy of this model for predicting the fusion enthalpies of organic 
compounds can possibly be improved by using a larger database. This will be possible by including more experimental data of fusion enthalpy that may become available in the future.

The Rule of Mixtures and Horvath's model for predicting fusion enthalpies of aqueous solutions had an average percent deviation of $75.9 \%$ and $142.9 \%$, respectively, from the experimentally measured values. The experiments revealed that the present models for predicting fusion enthalpies of aqueous solutions are not reliable. For this reason a new model, termed the "Modified Mixture Rule," was developed and evaluated.

This Modified Mixture Rule was employed for predicting the fusion enthalpies of 33 aqueous solutions. It had an average percent deviation of $12.5 \%$ when compared to experimentally measured values. The results show that the Modified Mixture Rule is far more accurate than the presently available two models (the Rule of Mixtures and Horvath's model) for predicting the fusion enthalpies of aqueous solutions. In the future, the accuracy of the Modified Mixture Rule may be further improved by considering more factors besides hydration. This may result in more accurate fusion enthalpy prediction modeling.

The Modified Mixture Rule requires the values of the hydration numbers in predicting the fusion enthalpy. The lack of reported values of hydration numbers for many solutes limits the application of the Modified Mixture Rule. As predicted from the Modified Mixture Rule, those aqueous solutions with a solute which has a low hydration number and a high value of enthalpy of fusion might be future candidate FHS materials. 


\section{References}

1. Smolders, P., Living in Space, Tab/Aero, (1986), p. 71.

2. Stine, H. G., Handbook for Space Colonists, Holt, Rinehart and Winston, New York, (1985), p. 72.

3. Selvadury, G., and Lomax, C., "Fusible Heat Sink Materials: Evaluation of Alternate Candidates", ICES-92, Seattle, WA (July, 1992).

4. Moureu, H., and Dode, M., "Chaleurs de formation de l'oxyde d'ethylene, de l'ethanediol et de quelques homologues", Societe Chimique de France Bulletin, (1937), pp. 637-647.

5. Pickard and Kenyon, "Investigation on the Rotato Power of Chemical Constituents, Part I: The Rotation of the Simplest Secondary Alcohols of the Fatty Series", J. Chem. Soc., Vol. 99, No. 45, (1911).

6. Weast, R. C., Ed., CRC Handbook of Chemistry and Physics, 70th Edition, CRC Press Inc, (1990), Section B, p. B-224.

7. Dean, J. A., Ed., Lange's Handbook of Chemistry, 13th Edition, McGraw Hill, (1985), Section 9, p. 9-107.

8. Darken, G., Physical Chemistry of Metals, McGraw-Hill, New York, (1953), p. 124.

9. Pauling, L., The Nature of the Chemical Bond, 3rd Edition, Cornell University, (1960), p. 465.

10. Eisenberg, D., and Kauzmann, W., The Structure and Properties of Water, Oxford University Press, (1969), p. 139.

11. Procopiu, S., "Relation entre la chateur de fusion et la temperature absolue de fusion des metaux monoatomiques", Comptes Rendus

hebdomadaires des Seances de l'Academie des Sciences, Vol. 223, (1946), p. 503. 
12. Walden, P., "Uber Die Schmelzwarme, Spezifische Kohasion Und Molekulargrosse Bei Der Schmelztemperatur", Zeitschrift fur Elektrochemie, Vol. 14, (1908), p. 713.

13. Partington, J. R., An Advanced Treatise for Physical Chemistry, Vol. 3. Longmans, London, (1952), p. 551.

14. Schierz, E. R., "The nature of the spatial configuration of organic molecules as the determining factor for the magnitude of molar heat of fusion.", American Chemical Abstract, Vol. 31, (1937), p. 2504.

15. Austin, J. E., "The relation between the molecular heat of fusion and the absolute temperature of fusion of monatomic metals and of chemical compounds", American Chemical Abstract, Vol. 42, (1948), p. 2169.

16. Chickos, J. S., "Estimating Entropies and Enthalpies of Fusion of Organic Compounds", J.Org.Chem., Vol. 56, No. 3, (1991), p. 927.

17. Chickos, J. S., "Estimating Entropies and Enthalpies of Fusion of Hydrocarbons", J.Org.Chem., Vol. 55, No. 12, (1990), p. 3833.

18. Horvath, A. L., Handbook of Aqueous Eletrolyte Solutions, Ellis Horwood Limited, (1985), p. 44.

19. Acree, W. E. Jr., "Thermodynamic properties of organic compounds: enthalpy of fusion and melting point temperature compilation", Thermochimica Acta, Vol. 189, No. 1, (1991), p. 37.

20. Weast, R. C., Ed., CRC Handbook of Chemistry and Physics, 70th Edition, CRC Press Inc., (1990), Section C, p. C-196.

21. Bockris, J. O., and Reddy, K. N., Modern Electrochemistry, Vol. 1, Plenum Press, New York, (1973), p. 47.

22. Samoilov, O. Y., Structure of Aqueous Electrolyte Solutions and the Hydration of Ions, Consultants Bureau, New York, (1965), p. 75. 
23. Bockris, J. O., and Reddy, K. N., Modern Electrochemistry, Vol. 1, Plenum Press, New York, (1973), p. 79.

24. Samoilov, O. Y., Structure of Aqueous Electrolyte Solutions and the Hydration of Ions, Consultants Bureau, New York, (1965), p. 81.

25. Robinson, R. A., Electrolyte Solutions, 2nd Edition, Academic Press Inc., New York, (1959), p. 246.

26. Weast, R. C., Ed., CRC Handbook of Chemistry and Physics, 70th Edition, CRC Press Inc., (1990), Section D, p. D-221.

27. Nemethy, G., and Scheraga, H. A., "Structure of Water and Hydrophobic Bonding in Proteins. IV : The Thermodynamic Properties of Liquid Deuterium Oxide", J. Chem. Phys., Vol. 41, (1964), p. 680.

28. Conway, B. E., "Electrolyte Solutions: Solvation and Structural Aspects", Annual Reviews of Physical Chemistry, Vol. 17, No. 3, (1966), p. 490.

29. Lennard-Jones, J., and Pople, J. A., "Molecular association in liquids I: Molecular association due to lone-pair electrons.", Proc. Roy. Soc., Vol. 205, p. 155.

30. Robinson, R. A., Electrolyte Solutions, 2nd Edition, Academic Press Inc., New York, (1959), p. 248. 


\section{Appendix A: Derivation of Horvath's Model}

In Equlibrium, the chemical potential of a liquid is equal to the solid.

$\mu_{\text {liquid }}\left(\mathrm{T}, \mathrm{P}, \mathrm{x}_{1}\right)=\mu_{\text {solid }}(\mathrm{T}, \mathrm{P})$

where $\mathrm{x}_{1}$ : molar fraction of solvent

$\mu_{\text {liquid }}\left(\mathrm{T}, \mathrm{P}, \mathrm{x}_{1}\right)=\mu_{\text {liquid }}^{*} \mathrm{RT} \ln \mathrm{a}_{1}$

$$
=\mu^{*} \text { liquid }+\mathrm{RT} \ln \mathrm{x}_{1} \text { (for ideal solution) }
$$

where $\mu^{*}$ liquid : chemical potential of pure liquid.

Combining Equation [1] and [2] yields

$$
\begin{aligned}
& \mu^{*} \text { liquid }+R T \ln \mathrm{x}_{1}=\mu_{\text {solid }}(\mathrm{T}, \mathrm{P}) \\
& \ln \mathrm{x}_{1}=-\left(\mu^{*} \text { liquid }-\mu_{\text {solid }}(\mathrm{T}, \mathrm{P})\right) / \mathrm{RT} \\
& \ln \mathrm{x}_{1}=-\left(\Delta \mathrm{G}_{\mathrm{m}}\right) / \mathrm{RT}
\end{aligned}
$$

Differentiation with respect to $\mathrm{T}$ yields

$$
\mathrm{dln} \mathrm{x}_{1} / \mathrm{dT}=-1 / \mathrm{R} *\left[\partial\left(\Delta \mathrm{G}_{\mathrm{m}} / \mathrm{T}\right) / \partial \mathrm{T}\right]
$$

Applying the Gibbs-Helmholtz Equation, below, to Equation 3:

$$
\begin{aligned}
& {\left[\partial\left(\Delta \mathrm{G}_{\mathrm{m}} / \mathrm{T}\right) / \partial \mathrm{T}\right]=-\Delta \mathrm{H}_{\mathrm{m}} / \mathrm{T}^{2}} \\
& \operatorname{dln} \mathrm{x}_{1} / \mathrm{dT}=\Delta \mathrm{H}_{\mathrm{m}} / R \mathrm{~T}^{2}
\end{aligned}
$$

Integrating Equation 4, from $\mathrm{x}_{1}=1$ ( pure solvent) to $\mathrm{x}_{1}=\mathrm{x}_{1}$, result in:

$$
\ln \mathrm{x}_{1}=\Delta \mathrm{H}_{\mathrm{m}} / \mathrm{R} *\left(1 / \mathrm{T}_{\mathrm{m}}-1 / \mathrm{T}_{\mathrm{m}}\right)
$$

where $\mathrm{T}^{0} \mathrm{~m}$ : melting point of pure solvent.

$\mathrm{T}_{\mathrm{m}}$ : melting point of the solution.

$$
\ln \left(1-\mathrm{x}_{2}\right)=\Delta \mathrm{H}_{\mathrm{m}} / \mathrm{R} *\left(1 / \mathrm{T}^{0} \mathrm{~m}-1 / \mathrm{T}_{\mathrm{m}}\right)
$$

where $\mathrm{x}_{2}$ : molar fraction of the solute 


\section{Appendix A: Derivation of Horvath's Model (continued)}

In dilute solutions, $\mathrm{x}_{2} \rightarrow>0$, therefore:

$$
\ln \left(1-x_{2}\right)=-x_{2}-1 / 2 x_{2}{ }^{2}-1 / 3 x_{2}{ }^{3}-\ldots=-x_{2}
$$

Combining Equations $6 \& 7$, yields

$$
-\mathrm{x}_{2}=\Delta \mathrm{H}_{\mathrm{m}} / \mathrm{R} *\left(1 / \mathrm{T}^{0} \mathrm{~m}-1 / \mathrm{T}_{\mathrm{m}}\right)
$$

Assuming there are $\mathrm{N}_{1}$ mole solvent and $\mathrm{N}_{2}$ mole solute,

$$
-\mathrm{N}_{2} /\left(\mathrm{N}_{1}+\mathrm{N}_{2}\right)=\Delta \mathrm{H}_{\mathrm{m}} / \mathrm{R} *\left(1 / \mathrm{T}^{0} \mathrm{~m}-1 / \mathrm{T}_{\mathrm{m}}\right)
$$

Approximately, $-\mathrm{N}_{2} /\left(\mathrm{N}_{1}+\mathrm{N}_{2}\right)=-\mathrm{N}_{2} / \mathrm{N}_{1}$, for the dilute case. Therefore,

$$
-\mathrm{N}_{2} / \mathrm{N}_{1}=\Delta \mathrm{H}_{\mathrm{m}} / \mathrm{R} *\left(1 / \mathrm{T}^{0} \mathrm{~m}-1 / \mathrm{T}_{\mathrm{m}}\right)
$$

After arrangement, Equation 9 can be rewritten as Equation 10.

$$
\mathrm{T}_{\mathrm{m}}=\mathrm{T}^{0}{ }_{\mathrm{m}} /\left[1+\left(\mathrm{R} * \mathrm{~T}^{0}{ }_{\mathrm{m}} * \mathrm{~N}_{2} /\left(\Delta \mathrm{H}_{\mathrm{m}} * \mathrm{~N}_{1}\right)\right)\right]
$$




\section{Appendix B: Values of $\Delta H_{m}$ of Solutes from Published Sources ${ }^{(6,19)}$}

\begin{tabular}{lc}
\hline Materials & Fusion enthalpy (cal/mol) \\
\hline Water & $1436^{(6)}$ \\
Magnesium chloride & $8100^{(6)}$ \\
Lithium bromide & $2900^{(6)}$ \\
Lithium chloride & $3200^{(6)}$ \\
Calcium chloride & $6100^{(6)}$ \\
Sodium chloride & $7220^{(6)}$ \\
Potassium chloride & $6410^{(6)}$ \\
Sodium bromide & $6140^{(6)}$ \\
Potassium chromate & $6920^{(6)}$ \\
Potassium bromide & $5000^{(6)}$ \\
Sodium nitrate & $3760^{(6)}$ \\
Potassium iodide & $4100^{(6)}$ \\
Cesium chloride & $3600^{(6)}$ \\
Sodium hydroxide & $2000^{(6)}$ \\
Silver nitrate & $2755^{(6)}$ \\
Potassium nitrate & $2840^{(6)}$ \\
Potassium sulfate & $8100^{(6)}$ \\
Potassium hydroxide & $1980^{(6)}$ \\
Potassium dichromate & $8770^{(6)}$ \\
Formic acid & $3040^{(6,19)}$ \\
Acetic acid & $2757^{(6,19)}$ \\
Ethylene glycol & $2685^{(6,19)}$ \\
Ethanol & $1200^{(6,19)}$ \\
Glycerol & $4416^{(6,19)}$ \\
\hline
\end{tabular}




\section{Appendix C: Heating Rate v.s. Weight of Sample}

As stated earlier, the DSC curve is "peak-like" due to delay of heat transfer. From this point of view, a heavier sample may need a slower heating rate to complete the phase transition.

To investigate how the sample weight affects the maximum allowable heating rate, different amounts of water was used. The results are shown below. In Table $\mathrm{C} 1$ the weight of water is approximately $30 \mathrm{mg}$, in Table C2 the weight of water is approximately $7 \mathrm{mg}$, and in Table C3 the weight of water is approximately $4 \mathrm{mg}$. Comparing the three tables below, the maximum allowable heating rates are $5{ }^{\circ} \mathrm{C} / \mathrm{min}$ for the $30 \mathrm{mg}$ sample, $40^{\circ} \mathrm{C} / \mathrm{min}$ for the $7 \mathrm{mg}$ sample, and $70^{\circ} \mathrm{C} / \mathrm{min}$ for the $4 \mathrm{mg}$ sample.

Table C1 : (Weight $30 \mathrm{mg}$ )

\begin{tabular}{ccc}
\hline $\begin{array}{c}\text { Weight of Water } \\
(\mathrm{mg})\end{array}$ & $\begin{array}{c}\text { Heating rate } \\
\left({ }^{\circ} \mathrm{C} / \mathrm{min}\right)\end{array}$ & $\begin{array}{c}\text { Fusion enthalpy } \\
(\mathrm{cal} / \mathrm{mol})\end{array}$ \\
\hline 38.8 & 0.5 & 1538 \\
27.0 & 1.0 & 1557 \\
38.0 & 2.0 & 1553 \\
26.3 & 5.0 & 1554 \\
37.0 & 10.0 & 1162 \\
\hline
\end{tabular}


Appendix C: Heating Rate v.s. Weight of Sample (continued)

Table C2: (weight $\sim 7 \mathrm{mg}$ )

\begin{tabular}{ccc}
\hline $\begin{array}{c}\text { Weight of Water } \\
\text { (mg) }\end{array}$ & $\begin{array}{c}\text { Heating rate } \\
\left({ }^{\circ} \mathrm{C} / \mathrm{min}\right)\end{array}$ & $\begin{array}{c}\text { Fusion enthalpy } \\
(\mathrm{cal} / \mathrm{mol})\end{array}$ \\
\hline 7.8 & 10 & 1428 \\
7.1 & 20 & 1459 \\
6.9 & 25 & 1487 \\
7.5 & 30 & 1458 \\
6.9 & 40 & 1488 \\
7.3 & 50 & 1246 \\
\hline
\end{tabular}

Table C3 : (weight $\sim 4 \mathrm{mg}$ )

\begin{tabular}{ccc}
\hline $\begin{array}{c}\text { Weight of Water } \\
(\mathrm{mg})\end{array}$ & $\begin{array}{c}\text { Heating rate } \\
\left({ }^{\circ} \mathrm{C} / \mathrm{min}\right)\end{array}$ & $\begin{array}{c}\text { Fusion enthalpy } \\
\text { (cal/mol) }\end{array}$ \\
\hline 4.4 & 10 & 1463 \\
4.2 & 30 & 1471 \\
4.5 & 50 & 1431 \\
3.9 & 70 & 1478 \\
4.2 & 90 & 1225 \\
\hline
\end{tabular}




\section{Appendix D: Sample Calculations of Fusion Enthalpies from the Differential Scanning Calorimeter}

The formula for determining the fusion enthalpy of water from the DSC is given by Equation 18 .

$$
\Delta \mathrm{H}_{\mathrm{m}}=[(\mathrm{R} * \mathrm{~A}) /(\mathrm{W} * \mathrm{~S})] * \mathrm{~K}^{\prime}
$$

Before determining $\Delta \mathrm{H}_{\mathrm{m}}$, the value of $\mathrm{K}^{\prime}$ should be obtained first. $\mathrm{K}^{\prime}$ is the instrument constant, determined after calibration with indium (In).

Equation 19 below is the formula for determining $\mathrm{K}^{\prime}$.

$$
\mathrm{K}^{\prime}=\left(\Delta \mathrm{H}_{\mathrm{m}(\mathrm{ref})}\right) /\left[\left(\mathrm{R}^{*} \mathrm{~A}\right) /\left(\mathrm{W}^{*} \mathrm{~S}\right)\right]
$$

where $\Delta \mathrm{H}_{\mathrm{m}}$ (ref) of indium is $6.80 \mathrm{cal} / \mathrm{g}$ (from Perkin-Elmer Catalogue), the values of $R, A, W$, and $S$ below, were determined experimentally.

$$
K^{\prime}=(6.80) /\left[\left(1^{*} 1.848\right) /\left(8.1^{*} 0.0332\right)\right]=0.99
$$

After the value of $\mathrm{K}^{\prime}$ was obtained, the value of the fusion enthalpy of water was then determined by Equation 18.

$$
\Delta \mathrm{H}_{\mathrm{m}}=[(\mathrm{R} * \mathrm{~A}) /(\mathrm{W} * \mathrm{~S})] * \mathrm{~K}^{\prime}
$$

The values of $R, A, W$, and $S$ below, were determined experimentally.

$$
\begin{aligned}
\Delta \mathrm{H}_{\mathrm{m}}=\left[\left(5^{*} 3.718\right) /(17.2 * 0.01327)\right] * 0.99 & =80.6 \mathrm{cal} / \mathrm{g} \\
& =1451 \mathrm{cal} / \mathrm{mol}
\end{aligned}
$$




\section{Appendix E: Calculations of the Accuracy of the DSC-4}

(1) Based on calibration runs with indium

$$
\begin{aligned}
\Delta \mathrm{H}_{\mathrm{m}} \text { (ref) } & =6.80 \mathrm{cal} / \mathrm{g} \text { (from Perkin-Elmer Catalogue) } \\
& =780.8 \mathrm{cal} / \mathrm{mol} \\
\Delta \mathrm{H}_{\mathrm{m}(\text { exp })} & =6.87 \mathrm{cal} / \mathrm{g}(\text { from DSC-4) } \\
& =789.0 \mathrm{cal} / \mathrm{mol} \\
\text { Accuracy } & =\left|\left(\Delta \mathrm{H}_{\mathrm{m}(\text { ref })}-\Delta \mathrm{H}_{\mathrm{m}(\text { exp })}\right)\right| \div\left(\Delta \mathrm{H}_{\mathrm{m}(\text { ref })}\right)=1.05 \%
\end{aligned}
$$

(2) Based on calibration runs with water

$$
\begin{aligned}
& \left.\Delta \mathrm{H}_{\mathrm{m} \text { (ref) }}=1436 \mathrm{cal} / \mathrm{mol} \text { (from Ref. } 6 \text { and } 7\right) \\
& \Delta \mathrm{H}_{\mathrm{m} \text { (exp) }}=1451 \mathrm{cal} / \mathrm{mol}(\text { from DSC- } 4) \\
& \text { Accuracy }=I\left(\Delta \mathrm{H}_{\mathrm{m}} \text { (ref) }-\Delta \mathrm{H}_{\mathrm{m}(\mathrm{exp})}\right) I \div\left(\Delta \mathrm{H}_{\mathrm{m}(\mathrm{ref})}\right)=1.04 \%
\end{aligned}
$$




\section{Appendix F: Calculations of Fusion Enthalpy from Chickos's Model}

1.Benzene,hexafluoro (C6F6)

$$
\begin{aligned}
\Delta \mathrm{S}_{\mathrm{m}} & =\sum(\mathrm{ni})(\mathrm{Ci})(\mathrm{Gi})+\sum(\mathrm{nj})(\mathrm{Cj})(\mathrm{Gj})+\sum(\mathrm{nk})(\mathrm{Ck})(\mathrm{Gk}) \\
& =0+\left(6^{*} 1.0^{*}(-1.02)\right)+\left(6^{*} 1.0^{*} 3.11\right) \\
& =12.54 \text { e.u. } \\
\mathrm{T}_{\mathrm{m}}= & 5.34^{\circ} \mathrm{C}(\text { from DSC-4) } \\
\Delta \mathrm{H}_{\mathrm{m}} & =\Delta \mathrm{S}_{\mathrm{m}} * \mathrm{~T}_{\mathrm{m}}=3490 \mathrm{kcal} / \mathrm{mol}=18.76 \mathrm{cal} / \mathrm{g}
\end{aligned}
$$

2.Heptanoic acid (CH3(CH2)5CO2H)

$$
\begin{aligned}
\Delta \mathrm{S}_{\mathrm{m}} & =\sum(\mathrm{ni})(\mathrm{Ci})(\mathrm{Gi})+\sum(\mathrm{nj})(\mathrm{Cj})(\mathrm{Gj})+\sum(\mathrm{nk})(\mathrm{Ck})(\mathrm{Gk}) \\
& =\left(1^{*} 1.0^{*} 4.38+4^{*} 1.0^{*} 2.25\right)+(1 * 1.0 * 2.25)+\left(1 * 1.0^{*} 3.56\right) \\
& =19.19 \text { e.u. } \\
\mathrm{T}_{\mathrm{m}}= & -10.14^{\circ} \mathrm{C}(\text { from DSC-4) } \\
\Delta \mathrm{H}_{\mathrm{m}} & =\Delta \mathrm{S}_{\mathrm{m}} * \mathrm{~T}_{\mathrm{m}}=5044 \mathrm{kcal} / \mathrm{mol}=38.74 \mathrm{cal} / \mathrm{g}
\end{aligned}
$$

3.Cyclohexanol,4-methyl (4-CH3C6H10OH)

$$
\begin{aligned}
\Delta \mathrm{S}_{\mathrm{m}}= & {[8.41+1.025(\mathrm{n}-3)]+\sum(\mathrm{ni})(\mathrm{Ci})(\mathrm{Gi})+\sum(\mathrm{nj})(\mathrm{Cj})(\mathrm{Gj}) } \\
& +\sum(\mathrm{nk})(\mathrm{Ck})(\mathrm{Gk}) \\
= & {[8.41+1.025(6-3)]+\left[1^{*} 1.0^{*}(-3.82)+1^{*} 1.0^{*} 4.38\right] } \\
& +\left[1^{*} 0.76^{*}(-3.82)\right]+\left[1^{*} 1.0^{*} 0.27\right] \\
= & 9.4118 \text { e.u. } \\
\mathrm{T}_{\mathrm{m}}= & -3.96^{\circ} \mathrm{C} \text { (from DSC-4) } \\
\Delta \mathrm{H}_{\mathrm{m}}= & \Delta \mathrm{S}_{\mathrm{m}} * \mathrm{~T}_{\mathrm{m}}=2532 \mathrm{kcal} / \mathrm{mol}=22.17 \mathrm{cal} / \mathrm{g}
\end{aligned}
$$




\section{Appendix F: Calculations of Fusion Enthalpy from Chickos's Model (continued)}

4.Benzene, 1,4-difluoro ( $66 \mathrm{H} 4 \mathrm{~F} 2)$

$$
\begin{aligned}
\Delta \mathrm{S}_{\mathrm{m}} & =\sum(\mathrm{ni})(\mathrm{Ci})(\mathrm{Gi})+\sum(\mathrm{nj})(\mathrm{Cj})(\mathrm{Gj})+\sum(\mathrm{nk})(\mathrm{Ck})(\mathrm{Gk}) \\
& =\left[4^{*} 1.0^{*} 1.54\right]+\left[2^{*} 1.0^{*}(-1.02)\right]+\left[2^{*} 1.0^{*} 3.11\right] \\
& =10.34 \text { e.u. } \\
\mathrm{T}_{\mathrm{m}} & =-22.79^{\circ} \mathrm{C}(\text { from DSC-4) } \\
\Delta \mathrm{H}_{\mathrm{m}} & =\Delta \mathrm{S}_{\mathrm{m}} * \mathrm{~T}_{\mathrm{m}}=2587 \mathrm{kcal} / \mathrm{mol}=22.67 \mathrm{cal} / \mathrm{g}
\end{aligned}
$$

5.Cyclohexanone ,2-methyl (2-CH3(C6H9O))

$$
\begin{aligned}
\Delta \mathrm{S}_{\mathrm{m}} & =[8.41+1.025(\mathrm{n}-3)]+\sum(\mathrm{ni})(\mathrm{Ci})(\mathrm{Gi})+\sum(\mathrm{nj})(\mathrm{Cj})(\mathrm{Gj}) \\
& +\sum(\mathrm{nk})(\mathrm{Ck})(\mathrm{Gk}) \\
& =[8.41+1.025(6-3)]+\left[1^{*} 1.0^{*}(-3.82)+1^{*} 1.0^{*} 4.38\right]+\left[1^{*} 0.86^{*}(-2.8)\right] \\
& +\left[1^{*} 1.0^{*}(-0.45)\right] \\
& =9.187 \text { e.u. } \\
\mathrm{T}_{\mathrm{m}} & =-14.14^{\circ} \mathrm{C}(\text { from DSC-4) } \\
\Delta \mathrm{H}_{\mathrm{m}} & =\Delta \mathrm{S}_{\mathrm{m}} * \mathrm{~T}_{\mathrm{m}}=2378 \mathrm{kcal} / \mathrm{mol}=21.20 \mathrm{cal} / \mathrm{g}
\end{aligned}
$$

6.Cinnamonitrile $(\mathrm{C} 6 \mathrm{H} 5 \mathrm{CH}=\mathrm{CHCN})$

$$
\begin{aligned}
\Delta \mathrm{S}_{\mathrm{m}} & =\sum(\mathrm{ni})(\mathrm{Ci})(\mathrm{Gi})+\sum(\mathrm{nj})(\mathrm{Cj})(\mathrm{Gj})+\sum(\mathrm{nk})(\mathrm{Ck})(\mathrm{Gk}) \\
& =\left[5^{*} 1.0^{*} 1.54+1^{*} 1.0^{*}(-1.02)+1^{*} 1.0^{*} 1.16\right]+\left[1^{*} 3.23^{*} 1.16\right] \\
& +\left[1^{*} 1.0^{*} 2.30\right] \\
& =13.8868 \mathrm{e} . \mathrm{u} . \\
\mathrm{T}_{\mathrm{m}}= & 5.08^{\circ} \mathrm{C}(\mathrm{from} \mathrm{DSC}-4) \\
\Delta \mathrm{H}_{\mathrm{m}} & =\Delta \mathrm{S}_{\mathrm{m}} * \mathrm{~T}_{\mathrm{m}}=3862 \mathrm{kcal} / \mathrm{mol}=29.89 \mathrm{cal} / \mathrm{g}
\end{aligned}
$$




\section{Appendix F: Calculations of Fusion Enthalpy from Chickos's Model (continued)}

7.Cyclooctatetraene (C8H8)

$$
\begin{aligned}
\Delta \mathrm{S}_{\mathrm{m}} & =[8.41+1.025(\mathrm{n}-3)]+\sum(\mathrm{ni})(\mathrm{Ci})(\mathrm{Gi}) \\
& =[8.41+1.025(8-3)]+\left[8^{*} 1.0^{*}(-1.04)\right] \\
& =5.215 \text { e.u. } \\
\mathrm{T}_{\mathrm{m}}= & -8.21^{\circ} \mathrm{C}(\text { from DSC-4) } \\
\Delta \mathrm{H}_{\mathrm{m}} & =\Delta \mathrm{S}_{\mathrm{m}} * \mathrm{~T}_{\mathrm{m}}=1381 \mathrm{kcal} / \mathrm{mol}=13.26 \mathrm{cal} / \mathrm{g}
\end{aligned}
$$

8. 4-methoxybenzaldehyde ( $\mathrm{CH} 3 \mathrm{OC} 6 \mathrm{H} 4 \mathrm{CHO})$

$$
\begin{aligned}
\Delta \mathrm{S}_{\mathrm{m}} & =\sum(\mathrm{ni})(\mathrm{Ci})(\mathrm{Gi})+\sum(\mathrm{nj})(\mathrm{Cj})(\mathrm{Gj})+\sum(\mathrm{nk})(\mathrm{Ck})(\mathrm{Gk}) \\
& =\left[4^{*} 1.0^{*} 1.54\right]+\left[2 * 1.0^{*}(-1.02)+1^{*} 1.0 * 4.38\right] \\
& +\left[1 * 1.0^{*} 4.70+1^{*} 1.0 * 0.26\right] \\
& =13.46 \text { e.u. } \\
\mathrm{T}_{\mathrm{m}}= & -1.89^{\circ} \mathrm{C}(\text { from } \mathrm{DSC}-4) \\
\Delta \mathrm{H}_{\mathrm{m}} & =\Delta \mathrm{S}_{\mathrm{m}} * \mathrm{~T}_{\mathrm{m}}=3649 \mathrm{kcal} / \mathrm{mol}=26.83 \mathrm{cal} / \mathrm{g}
\end{aligned}
$$

9.Indene $(\mathrm{C} 9 \mathrm{H} 8)$

$$
\begin{aligned}
\Delta \mathrm{S}_{\mathrm{m}}= & {[8.41+1.025(\mathrm{n}-3)]+\sum(\mathrm{ni})(\mathrm{Ci})(\mathrm{Gi}) } \\
= & {[8.41+1.025(5-3)] } \\
& +\left[4^{*} 1.0^{*} 1.54+2 * 1.0 *(-2.8)+2 * 1.0 *(-1.04)\right] \\
= & 8.94 \text { e.u. } \\
\mathrm{T}_{\mathrm{m}}= & -6.15^{\circ} \mathrm{C}(\text { from DSC-4) } \\
\Delta \mathrm{H}_{\mathrm{m}}= & \Delta \mathrm{S}_{\mathrm{m}} * \mathrm{~T}_{\mathrm{m}}=2386 \mathrm{kcal} / \mathrm{mol}=20.57 \mathrm{cal} / \mathrm{g}
\end{aligned}
$$




\section{Appendix F: Calculations of Fusion Enthalpy from Chickos's Model (continued)}

10.Cyclohexane ,1,2-dibromo (1,2-Br2C6H10)

$$
\begin{aligned}
\Delta \mathrm{S}_{\mathrm{m}} & =[8.41+1.025(\mathrm{n}-3)]+\sum(\mathrm{ni})(\mathrm{Ci})(\mathrm{Gi})+\sum(\mathrm{nj})(\mathrm{Cj})(\mathrm{Gj}) \\
& +\sum(\mathrm{nk})(\mathrm{Ck})(\mathrm{Gk}) \\
& =[8.41+1.025(6-3)]+0+\left[2 * 0.76^{*}(-3.82)\right]+\left[2^{*} 1.0^{*} 4.29\right] \\
& =14.2586 \text { e.u. } \\
\mathrm{T}_{\mathrm{m}}= & -4.98^{\circ} \mathrm{C}(\text { from DSC-4) } \\
\Delta \mathrm{H}_{\mathrm{m}} & =\Delta \mathrm{S}_{\mathrm{m}} * \mathrm{~T}_{\mathrm{m}}=3822 \mathrm{kcal} / \mathrm{mol}=15.79 \mathrm{cal} / \mathrm{g}
\end{aligned}
$$

11.Biphenyl, 2-methyl (2-CH3C6H4C6H5)

$$
\begin{aligned}
\Delta \mathrm{S}_{\mathrm{m}} & =\sum(\mathrm{ni})(\mathrm{Ci})(\mathrm{Gi}) \\
& =\left[9^{*} 1.0^{*} 1.54+2^{*} 1.0 *(-1.02)+1 * 1.0^{*}(-2.47)+1^{*} 1.0 * 4.38\right] \\
& =13.73 \text { e.u. } \\
\mathrm{T}_{\mathrm{m}}= & -0.48^{\circ} \mathrm{C}(\text { from } \mathrm{DSC}-4) \\
\Delta \mathrm{H}_{\mathrm{m}} & =\Delta \mathrm{S}_{\mathrm{m}} * \mathrm{~T}_{\mathrm{m}}=3742 \mathrm{kcal} / \mathrm{mol}=22.24 \mathrm{cal} / \mathrm{g}
\end{aligned}
$$

12.Naphthalene ,1,2-dihydro (C10H10)

$$
\begin{aligned}
\Delta \mathrm{S}_{\mathrm{m}} & =[8.41+1.025(\mathrm{n}-3)]+\sum(\mathrm{ni})(\mathrm{Ci})(\mathrm{Gi}) \\
& =[8.41+1.025(6-3)] \\
& +\left[4^{*} 1.0^{*} 1.54+1^{*} 1.0 *(-1.02)+1^{*} 1.0^{*}(-2.47)+2^{*} 1.0 *(-1.04)\right] \\
& =12.075 \text { e.u. } \\
\mathrm{T}_{\mathrm{m}}= & -10.05^{\circ} \mathrm{C}(\text { from DSC-4) } \\
\Delta \mathrm{H}_{\mathrm{m}} & =\Delta \mathrm{S}_{\mathrm{m}} * \mathrm{~T}_{\mathrm{m}}=3175 \mathrm{kcal} / \mathrm{mol}=24.39 \mathrm{cal} / \mathrm{g}
\end{aligned}
$$


Appendix F: Calculations of Fusion Enthalpy from Chickos's Model (continued)

13.Piperidine (C5H10NH)

$$
\begin{aligned}
\Delta \mathrm{S}_{\mathrm{m}} & =[8.41+1.025(\mathrm{n}-3)]+\sum(\mathrm{nk})(\mathrm{Ck})(\mathrm{Gk}) \\
& =[8.41+1.025(6-3)]+[1 * 1.0 * 0.44] \\
& =11.925 \text { e.u. } \\
\mathrm{T}_{\mathrm{m}}= & -18.46^{\circ} \mathrm{C}(\text { from DSC-4) } \\
\Delta \mathrm{H}_{\mathrm{m}} & =\Delta \mathrm{S}_{\mathrm{m}} * \mathrm{~T}_{\mathrm{m}}=3035 \mathrm{kcal} / \mathrm{mol}=35.64 \mathrm{cal} / \mathrm{g}
\end{aligned}
$$




\section{Appendix G: Sample Calculations of Fusion Enthalpies from the Rule of Mixtures}

Assume the total weight for the solution is 100 grams for all the following solutions.

(1) $\mathrm{MgCl}_{2}(1 \%)$ :

for $\mathrm{MgCl}_{2}$ (wt: $95.21, \Delta \mathrm{H}_{\mathrm{a}}=8100 \mathrm{cal} / \mathrm{mol}$ )

for Water (wt: $18, \Delta \mathrm{H}_{\mathrm{H} 2 \mathrm{O}}=1436 \mathrm{cal} / \mathrm{mol}$ )

Moles of Solute $=0.0105$, Moles of Water $=5.5$, Total moles $=5.5105$

$$
\begin{aligned}
\Delta \mathrm{H}_{\mathrm{m}(\mathrm{aq})} & =\left[\mathrm{X}_{\mathrm{a}} \Delta \mathrm{H}_{\mathrm{a}}+\mathrm{X}_{\mathrm{H} 2 \mathrm{O}} \Delta \mathrm{H}_{\mathrm{H} 2 \mathrm{O}}\right] \\
& =[(0.0105 / 5.5105) *(8100)+(5.5 / 5.5105) *(1436)] \\
& =1449 \mathrm{cal} / \mathrm{mol}
\end{aligned}
$$

(2) $\mathrm{MgCl}_{2}(5 \%)$ :

Moles of Solute $=0.0525$, Moles of Water $=5.278$, Total moles $=5.330$

$$
\begin{aligned}
\Delta \mathrm{H}_{\mathrm{m}(\mathrm{aq})} & =\left[\mathrm{X}_{\mathrm{a}} \Delta \mathrm{H}_{\mathrm{a}}+\mathrm{X}_{\mathrm{H} 2 \mathrm{O}} \Delta \mathrm{H}_{\mathrm{H} 2 \mathrm{O}}\right] \\
& =[(0.0525 / 5.330) *(8100)+(5.278 / 5.330) *(1436)] \\
& =1502 \mathrm{cal} / \mathrm{mol}
\end{aligned}
$$

(3) $\mathrm{MgCl}_{2}(10 \%)$ :

Moles of Solute $=0.105$, Moles of Water $=5$, Total moles $=5.105$

$$
\begin{aligned}
\Delta \mathrm{H}_{\mathrm{m}(\mathrm{aq})} & =\left[\mathrm{X}_{\mathrm{a}} \Delta \mathrm{H}_{\mathrm{a}}+\mathrm{X}_{\mathrm{H} 20} \Delta \mathrm{H}_{\mathrm{H} 2 \mathrm{O}}\right] \\
& =[(0.105 / 5.105) *(8100)+(5 / 5.105) *(1436)] \\
& =1573 \mathrm{cal} / \mathrm{mol}
\end{aligned}
$$

(4) $\mathrm{MgCl}_{2}(15 \%)$ :

Moles of Solute $=0.158$, Moles of Water $=4.722$, Total moles $=4.880$

$$
\begin{aligned}
\Delta \mathrm{H}_{\mathrm{m}(\mathrm{aq})} & =\left[\mathrm{X}_{\mathrm{a}} \Delta \mathrm{H}_{\mathrm{a}}+\mathrm{X}_{\mathrm{H} 2 \mathrm{O}} \Delta \mathrm{H}_{\mathrm{H} 2 \mathrm{O}}\right] \\
& =[(0.158 / 4.880) *(8100)+(4.722 / 4.880) *(1436)]=1651 \mathrm{cal} / \mathrm{mol}
\end{aligned}
$$




\section{Appendix H: Sample Calculations of Fusion Enthalpies from Horvath's Model}

Assume the total weight for the solution is 100 grams.

(1) $\mathrm{MgCl}_{2}(1 \%)$ :

for $\mathrm{MgCl}_{2}$ (wt: 95.21), for Water (wt: 18)

$\left(\mathrm{MgCl}_{2} \rightarrow \mathrm{Mg}^{+2}+2 \mathrm{Cl}^{-}\right) 1$ mole of $\mathrm{MgCl} 2$ dissociates to 3 mole of ions,

therefore $\mathrm{N} 2=(\mathrm{I} / 95.21) * 3=0.03151$

$\mathrm{N} 1=(99 / 18)=5.5$

$\mathrm{T}_{\mathrm{m}}=-0.13^{\circ} \mathrm{C}=272.87^{\circ} \mathrm{K}$ (from experiment)

$\Delta \mathrm{H}_{\mathrm{m}}=\mathrm{R}^{*} \mathrm{~T}_{\mathrm{m}} 0 *(\mathrm{~N} 2 / \mathrm{N} 1) *\left[\mathrm{~T}_{\mathrm{m}} /\left(\mathrm{T}_{\mathrm{m}}{ }^{0}-\mathrm{T}_{\mathrm{m}}\right)\right]$

$$
=1.987 * 273 *(0.03151 / 5.5) *(272.87 / 0.13)=6524 \mathrm{cal} / \mathrm{mol}
$$

(2) $\mathrm{MgCl}_{2}(5 \%)$ :

$$
\begin{aligned}
\mathrm{N} 2 & =(5 / 95.21) * 3=0.15755 \quad \mathrm{~N} 1=(95 / 18)=5.2778 \\
\mathrm{~T}_{\mathrm{m}} & =-6.53^{\circ} \mathrm{C}=266.47^{\circ} \mathrm{K}(\text { from experiment }) \\
\Delta \mathrm{H}_{\mathrm{m}} & =\mathrm{R}^{*} \mathrm{~T}_{\mathrm{m}} 0 *(\mathrm{~N} 2 / \mathrm{N} 1) *\left[\mathrm{~T}_{\mathrm{m}} /\left(\mathrm{T}_{\mathrm{m}}{ }^{0}-\mathrm{T}_{\mathrm{m}}\right)\right] \\
& =1.987^{*} 273^{*}(0.15755 / 5.2778) *(266.47 / 6.53)=661 \mathrm{cal} / \mathrm{mol}
\end{aligned}
$$

(3) $\mathrm{MgCl}_{2}(10 \%)$ :

$$
\begin{aligned}
& \mathrm{N} 2=(10 / 95.21) * 3=0.3151 \quad \mathrm{~N} 1=(90 / 18)=5 \\
& \mathrm{~T}_{\mathrm{m}}=-14.43^{\circ} \mathrm{C}=258.57^{\circ} \mathrm{K}(\text { from experiment }) \\
& \begin{aligned}
\Delta \mathrm{H}_{\mathrm{m}} & =\mathrm{R}^{*} \mathrm{~T}_{\mathrm{m}} 0 *(\mathrm{~N} 2 / \mathrm{N} 1) *\left[\mathrm{~T}_{\mathrm{m}} /\left(\mathrm{T}_{\mathrm{m}}{ }^{0}-\mathrm{T}_{\mathrm{m}}\right)\right] \\
& =1.987^{*} 273 *(0.3151 / 5) *(258.57 / 14.43)=613 \mathrm{cal} / \mathrm{mol}
\end{aligned}
\end{aligned}
$$

(4) $\mathrm{MgCl}_{2}(15 \%)$ :

$$
\begin{aligned}
\mathrm{N} 2 & =(15 / 95.21) * 3=0.4726 \quad \mathrm{~N} 1=(95 / 18)=4.7222 \\
\mathrm{~T}_{\mathrm{m}} & =-24.94{ }^{\circ} \mathrm{C}=248.06{ }^{\circ} \mathrm{K} \text { (from experiment) } \\
\Delta \mathrm{H}_{\mathrm{m}} & =\mathrm{R}^{*} \mathrm{~T}_{\mathrm{m}} 0 *(\mathrm{~N} 2 / \mathrm{N} 1) *\left[\mathrm{~T}_{\mathrm{m}} /\left(\mathrm{T}_{\mathrm{m}}{ }^{0}-\mathrm{T}_{\mathrm{m}}\right)\right] \\
& =1.987 * 273 *(0.4726 / 4.7222) *(248.06 / 24.94)=540 \mathrm{cal} / \mathrm{mol}
\end{aligned}
$$


Appendix I: Hydration Numbers of Electrolytes(25)

\begin{tabular}{lc}
\hline Material & Hydration number (25) \\
\hline $\mathrm{MgCl}_{2}$ & 13.7 \\
$\mathrm{LiBr}$ & 7.6 \\
$\mathrm{LiCl}$ & 7.1 \\
$\mathrm{CaCl}$ & \\
$\mathrm{NaCl}$ & 12.0 \\
$\mathrm{NaBr}$ & 3.5 \\
$\mathrm{KCl}$ & 4.2 \\
$\mathrm{KBr}$ & 1.9 \\
$\mathrm{KI}$ & 2.1 \\
$\mathrm{NiCl}$ & 2.5 \\
& 13.0 \\
\hline
\end{tabular}




\section{Appendix J: Hydration Numbers of Non-electrolytes}

Table $\mathrm{J}(\mathrm{J} 1 \sim \mathrm{J} 5)$ in the next five pages are the calculated hydration numbers of 5 non-electrolytes. The first column is the weight percent of solute. The second column is the molar concentration of solution (M). The third column (Co- $\mathrm{Cw}$ ) means the amount of water displaced by an anhydrous solute in a unit of $(g / l)$. The fourth column is the calculated hydration numbers. According to the CRC Handbook, the value of "(Co- $\mathrm{Cw}) /(18.015 * \mathrm{M})$ " is defined as the mole number of water displaced by one mole solute and this value is equivalent to the primary hydration number.

Second Column (M) (unit: g-mol//) : (after Ref. 26)

Third Column (Co-Cw) (unit: g/l) : (after Ref. 26)

Fourth Column: Hydration number (Calculated)

$=(\mathrm{Co}-\mathrm{Cw}) /(18.015 * \mathrm{M})$ (unit: $\mathrm{mol}$ water $/ \mathrm{mol}$ solute $)$ 
Table J (1): Hydration Number of Formic Acid

\begin{tabular}{cccc}
\hline Solute wt\% & $\begin{array}{c}\text { Molarity }(\mathrm{M})(26) \\
(\mathrm{g}-\mathrm{mol} / \mathrm{l})\end{array}$ & $\begin{array}{c}\mathrm{C}_{0}-\mathrm{C}_{\mathrm{W}}(26) \\
(\mathrm{g} / \mathrm{l})\end{array}$ & Hydration number \\
\hline 0.5 & 0.109 & 3.8 & 1.94 \\
1.0 & 0.217 & 7.7 & 1.97 \\
2.0 & 0.436 & 15.3 & 1.95 \\
3.0 & 0.655 & 23.1 & 1.96 \\
4.0 & 0.876 & 30.8 & 1.95 \\
5.0 & 1.097 & 38.6 & 1.95 \\
10.0 & 2.221 & 78.1 & 1.95 \\
12.0 & 2.678 & 94.2 & 1.95 \\
14.0 & 3.139 & 110.5 & 1.95 \\
16.0 & 3.605 & 127.1 & 1.96 \\
18.0 & 4.074 & 143.9 & 1.96 \\
20.0 & 4.548 & 160.9 & 1.96 \\
24.0 & 5.507 & 195.5 & 1.97 \\
28.0 & 6.481 & 231.1 & 1.98 \\
32.0 & 7.471 & 267.5 & 1.99 \\
\hline
\end{tabular}


Table J (2): Hydration Number of Acetic Acid

\begin{tabular}{rccc}
\hline Solute wt\% & $\begin{array}{c}\text { Molarity }(\mathrm{M})(26) \\
(\mathrm{g}-\mathrm{mol} / \mathrm{l})\end{array}$ & $\begin{array}{c}\mathrm{C}_{0}-\mathrm{C}_{\mathrm{w}}(26) \\
(\mathrm{g} / \mathrm{l})\end{array}$ & Hydration number \\
\hline 1.0 & 0.166 & 8.6 & 2.88 \\
2.0 & 0.333 & 17.2 & 2.87 \\
3.0 & 0.501 & 25.9 & 2.87 \\
4.0 & 0.669 & 34.5 & 2.86 \\
5.0 & 0.837 & 43.3 & 2.87 \\
6.0 & 1.006 & 52.0 & 2.87 \\
7.0 & 1.175 & 60.8 & 2.87 \\
8.0 & 1.345 & 69.6 & 2.87 \\
9.0 & 1.515 & 78.5 & 2.88 \\
10.0 & 1.685 & 87.4 & 2.88 \\
11.0 & 1.856 & 96.3 & 2.88 \\
12.0 & 2.028 & 105.3 & 2.88 \\
13.0 & 2.200 & 114.3 & 2.88 \\
14.0 & 2.372 & 123.3 & 2.89 \\
15.0 & 2.545 & 132.4 & 2.89 \\
20.0 & 3.414 & 178.2 & 2.90 \\
\hline
\end{tabular}


Table J (3): Hydration Number of Ethylene Glycol

\begin{tabular}{cccc}
\hline Solute wt\% & $\begin{array}{c}\text { Molarity }(\mathrm{M})(26) \\
(\mathrm{g}-\mathrm{mol} / \mathrm{l})\end{array}$ & $\begin{array}{c}\mathrm{C}_{0}-\mathrm{C}_{\mathrm{w}}(26) \\
(\mathrm{g} / \mathrm{l})\end{array}$ & Hydration number \\
\hline 1.0 & 0.161 & 8.8 & 3.03 \\
2.0 & 0.322 & 17.6 & 3.03 \\
4.0 & 0.646 & 35.2 & 3.02 \\
6.0 & 0.972 & 52.9 & 3.02 \\
8.0 & 1.299 & 70.6 & 3.02 \\
10.0 & 1.629 & 88.5 & 3.02 \\
12.0 & 1.959 & 106.4 & 3.01 \\
16.0 & 2.626 & 142.5 & 3.01 \\
20.0 & 3.300 & 178.9 & 3.01 \\
28.0 & 4.669 & 253.0 & 3.01 \\
\hline
\end{tabular}


Table J (4): Hydration Number of Ethanol

\begin{tabular}{cccc}
\hline Solute wt\% & $\begin{array}{c}\text { Molarity }(\mathrm{M})(26) \\
(\mathrm{g}-\mathrm{mol} / \mathrm{l})\end{array}$ & $\begin{array}{c}\mathrm{C}_{0}-\mathrm{C}_{\mathrm{w}}(26) \\
(\mathrm{g} / \mathrm{l})\end{array}$ & Hydration number \\
\hline 1.0 & 0.216 & 11.8 & 3.03 \\
2.0 & 0.432 & 23.6 & 3.03 \\
4.0 & 0.860 & 46.9 & 3.03 \\
6.0 & 1.286 & 69.7 & 3.01 \\
8.0 & 1.710 & 92.3 & 3.00 \\
9.5 & 2.026 & 109.0 & 2.99 \\
10.0 & 2.131 & 114.5 & 2.98 \\
12.0 & 2.550 & 136.6 & 2.97 \\
16.0 & 3.382 & 180.2 & 2.96 \\
20.0 & 4.205 & 223.3 & 2.95 \\
24.0 & 5.018 & 266.2 & 2.94 \\
\hline
\end{tabular}


Table J (5): Hydration Number of Glycerol

\begin{tabular}{cccc}
\hline Solute wt\% & $\begin{array}{c}\text { Molarity }(\mathrm{M})^{(26)} \\
(\mathrm{g}-\mathrm{mol} / \mathrm{l})\end{array}$ & $\begin{array}{c}\mathrm{C}_{0}-\mathrm{C}_{\mathrm{w}}(26) \\
(\mathrm{g} / \mathrm{l})\end{array}$ & Hydration number \\
\hline 1.0 & 0.109 & 7.7 & 3.92 \\
2.0 & 0.218 & 15.5 & 3.95 \\
4.0 & 0.438 & 31.2 & 3.95 \\
6.0 & 0.659 & 46.9 & 3.95 \\
8.0 & 0.883 & 62.9 & 3.95 \\
10.0 & 1.109 & 78.9 & 3.95 \\
16.0 & 1.800 & 128.0 & 3.95 \\
24.0 & 2.752 & 195.6 & 3.95 \\
32.0 & 3.742 & 265.9 & 3.94 \\
40.0 & 4.771 & 339.2 & 3.95 \\
\hline
\end{tabular}




\section{Appendix K: Sample Calculations of Fusion Enthalpies from the Modified Mixture Rule}

Assume the total weight for the solution is 100 grams.

(1) $\mathrm{MgCl}_{2}(1 \%)$ :

for $\mathrm{MgCl}_{2}$ (wt: $95.21, \mathrm{~h}=13.7, \Delta \mathrm{H}_{\mathrm{a}}=8100 \mathrm{cal} / \mathrm{mol}$ )

for Water (wt: $18, \Delta \mathrm{H}_{\mathrm{H} 2 \mathrm{O}}=1436 \mathrm{cal} / \mathrm{mol}$ )

Moles of Solute $=0.0105$, Moles of Water $=5.5$, Total moles $=5.5105$ $\Delta \mathrm{H}_{\mathrm{m}(\mathrm{aq})}=\left[\mathrm{X}_{\mathrm{a}} \Delta \mathrm{H}_{\mathrm{a}}+\mathrm{X}_{\mathrm{H} 2 \mathrm{O}} \Delta \mathrm{H}_{\mathrm{H} 2 \mathrm{O}}\right]-\left(\mathrm{X}_{\mathrm{a}}\right) *(\mathrm{~h}) *(\mathrm{H}$ bond energy in water $)=$ $[(0.0105 / 5.5105) *(8100)+(5.5 / 5.5105) *(1436)]-(0.0105 / 5.5105) *(13.7) *$ $(3000)=1370 \mathrm{cal} / \mathrm{mol}$

(2) $\mathrm{MgCl}_{2}(5 \%)$ :

Moles of Solute $=0.0525$, Moles of Water $=5.278$, Total moles $=5.330$ $\Delta \mathrm{H}_{\mathrm{m}(\mathrm{aq})}=\left[\mathrm{X}_{\mathrm{a}} \Delta \mathrm{H}_{\mathrm{a}}+\mathrm{X}_{\mathrm{H} 2 \mathrm{O}} \Delta \mathrm{H}_{\mathrm{H} 2 \mathrm{O}}\right]-\left(\mathrm{X}_{\mathrm{a}}\right) *(\mathrm{~h}) *(\mathrm{H}$ bond energy in water $)$ $=[(0.0525 / 5.330) *(8100)+(5.278 / 5.330) *(1436)]-(0.0525 / 5.330) *(13.7) *$ $(3000)=1097 \mathrm{cal} / \mathrm{mol}$

(3) $\mathrm{MgCl}_{2}(10 \%)$ :

Moles of Solute $=0.105$, Moles of Water $=5$, Total moles $=5.105$ $\Delta \mathrm{H}_{\mathrm{m}(\mathrm{aq})}=\left[\mathrm{X}_{\mathrm{a}} \Delta \mathrm{H}_{\mathrm{a}}+\mathrm{X}_{\mathrm{H} 2 \mathrm{O}} \Delta \mathrm{H}_{\mathrm{H} 2 \mathrm{O}}\right]-\left(\mathrm{X}_{\mathrm{a}}\right) *(\mathrm{~h}) *(\mathrm{H}$ bond energy in water $)$ $=[(0.105 / 5.105) *(8100)+(5 / 5.105) *(1436)]-(0.105 / 5.105) *(13.7) *(3000)$ $=727 \mathrm{cal} / \mathrm{mol}$

(4) $\mathrm{MgCl}_{2}(15 \%)$ :

Moles of Solute $=0.158$, Moles of Water $=4.722$, Total moles $=4.880$ $\Delta \mathrm{H}_{\mathrm{m}(\mathrm{aq})}=\left[\mathrm{X}_{\mathrm{a}} \Delta \mathrm{H}_{\mathrm{a}}+\mathrm{X}_{\mathrm{H} 2 \mathrm{O}} \Delta \mathrm{H}_{\mathrm{H} 2 \mathrm{O}}\right]-\left(\mathrm{X}_{\mathrm{a}}\right) *(\mathrm{~h}) *(\mathrm{H}$ bond energy in water $)$ $=[(0.158 / 4.880) *(8100)+(4.722 / 4.880) *(1436)]-(0.158 / 4.880) *(13.7) *$ $(3000)=324 \mathrm{cal} / \mathrm{mol}$ 


\section{Appendix L: Calculations of Maximum Concentration in the Modified Mixture Rule}

Assume the total weight of the following solutions is 100 grams, including $\mathrm{m}$ gram of the solute and $(100-\mathrm{m})$ grams of water.

1) Formic acid: (wt $=46.03$, hydration number $=1.99$ )

$$
(\mathrm{m} / 46.03) *(1.99) /[(100-\mathrm{m}) / 18]=25 \%=\Rightarrow \mathrm{m}=24.3 \%
$$

2) Acetic acid : (wt $=60.05$, hydration number $=2.90$ )

$$
(\mathrm{m} / 60.05) *(2.90) /[(100-\mathrm{m}) / 18]=25 \%==>\mathrm{m}=22.3 \%
$$

3) Ethylene glycol : ( $w t=62.07$, hydration number $=3.01$ )

$$
(\mathrm{m} / 62.07) *(3.01) /[(100-\mathrm{m}) / 18]=25 \%==>\mathrm{m}=22.3 \%
$$

4) Ethanol : ( $w t=46.07$, hydration number $=2.94$ )

$$
(\mathrm{m} / 46.07) *(2.94) /[(100-\mathrm{m}) / 18]=25 \%=\Rightarrow \mathrm{m}=17.9 \%
$$

5) Glycerol : (wt=92.09, hydration number $=3.95$ )

$$
(\mathrm{m} / 92.09) *(3.95) /[(100-\mathrm{m}) / 18]=25 \%==>\mathrm{m}=24.5 \%
$$

6) Magnesium chloride : ( $w t=95.21$, hydration number=13.7)

$$
(\mathrm{m} / 95.21) *(13.7) /[(100-\mathrm{m}) / 18]=25 \%=\Rightarrow \mathrm{m}=8.8 \%
$$

7) Lithium bromide : ( $w t=86.85$, hydration number $=7.6$ )

$$
(\mathrm{m} / 86.85) *(7.6) /[(100-\mathrm{m}) / 18]=25 \% \Rightarrow \mathrm{m}=13.7 \%
$$

8) Lithium chloride : ( $w t=42.39$, hydration number $=7.1$ )

$$
(\mathrm{m} / 42.39) *(7.1) /[(100-\mathrm{m}) / 18]=25 \% \Rightarrow \mathrm{m}=7.7 \%
$$

9) Calcium chloride : $(w t=111$, hydration number $=12.0)$

$$
(\mathrm{m} / 111) *(12.0) /[(100-\mathrm{m}) / 18]=25 \%==>\mathrm{m}=11.4 \%
$$

10) Sodium chloride : (wt $=58.44$, hydration number $=3.5$ )

$$
(\mathrm{m} / 58.44) *(3.5) /[(100-\mathrm{m}) / 18]=25 \% \Rightarrow \mathrm{m}=18.8 \%
$$




\section{Appendix M: Calculations of Cooling Capacities}

The calculations contained in this appendix have been performed in a cal/g basis in order to permit easy comparison with the results obtained by Selvaduray and Lomax. The fusion enthalpy and heat capacity data on a $\mathrm{cal} / \mathrm{g}$ basis are presented in Table M1.

1) Water

$$
\begin{aligned}
& \Delta \mathrm{H}_{\text {tot }}=\int_{\mathrm{T}_{\mathrm{s} . \mathrm{i}}}^{\mathrm{T}_{\mathrm{m}}} \mathrm{c}_{\mathrm{p} . \mathrm{s}} \mathrm{dT}+\Delta \mathrm{H}_{\mathrm{m}}+\int_{\mathrm{T}_{\mathrm{m}}}^{\mathrm{T}_{\mathrm{l} . \mathrm{f}}} \mathrm{c}_{\mathrm{p} . \mathrm{l}} \mathrm{dT} \\
& =0.52 *(0.087-(-13))+80.6+1.06 *(5-0.087)=92.6(\mathrm{cal} / \mathrm{g})
\end{aligned}
$$

2) Heptanoic acid

$$
\Delta \mathrm{H}_{\mathrm{tot}}=0.581 *(-10.14-(-13))+28.26+0.387 *(5-(-10.14))=35.78(\mathrm{cal} / \mathrm{g})
$$

3) Cyclohexanol, 4-methyl,cis

$$
\Delta \mathrm{H}_{\text {tot }}=0.30 *(-3.96-(-13))+18.16+0.46 *(5-(-3.96))=24.99(\mathrm{cal} / \mathrm{g})
$$

4) Cyclooctatetraene

$$
\Delta \mathrm{H}_{\text {tot }}=0.31 *(-8.21-(-13))+23.28+0.37 *(5-(-8.21))=29.65(\mathrm{cal} / \mathrm{g})
$$

5) 4-methoxybenzaldehyde

$$
\Delta \mathrm{H}_{\text {tot }}=0.345 *(-1.89-(-13))+27.81+0.379 *(5-(-1.89))=34.25(\mathrm{cal} / \mathrm{g})
$$

6) Indene

$$
\Delta \mathrm{H}_{\mathrm{tot}}=0.36 *(-6.15-(-13))+15.10+0.45 *(5-(-6.15))=22.58(\mathrm{cal} / \mathrm{g})
$$

7) Cyclohexane,1.2-dibromo

$$
\Delta \mathrm{H}_{\text {tot }}=0.164 *(-4.98-(-13))+11.97+0.205 *(5-(-4.98))=15.33(\mathrm{cal} / \mathrm{g})
$$

8) Biphenyl,2-methyl

$$
\Delta \mathrm{H}_{\text {tot }}=0.25 *(-0.48-(-13))+17.03+0.41 *(5-(-0.48))=22.40(\mathrm{cal} / \mathrm{g})
$$

9) Naphthalene,1.2-dihydro

$$
\Delta \mathrm{H}_{\text {tot }}=0.315 *(-10.05-(-13))+18.82+0.375 *(5-(-10.05))=25.39(\mathrm{cal} / \mathrm{g})
$$




\section{Appendix M: Calculations of Cooling Capacities (continued)}

10) Lithium chloride (4\%)

$$
\Delta \mathrm{H}_{\text {tot }}=0.65 *(-7.96-(-13))+50.20+0.91 *(5-(-7.96))=65.26(\mathrm{cal} / \mathrm{g})
$$

11) Potassium chloride (9\%)

$$
\Delta \mathrm{H}_{\text {tot }}=0.43 *(-8.55-(-13))+71.09+0.76 *(5-(-8.55))=83.30(\mathrm{cal} / \mathrm{g})
$$

12) Potassium chromate (18\%)

$$
\Delta \mathrm{H}_{\text {tot }}=0.31 *(-8.7-(-13))+70.25+0.85 *(5-(-8.7))=83.22(\mathrm{cal} / \mathrm{g})
$$

13) Potassium bromide (13\%)

$$
\Delta \mathrm{H}_{\text {tot }}=0.39 *(-11.04-(-13))+67.3+0.9 *(5-(-11.04))=82.50(\mathrm{cal} / \mathrm{g})
$$

14) Sodium hydroxide $(4.5 \%)$

$$
\Delta \mathrm{H}_{\text {tot }}=0.6 *(-7.27-(-13))+39.9+0.85 *(5-(-7.27))=53.76(\mathrm{cal} / \mathrm{g})
$$

15) Silver nitrate $(16 \%)$

$$
\Delta \mathrm{H}_{\text {tot }}=0.34 *(-7.72-(-13))+70.05+0.87 *(5-(-7.72))=82.91(\mathrm{cal} / \mathrm{g})
$$

16) Potassium nitrate (10\%)

$$
\Delta \mathrm{H}_{\mathrm{tot}}=0.33 *(-2.41-(-13))+80.7+0.87 *(5-(-2.41))=90.64(\mathrm{cal} / \mathrm{g})
$$

17) Potassium sulfate (5\%)

$$
\Delta \mathrm{H}_{\text {tot }}=0.40 *(-0.81-(-13))+79.21+0.91 *(5-(-0.81))=89.37(\mathrm{cal} / \mathrm{g})
$$

18) Potassium hydroxide (6\%)

$$
\Delta \mathrm{H}_{\text {tot }}=0.70 *(-7.26-(-13))+49.09+0.56 *(5-(-7.26))=59.97(\mathrm{cal} / \mathrm{g})
$$

19) Potassium dichromate (2.5\%)

$$
\Delta \mathrm{H}_{\text {tot }}=0.40 *(-0.02-(-13))+83.94+1.10 *(5-(-0.02))=94.65(\mathrm{cal} / \mathrm{g})
$$

20) Formic acid (10\%)

$$
\Delta \mathrm{H}_{\text {tot }}=0.58 *(-7.53-(-13))+56.55+0.83 *(5-(-7.53))=70.12(\mathrm{cal} / \mathrm{g})
$$




\section{Appendix M: Calculations of Cooling Capacities (continued)}

21) Acetic acid (13\%)

$$
\Delta \mathrm{H}_{\mathrm{tot}}=0.6 *(-8.54-(-13))+56.12+1.0 *(5-(-8.54))=72.33(\mathrm{caV} / \mathrm{g})
$$

22) Ethylene glycol (12\%)

$$
\Delta \mathrm{H}_{\text {tot }}=0.74 *(-5.52-(-13))+56.90+1.20 *(5-(-5.52))=75.05(\mathrm{cal} / \mathrm{g})
$$

23) Ethanol (9.5\%)

$$
\Delta \mathrm{H}_{\text {tot }}=0.78 *(-6.72-(-13))+49.92+1.0 *(5-(-6.72))=66.54(\mathrm{cal} / \mathrm{g})
$$

24) Glycerol (16\%)

$$
\Delta \mathrm{H}_{\text {tot }}=0.63 *(-7.95-(-13))+45.81+0.92 *(5-(-7.95))=60.90(\mathrm{cal} / \mathrm{g})
$$




\section{Appendix M: Calculations of Cooling Capacities (continued)}

Table M1. Fusion Enthalpy and Heat Capacity of FHS Candidates

\begin{tabular}{llll}
\hline FHS candidate & $\begin{array}{c}\Delta \mathrm{H}_{\mathrm{m}} \\
(\mathrm{cal} / \mathrm{g})\end{array}$ & $\begin{array}{c}\mathrm{C}_{\mathrm{p}, \mathrm{s}} \\
\left(\mathrm{cal} / \mathrm{g}^{\circ} \mathrm{C}\right)\end{array}$ & $\begin{array}{c}\mathrm{C}_{\mathrm{p}, \mathrm{l}} \\
\left(\mathrm{cal} / \mathrm{g}{ }^{\circ} \mathrm{C}\right)\end{array}$ \\
\hline Water & 80.6 & 0.52 & 1.06 \\
Heptanoic acid & 28.26 & 0.581 & 0.387 \\
Cyclohexanol,4-methyl(cis) & 18.16 & 0.30 & 0.46 \\
Cyclooctatetraene & 23.28 & 0.31 & 0.37 \\
4-Methoxybenzaldehyde & 27.81 & 0.345 & 0.379 \\
Indene & 15.10 & 0.36 & 0.45 \\
Cyclohexane,1,2-dibromo & 11.97 & 0.164 & 0.205 \\
Biphenyl,2-methyl & 17.03 & 0.25 & 0.41 \\
1,2-dihydronaphthalene & 18.82 & 0.315 & 0.375 \\
Potassium chloride(9\%) & 71.09 & 0.43 & 0.76 \\
Lithium chloride(4\%) & 50.20 & 0.65 & 0.91 \\
Potassium chromate(18\%) & 70.25 & 0.31 & 0.85 \\
Potassium bromide(13\%) & 67.3 & 0.39 & 0.90 \\
Sodium hydroxide(4.5\%) & 39.9 & 0.60 & 0.85 \\
Silver nitrate(16\%) & 70.05 & 0.34 & 0.87 \\
Potassium nitrate(10\%) & 80.7 & 0.33 & 0.87 \\
Potassium sulfate(5\%) & 79.21 & 0.40 & 0.91 \\
Potassium hydroxide(6\%) & 49.09 & 0.70 & 0.56 \\
Potassium dichromate(2.5\%) & 83.94 & 0.40 & 1.10 \\
Formic acid(10\%) & 56.55 & 0.58 & 0.83 \\
Acetic acid(13\%) & 56.12 & 0.60 & 1.0 \\
Ethylene glycol(12\%) & 56.90 & 0.74 & 1.20 \\
Ethanol(9.5\%) & 49.92 & 0.78 & 1.0 \\
Glycerol(16\%) & 45.81 & 0.63 & 0.92 \\
\hline & & & \\
\hline
\end{tabular}

